\title{
An azulene-derived fluorescent probe for bioimaging: Detection of reactive oxygen and nitrogen species by two-photon microscopy
}

${ }^{\ddagger}$ Lloyd C. Murfin, ${ }^{1}$ Maria Weber, ${ }^{1,2}{ }^{\ddagger}$ Sang Jun Park, ${ }^{3, \ddagger}$ Won Tae Kim, ${ }^{3, \$}$ Carlos M. Lopez-Alled, ${ }^{1,2}$ Claire L. McMullin, ${ }^{1}$ Fabienne Pradaux-Caggiano, ${ }^{1}$ Catherine L. Lyall, ${ }^{4}$ Gabriele Kociok-Köhn, ${ }^{4}$ Jannis Wenk, ${ }^{2,5}$ Steven D. Bull, ${ }^{1}$ Juyoung Yoon, ${ }^{6}$ Hwan Myung Kim, ${ }^{3 *}$ Tony D. James,${ }^{1,2^{*}}$ and Simon E. Lewis ${ }^{1,2^{*}}$

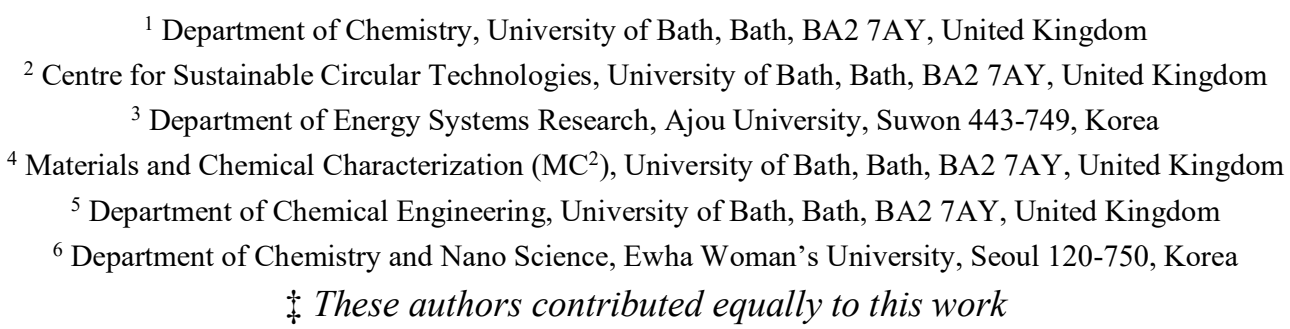

\section{ELECTRONIC SUPPLEMENTARY INFORMATION}

Reagents, General Procedure and Equipment.

Page S2

Synthetic Procedures .

Fluorescence Emission \& Excitation Spectra .

Page S5

UV/Vis Absorption Spectra .

Fluorescence Dependence on Solvent Polarity

Fluorescence Dependence on $\mathrm{pH}$

NMR Study of 2

Computational Prediction of $\mathrm{pKa}$ Values for $\mathbf{2}$

Fluorescence Response of 1 to $\mathrm{H}_{2} \mathrm{O}_{2}$.

Fluorescence Response of 1 to $\mathrm{ONOO}^{-}$

Selectivity of 1 Towards Multiple ROS

$\mathrm{UV} / \mathrm{V}$ is Kinetic experiment with $\mathrm{H}_{2} \mathrm{O}_{2}$

$\mathrm{UV} / \mathrm{V}$ is Titration with $\mathrm{H}_{2} \mathrm{O}_{2}$.

Page S10

Page S12

Page S13

Page S14

Page S16

Page S19

Page S20

Page S22

Page S23

Page S26

Page S27

$\mathrm{UV} / \mathrm{V}$ is Titration with $\mathrm{ONOO}^{-}$

Two-Photon Microscopy Results

Comparison of $\mathbf{2}$ with other Fluorophores

Page S29

Page S31

Page S34

NMR Spectra of 2

$\mathrm{X}$-ray crystallographic details .

Computational Data .

Fluorescence Quantum Yield Calculations

References

Page S35

Page S36

Page S41

Page S45

Page S47 


\section{Reagents, General Procedure and Equipment}

Solvents and reagents used were reagent grade, purchased from Fisher Scientific, Sigma-Aldrich, Fluorochem, and Cayman Chemical. All chemicals and solvents purchased were used without further purification.

Unless stated otherwise, ambient conditions were used for each reaction. Inert conditions were achieved using anhydrous solvents and by allowing the reaction to proceed under an atmosphere of nitrogen. Anhydrous solvents were dried using an Innovative Technology PS-4007 Solvent Purification System.

Mass spectra were recorded on a microTOF mass spectrometer, with electrospray ionization (ESI) used as the ionization method. All ${ }^{1} \mathrm{H}$ and ${ }^{13} \mathrm{C}$ NMR spectra were obtained from a $500 \mathrm{MHz}$ Agilent ProPulse, for which proton decoupling was active for ${ }^{13} \mathrm{C}$ NMR. All chemical shift values $(\delta)$ are reported in ppm relative to tetramethylsilane (internal standard), referenced to the residual solvent peak of the deuterated solvent used. Multiplicity of the recorded peaks are listed as $\mathrm{s}$ for singlet, $\mathrm{d}$ for doublet, $\mathrm{t}$ for triplet, $\mathrm{q}$ for quartet, or $\mathrm{m}$ for multiplet. Coupling constants $(\mathrm{J} / \mathrm{Hz})$ are given where calculable.

Fluorescence measurements were performed on a BMG Labtech CLARIOstar ${ }^{\circledR}$ using Greiner bio-one microplates, 96 well, PS, f-bottom (chimney well), black walled. Data were collected via the BMG Labtech Clariostar data analysis software package MARS. All solvents used in fluorescence measurements were HPLC or fluorescence grade and the water was deionized. All pH measurements taken during fluorescence/absorption experiments were recorded on a Hanna Instruments HI 9321 Microprocessor $\mathrm{pH}$ meter which was routinely calibrated using Fisher Chemicals standard buffer solutions (pH 4.0 - phthalate, 7.0 - phosphate, and 10.0 - borate). Phosphate buffered saline (PBS) was freshly prepared from $52 \%$ methanol in water (v/v) with $\mathrm{KCl}(10 \mathrm{mM}), \mathrm{KH}_{2} \mathrm{PO}_{4}(2.752 \mathrm{mM})$ and $\mathrm{Na}_{2} \mathrm{HPO}_{4}(2.757 \mathrm{mM})$. The PBS buffer was adjusted to $\mathrm{pH} 8.2$ with $1 \mathrm{M} \mathrm{HCl}(\mathrm{aq})$. $\mathrm{ONOO}^{-}$stock solutions were freshly prepared each time prior to usage. A solution of $3 \mathrm{M} \mathrm{NaOH}$ was cooled to $0{ }^{\circ} \mathrm{C}$ to which simultaneously $0.7 \mathrm{M} \mathrm{H}_{2} \mathrm{O}_{2}, 0.6 \mathrm{M} \mathrm{NaNO}_{2}$

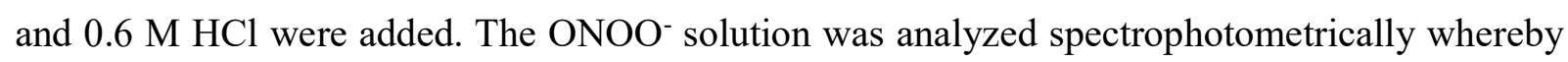
the concentration of $\mathrm{ONOO}^{-}$was estimated through $\varepsilon=1670 \pm 50 \mathrm{~cm}^{-1} \mathrm{M}^{-1}$ at $302 \mathrm{~nm}$ in $0.1 \mathrm{M}$ $\mathrm{NaOH}$ (aq.). Hydrogen peroxide $\left(\mathrm{H}_{2} \mathrm{O}_{2}\right)$ is commercially available whereby the concentration of $\mathrm{H}_{2} \mathrm{O}_{2}$ was determined through spectrophotometrical analysis with $\varepsilon=43.6 \mathrm{~cm}^{-1} \mathrm{M}^{-1}$ at $240 \mathrm{~nm}$. 
Sodium hypochlorite $(\mathrm{NaOCl})$ is commercially available whereby the concentration of ${ }^{-} \mathrm{OCl}$ was determined through spectrophotometrical analysis with $\varepsilon=250 \mathrm{~cm}^{-1} \mathrm{M}^{-1}$ at $292 \mathrm{~nm}$. ${ }^{1} \mathrm{O}_{2}$ was generated by the reaction of $\mathrm{H}_{2} \mathrm{O}_{2}(1 \mathrm{mM})$ with $\mathrm{NaClO}(1 \mathrm{mM}) . \mathrm{H}_{2} \mathrm{O}_{2}$ was slowly added to aq. $\mathrm{NaOCl}$ and stirred for $2 \mathrm{~min}$. ROO• was generated from 2, 2'-azobis (2-amidinopropane) dihydrochloride. AAPH (2,2' -azobis (2-amidinopropane) dihydrochloride, $10 \mathrm{M}$ ) was added in deionized water, and then stirred at $37{ }^{\circ} \mathrm{C}$ for $30 \mathrm{~min} . \mathrm{O}_{2}{ }^{--}$was generated from $\mathrm{KO}_{2}$ (1 eq) and 18 crown-6 (2.5 eq) dissolved in DMSO. HO• was generated by Fenton reaction: ferrous chloride (1 M) was added in the presence of 10 eq of $\mathrm{H}_{2} \mathrm{O}_{2}(37.0 \mathrm{wt} \%)$. Fluorescence titrations of ROS/RNS were carried out at $25{ }^{\circ} \mathrm{C}$ in PBS buffer $\mathrm{pH}$ 8.2. Different concentrations of ROS/RNS were prepared accordingly and investigated with the sensor at a concentration of $500 \mathrm{nM}$.

All UV-Vis experiments were performed on a Shimadzu UV-1800 UV spectrometer, for which a quartz cuvette of $1 \mathrm{~cm}$ path length was used. Experiments were performed in a mixture of PBS buffer (which consisted of $52 \% \mathrm{H}_{2} \mathrm{O}: 48 \% \mathrm{MeOH}$, v/v), with either DMSO or MeCN, pH $=8.2$.

For cell results, two-photon fluorescence images were acquired with a multiphoton microscopes (Leica TCS SP8 MP) and spectral confocal with $\times 40$ magnification. 1 was excited at $800 \mathrm{~nm}$ by a mode-locked femtosecond Ti:Sapphire laser source (Mai Tai HP) with $2.97 \mathrm{~W}$ output power, corresponding to $\sim 1.08 \times 10^{6} \mathrm{~W} \mathrm{~cm}^{-2}$ in the focal plane. All cells were cultured on a glass bottom cell culture dish (NEST) for 2 days at $37^{\circ} \mathrm{C}$ with $5 \% \mathrm{CO}_{2}$ maintained. Before imaging, the medium was replaced with serum-free medium and stained with $1(5 \mu \mathrm{M})$. To achieve this, $5 \mu \mathrm{L}$ of a $1 \mathrm{mM}$ stock solution of $\mathbf{1}$ in DMSO was added to the medium to a total volume of $1 \mathrm{~mL}$, giving the desired $5 \mu \mathrm{M}$ concentration of 1 in DMSO/water 0.5:99.5 ratio. MEM (WelGene) was used for HeLa cell (ATCC) culture and DMEM (WelGene) was used for RAW 264.7 cell (ATCC) culture. 10\% FBS (WelGene), penicillin (100 units $\left.\mathrm{mL}^{-1}\right)$ and streptomycin $\left(100 \mu \mathrm{g} \mathrm{mL}^{-1}\right)$ were added to each culture medium.

Cell viability was determined using an MTT kit (AbCareBio CL) assay to assess cytotoxicity. RAW 264.7 macrophages were incubated in a 96-well plate for $24 \mathrm{~h}$, and then to each, differing concentrations of $1(0-50 \mu \mathrm{M})$ was added. After incubation for $4 \mathrm{~h}$, the culture medium was changed to $10 \%$ MTT-containing serum-free medium, and further incubated for $3 \mathrm{~h}$. The MTT containing medium was removed and DMSO ( $5 \mu \mathrm{L}$ per $1 \mathrm{~mL}$ culture medium) was added to dissolve the precipitate. Absorbance was measured at $570 \mathrm{~nm}$. In the photostability 
studies, the changes in two-photon excitation intensity of 1-labeled RAW 264.7 macrophages were measured at intervals of 2 seconds for $1 \mathrm{~h}$, and the fluorescence intensity recorded for $1 \mathrm{~h}$ at 2 second intervals in $x y t$ mode. The fluorescence intensities were recorded at $400-600 \mathrm{~nm}$ upon excitation on $800 \mathrm{~nm}$ with femto-second pulses. Exogenous $\mathrm{ONOO}^{-}$was synthesized according to Patel and Darley-Usmar, ${ }^{[1]}$ for which the concentration was measured by an S-3100 UV-Vis spectrophotometer.

For the rat hippocampal slices, Sprague Dawley (SD) rats were purchased from KOATECH. Brain tissue was extracted from a two-week-old male SD rat and cut into $400 \mu \mathrm{m}$ slices in DPBS (Gibco) using a vibrating blade microtome (Leica). Hippocampus slices were stained with $1(50 \mu \mathrm{M})$ and incubated for $1 \mathrm{~h}$ at $37{ }^{\circ} \mathrm{C}$, under a $5 \% \mathrm{CO}_{2}$ atmosphere. Slices were washed with DPBS and moved to glass-bottomed dishes. Tissue images were acquired using 800 $\mathrm{nm}$ as the excitation wavelength and a 400-600 nm emission window. 


\section{Synthesis}

Synthetic Scheme for AzuFluor 483-Bpin (1)

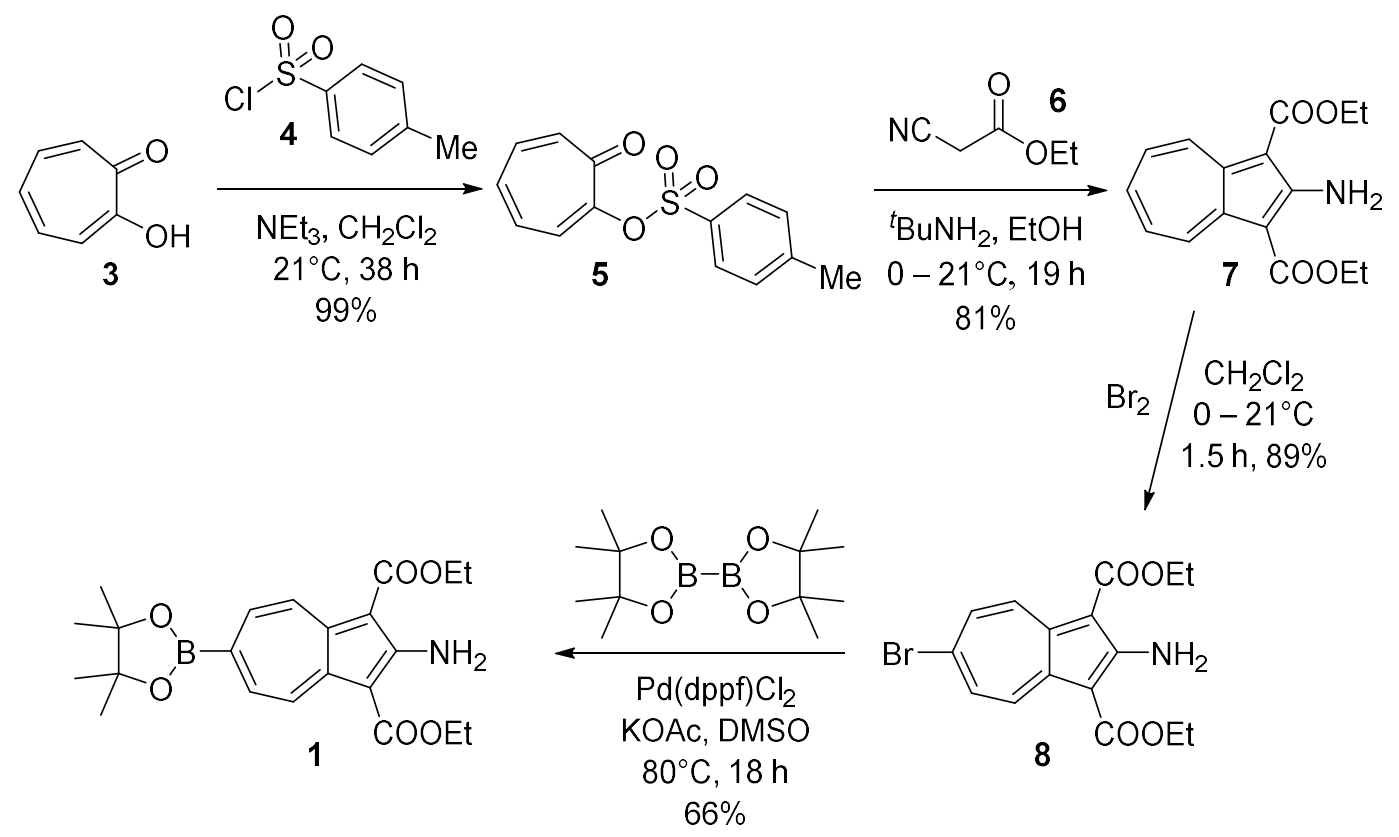




\section{7-Oxocyclohepta-1,3,5-trien-1-yl 4-methylbenzenesulfonate (5)}

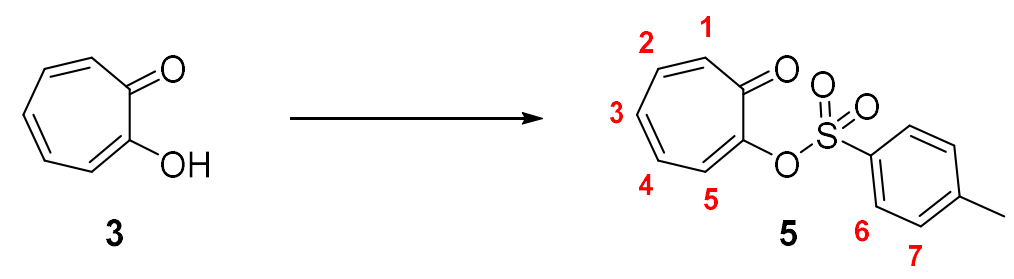

Under an atmosphere of nitrogen, tropolone 3 (5.00 g, $40.94 \mathrm{mmol}, 1.0 \mathrm{eqv})$ and tosyl chloride 4 (7.81 g, $40.94 \mathrm{mmol}, 1.0$ eqv) were dissolved in anhydrous $\mathrm{CH}_{2} \mathrm{Cl}_{2}(60 \mathrm{~mL})$, to which $\mathrm{NEt}_{3}$ (5.71 mL, $40.94 \mathrm{mmol}, 1.0 \mathrm{eqv}$ ) was added dropwise. The solution was further diluted in $\mathrm{CH}_{2} \mathrm{Cl}_{2}$ $(60 \mathrm{~mL})$ to prevent a suspension from forming, and left to stir for 38 hours, affording a yellow slurry. The reaction was quenched with ice, extracted with $\mathrm{CH}_{2} \mathrm{Cl}_{2}(3 \times 100 \mathrm{~mL})$, dried with $\mathrm{MgSO}_{4}$, filtered and concentrated under reduced pressure affording 7-oxocyclohepta-1,3,5-trien1-yl 4-methylbenzenesulfonate 5 as a crystalline yellow solid (11.30 g, $99 \%$ ) without any further purification required.

$\delta_{\mathrm{H}}\left(500 \mathrm{MHz}, \mathrm{CDCl}_{3}\right) 7.91\left(2 \mathrm{H}, \mathrm{d}, J 8.3 \mathrm{~Hz}, \mathrm{H}^{6}\right), 7.46\left(1 \mathrm{H}, \mathrm{d}, J 9.4 \mathrm{~Hz}, \mathrm{H}^{1}\right), 7.33(2 \mathrm{H}, \mathrm{d}, J 8.1 \mathrm{~Hz}$, $\left.\mathrm{H}^{7}\right), 7.21$, (1H, ddd, $\left.J 12.3,7.9,1.1 \mathrm{~Hz}, \mathrm{H}^{4}\right), 7.15\left(1 \mathrm{H}, \mathrm{d}, J 12.3 \mathrm{~Hz}, \mathrm{H}^{5}\right), 7.08(1 \mathrm{H}$, ddd, $J 11.6$, 7.9, $\left.1.1 \mathrm{~Hz}, \mathrm{H}^{3}\right), 6.98\left(1 \mathrm{H}, \mathrm{ddt}, J 10.9,9.4,1.3 \mathrm{~Hz}, \mathrm{H}^{2}\right), 2.45\left(3 \mathrm{H}, \mathrm{s}, \mathrm{CH}_{3}\right) \mathrm{ppm} . \delta_{\mathrm{C}}(125 \mathrm{MHz}$, $\left.\mathrm{CDCl}_{3}\right) 179.5(\mathrm{C}=\mathrm{O}), 155.3(\mathrm{O}-\mathrm{C}), 145.6(\mathrm{SC}), 141.3\left(\mathrm{C}^{5}\right), 136.4\left(\mathrm{C}^{4}\right), 134.8\left(\mathrm{C}^{3}\right), 133.6\left(\mathrm{CH}_{3} \underline{\mathrm{C}}\right)$, $130.9\left(\mathrm{C}^{2}\right), 130.0\left(\mathrm{C}^{1}\right), 129.7\left(\mathrm{C}^{7}\right), 128.7\left(\mathrm{C}^{6}\right), 21.9\left(\mathrm{CH}_{3}\right) \mathrm{ppm}$. Analytical data in agreement with those previously reported. ${ }^{[2]}$ 


\section{Diethyl 2-aminoazulene-1,3-dicarboxylate (7)}

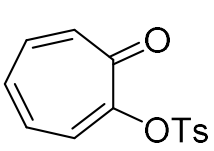

5

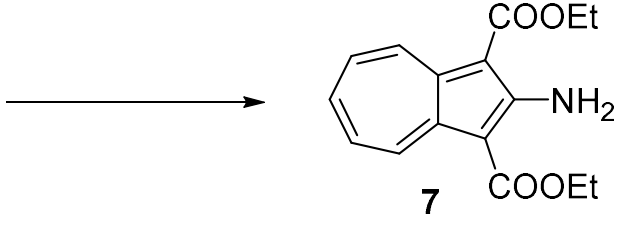

7-Oxocyclohepta-1,3,5-trien-1-yl 4-methylbenzenesulfonate 5 (4.50 g, 16.29 mmol, 1.0 eqv) and ethyl cyanoacetate $6(3.82 \mathrm{~mL}, 35.83 \mathrm{mmol}, 2.2$ eqv) were dissolved in ethanol $(80 \mathrm{~mL})$ and cooled to $0{ }^{\circ} \mathrm{C}$, to which $t$-butylamine $(4.28 \mathrm{~mL}, 40.72 \mathrm{mmol}, 2.5 \mathrm{eqv})$ was added dropwise. The solution was left to stir for $19 \mathrm{~h}$, during which the system warmed to room temperature and the product, an orange precipitate, had formed. The precipitate was filtered and the filtrate concentrated to $\sim 30 \mathrm{~mL}$ under reduced pressure, cooled to $0{ }^{\circ} \mathrm{C}$, to which water $(100 \mathrm{~mL})$ was added to further precipitate the product. The precipitate was filtered, washed with water and dried under vacuum to afford diethyl 2-aminoazulene-1,3-dicarboxylate $7(3.80 \mathrm{~g}, 81 \%)$ as a bright orange solid without any further purification required.

$\delta_{\mathrm{H}}\left(500 \mathrm{MHz}, \mathrm{CDCl}_{3}\right) 9.16\left(2 \mathrm{H}, \mathrm{d}, J 10.2 \mathrm{~Hz}, \mathrm{H}^{4}, \mathrm{H}^{8}\right), 7.79\left(2 \mathrm{H}\right.$, br. s, $\left.\mathrm{NH}_{2}\right), 7.55(2 \mathrm{H}, \mathrm{t}, J 10.3 \mathrm{~Hz}$, $\left.\mathrm{H}^{5}, \mathrm{H}^{7}\right), 7.47-7.41\left(1 \mathrm{H}, \mathrm{m}, \mathrm{H}^{6}\right), 4.47\left(4 \mathrm{H}, \mathrm{q}, J 7.1 \mathrm{~Hz}, \mathrm{CH}_{2}\right), 1.49\left(6 \mathrm{H}, \mathrm{t}, J 7.1 \mathrm{~Hz}, \mathrm{CH}_{3}\right) \mathrm{ppm} . \delta_{\mathrm{C}}$ $\left(125 \mathrm{MHz}, \mathrm{CDCl}_{3}\right) 166.7(\mathrm{C}=\mathrm{O}), 162.6\left(\mathrm{C}^{2}\right), 146.3\left(\mathrm{C}^{3 \mathrm{a}}, \mathrm{C}^{8 \mathrm{a}}\right), 133.0\left(\mathrm{C}^{6}\right), 132.7\left(\mathrm{C}^{5}, \mathrm{C}^{7}\right), 131.6$ $\left(\mathrm{C}^{4}, \mathrm{C}^{8}\right), 99.9\left(\mathrm{C}^{1}, \mathrm{C}^{3}\right), 60.0\left(\mathrm{CH}_{2}\right), 14.8\left(\mathrm{CH}_{3}\right)$ ppm. HRMS (ESI+) $\mathrm{m} / z$ calcd for $\left(\mathrm{C}_{16} \mathrm{H}_{17} \mathrm{NO}_{4}+\mathrm{Na}\right)^{+}, 310.1050$; found 310.1063 . Analytical data in agreement with those previously reported. ${ }^{[3]}$ 


\section{Diethyl 2-amino-6-bromoazulene-1,3-dicarboxylate (8)}<smiles>CCOC(=O)c1c2cccccc-2c(C(=O)OCC)c1N</smiles><smiles>CCOC(=O)c1c2ccc(Br)ccc-2c(C(=O)OCC)c1N</smiles>

Diethyl 2-aminoazulene-1,3-dicarboxylate $7(1.00 \mathrm{~g}, 3.48 \mathrm{mmol}, 1.0 \mathrm{eqv})$ was dissolved in anhydrous $\mathrm{CH}_{2} \mathrm{Cl}_{2}(20 \mathrm{~mL})$ and cooled to $0{ }^{\circ} \mathrm{C}$, to which bromine $(0.20 \mathrm{~mL}, 3.83 \mathrm{mmol}, 1.1 \mathrm{eqv})$ was added over a $20 \mathrm{~min}$ period. The solution was warmed to room temperature and stirred for 1.5 hours. The reaction was quenched with water $(150 \mathrm{~mL})$, separated and the aqueous layer was extracted with $\mathrm{CH}_{2} \mathrm{Cl}_{2}(2 \times 50 \mathrm{~mL})$. The collected organic extracts were dried with $\mathrm{MgSO}_{4}$, filtered and concentrated under reduced pressure. The crude product was recrystallized from toluene/ hexane to give diethyl 2-amino-6-bromoazulene-1,3-dicarboxylate $\mathbf{8}$ as a brown crystalline solid $(1.14 \mathrm{~g}, 89 \%)$.

$\delta_{\mathrm{H}}\left(500 \mathrm{MHz}, \mathrm{CDCl}_{3}\right) 8.86\left(2 \mathrm{H}, \mathrm{d}, J 11.1 \mathrm{~Hz}, \mathrm{H}^{4}, \mathrm{H}^{8}\right), 7.82\left(4 \mathrm{H}, \mathrm{m}, \mathrm{H}^{5}, \mathrm{H}^{7}, \mathrm{NH}_{2}\right), 4.46(4 \mathrm{H}, \mathrm{q}, J$ $\left.7.1 \mathrm{~Hz}, \mathrm{CH}_{2}\right), 1.47\left(6 \mathrm{H}, \mathrm{t}, J 7.1 \mathrm{~Hz}, \mathrm{CH}_{3}\right)$ ppm. $\delta \mathrm{C}\left(125 \mathrm{MHz}, \mathrm{CDCl}_{3}\right) 166.4(\mathrm{C}=\mathrm{O}), 162.5\left(\mathrm{C}^{2}\right)$, $144.5\left(\mathrm{C}^{3 \mathrm{a}}, \mathrm{C}^{8 \mathrm{a}}\right), 135.5\left(\mathrm{C}^{5}, \mathrm{C}^{7}\right), 129.7\left(\mathrm{C}^{4}, \mathrm{C}^{8}\right), 128.6(\mathrm{CBr}), 101.2\left(\mathrm{C}^{1}, \mathrm{C}^{3}\right), 60.3\left(\mathrm{CH}_{2}\right), 14.8\left(\mathrm{CH}_{3}\right)$ ppm. HRMS (ESI+) $\mathrm{m} / z$ calcd for $\left(\mathrm{C}_{16} \mathrm{H}_{16} \mathrm{BrNO}_{4}+\mathrm{Na}\right)^{+}, 388.0155$; found 388.0149. Analytical data in agreement with those previously reported. ${ }^{[4]}$ 
Diethyl 2-amino-6-(4,4,5,5-tetramethyl-1,3,2-dioxaborolan-2-yl)azulene-1,3dicarboxylate (1)

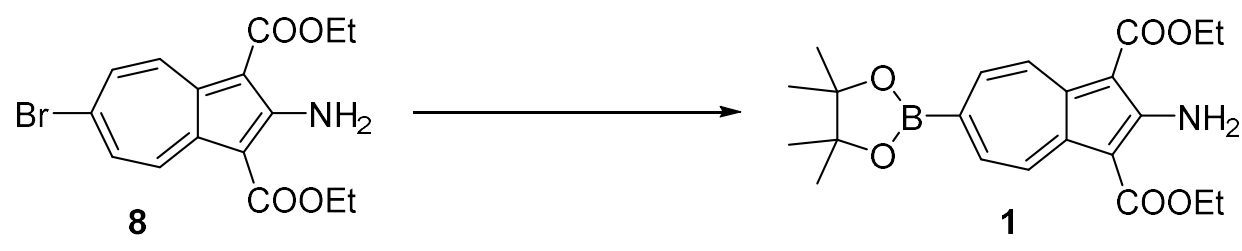

Under an atmosphere of nitrogen, diethyl 2-amino-6-bromoazulene-1,3-dicarboxylate 8 (6.50 g, $17.75 \mathrm{mmol}, 1.00 \mathrm{eqv})$, [1,1'-bis(diphenylphosphino)ferrocene]dichloropalladium(II) (0.65 g, $0.89 \mathrm{mmol}, 0.05 \mathrm{eqv})$, bis(pinacolato)diboron ( $4.96 \mathrm{~g}, 19.53 \mathrm{mmol}, 1.10 \mathrm{eqv})$ and potassium acetate $(5.23 \mathrm{~g}, 52.25 \mathrm{mmol}, 3.00 \mathrm{eqv})$ were combined, to which anhydrous DMSO (60 $\mathrm{mL})$ was added. The mixture was heated at $80{ }^{\circ} \mathrm{C}$ for 18 hours, after which it was cooled to room temperature. The mixture was diluted with water $(100 \mathrm{~mL})$ then extracted with $\mathrm{CH}_{2} \mathrm{Cl}_{2}$ $(4 \times 50 \mathrm{~mL})$. The combined organic extract was washed with water $(200 \mathrm{~mL})$, dried over $\mathrm{MgSO}_{4}$, filtered and concentrated under reduced pressure. The crude product was purified via column chromatography, eluting with EtOAc:Petrol $\left(2: 8, \mathrm{R}_{\mathrm{f}}=0.60\right)$ to give 2-amino-6-(4,4,5,5tetramethyl-1,3,2-dioxaborolan-2-yl)azulene-1,3-dicarboxylate (4.82 g, 66\%) 1 as a bright orange solid.

$\delta_{\mathrm{H}}\left(500 \mathrm{MHz}, \mathrm{CDCl}_{3}\right) 9.06\left(2 \mathrm{H}, \mathrm{d}, J 11.0 \mathrm{~Hz}, \mathrm{H}^{4}, \mathrm{H}^{8}\right), 8.03\left(2 \mathrm{H}, \mathrm{d}, J \mathrm{H}^{5}, \mathrm{H}^{7}\right), 4.44(4 \mathrm{H}, \mathrm{q}, J 7.1 \mathrm{~Hz}$, $\left.\mathrm{CH}_{2}\right), 1.46\left(6 \mathrm{H}, \mathrm{t}, J 7.1 \mathrm{~Hz}, \mathrm{CH}_{3}\right)$ ppm. $\delta_{\mathrm{C}}\left(125 \mathrm{MHz}, \mathrm{CDCl}_{3}\right) \delta_{\mathrm{C}}\left(125 \mathrm{MHz}, \mathrm{CDCl}_{3}\right) 166.7(\mathrm{C}=\mathrm{O})$, 163.6 $\left(\mathrm{C}^{2}\right), 147.5\left(\mathrm{C}^{3 \mathrm{a}}, \mathrm{C}^{8 \mathrm{a}}\right), 138.7\left(\mathrm{C}^{4}, \mathrm{C}^{8}\right), 130.4\left(\mathrm{C}^{5}, \mathrm{C}^{7}\right), 99.8\left(\mathrm{C}^{6}\right), 84.7\left(\underline{\mathrm{C}}\left(\mathrm{CH}_{3}\right)_{2}\right), 59.9\left(\mathrm{CH}_{2}\right)$, $25.0\left(\mathrm{C}\left(\underline{\mathrm{CH}}_{3}\right)_{2}\right), 14.7\left(\mathrm{CH}_{2} \underline{\mathrm{CH}} 3\right)$ ppm. HRMS $(\mathrm{ESI}+) \mathrm{m} / z$ calcd for $\left(\mathrm{C}_{22} \mathrm{H}_{28} \mathrm{BNO}_{6}+\mathrm{Na}\right)^{+}, 436.1902$; found 436.2021. Analytical data in agreement with those previously reported. ${ }^{[5]}$ 


\section{Fluorescence Emission \& Excitation Spectra}

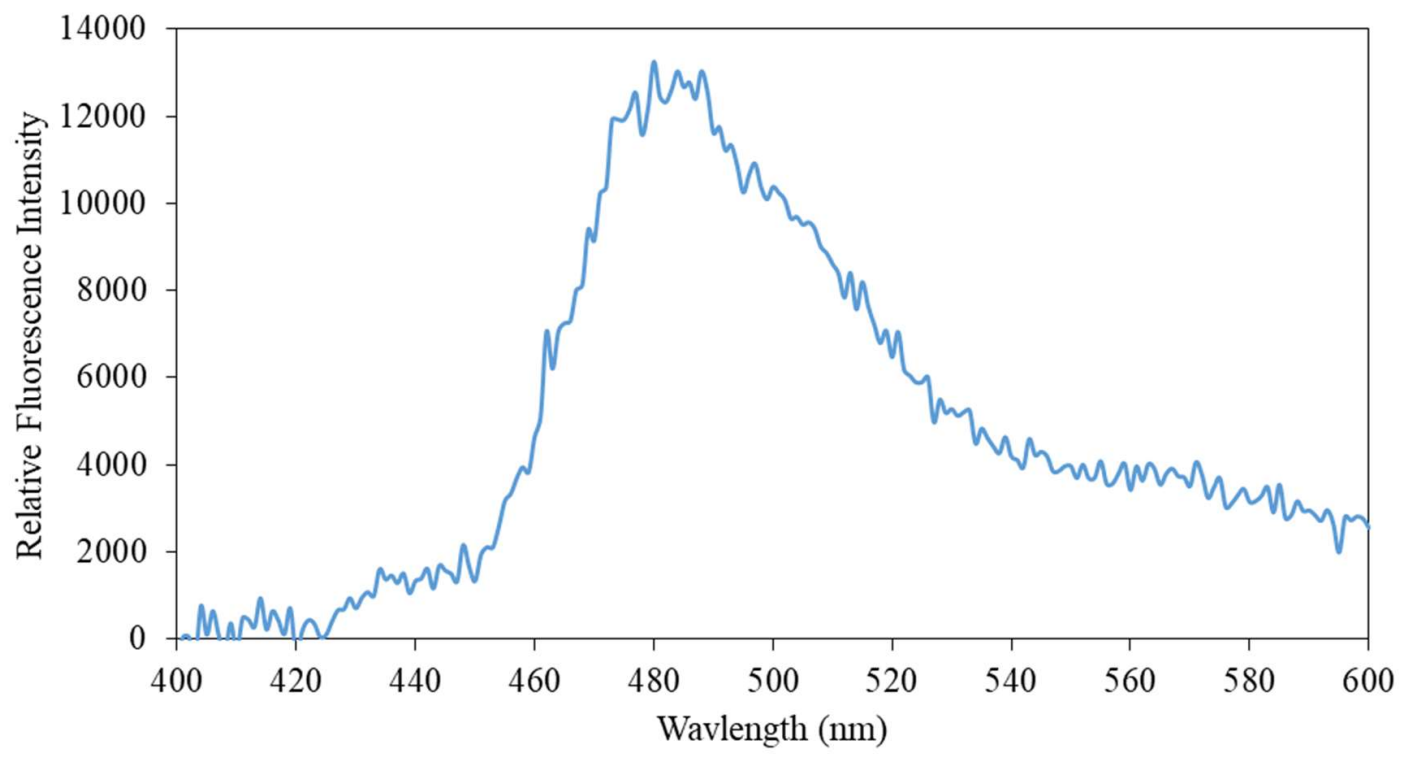

Figure S1. Emission spectrum of $1(5 \mu \mathrm{M})$ in PBS buffer $52 \% \mathrm{MeOH}: 48 \% \mathrm{H}_{2} \mathrm{O}(\mathrm{v} / \mathrm{v}), \mathrm{pH}=8.2$ at $25^{\circ} \mathrm{C}$ at $\lambda_{\text {ex }}=340$ (bandwidth 10) $\mathrm{nm}$. Fluorescence intensities were measured on a BMG Labtech CLARIOstar plate reader. 


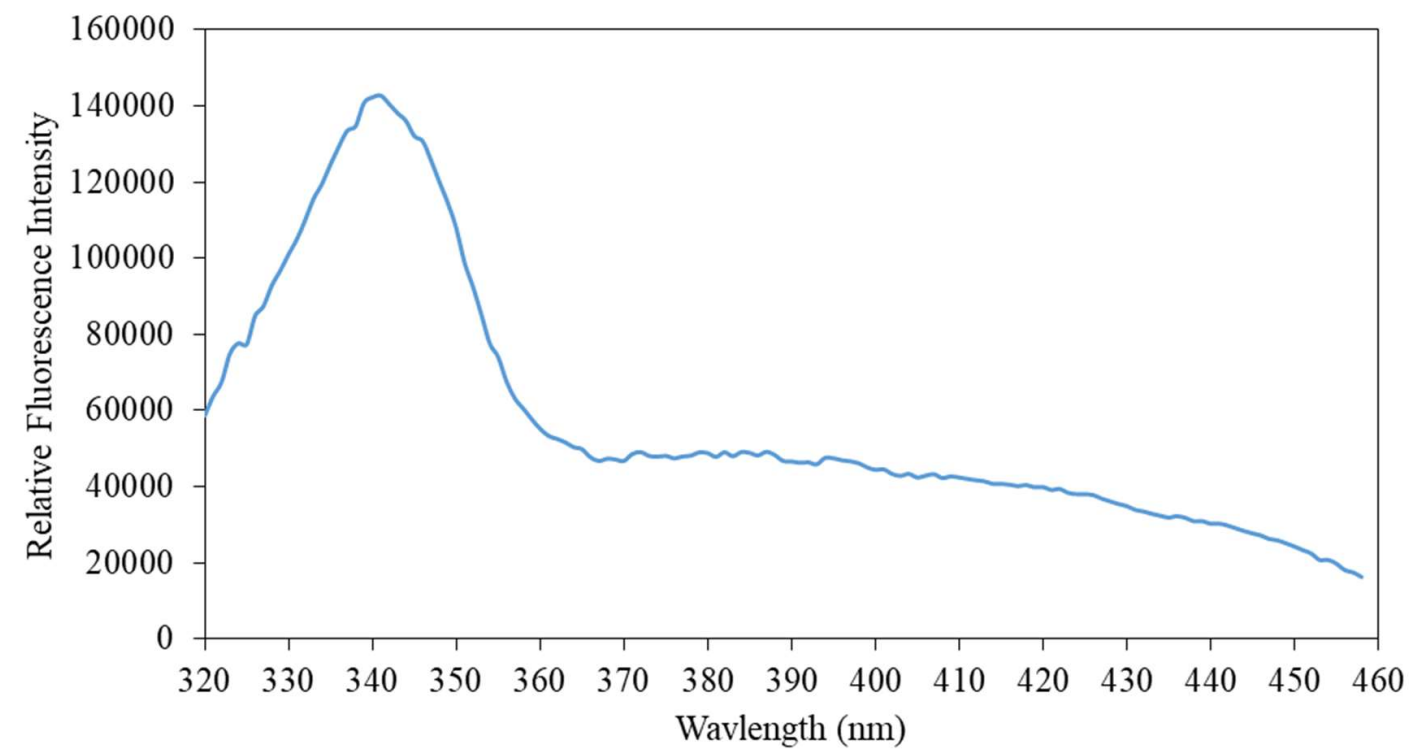

Figure S2: Excitation spectrum of $2(5 \mu \mathrm{M})$ in PBS buffer $52 \% \mathrm{MeOH}: 48 \% \mathrm{H}_{2} \mathrm{O}(\mathrm{v} / \mathrm{v}), \mathrm{pH}=8.2$ at $25{ }^{\circ} \mathrm{C}$ at $\lambda_{\mathrm{em}}=483$ (bandwidth 10) nm. Fluorescence intensities were measured on a BMG Labtech CLARIOstar plate reader.

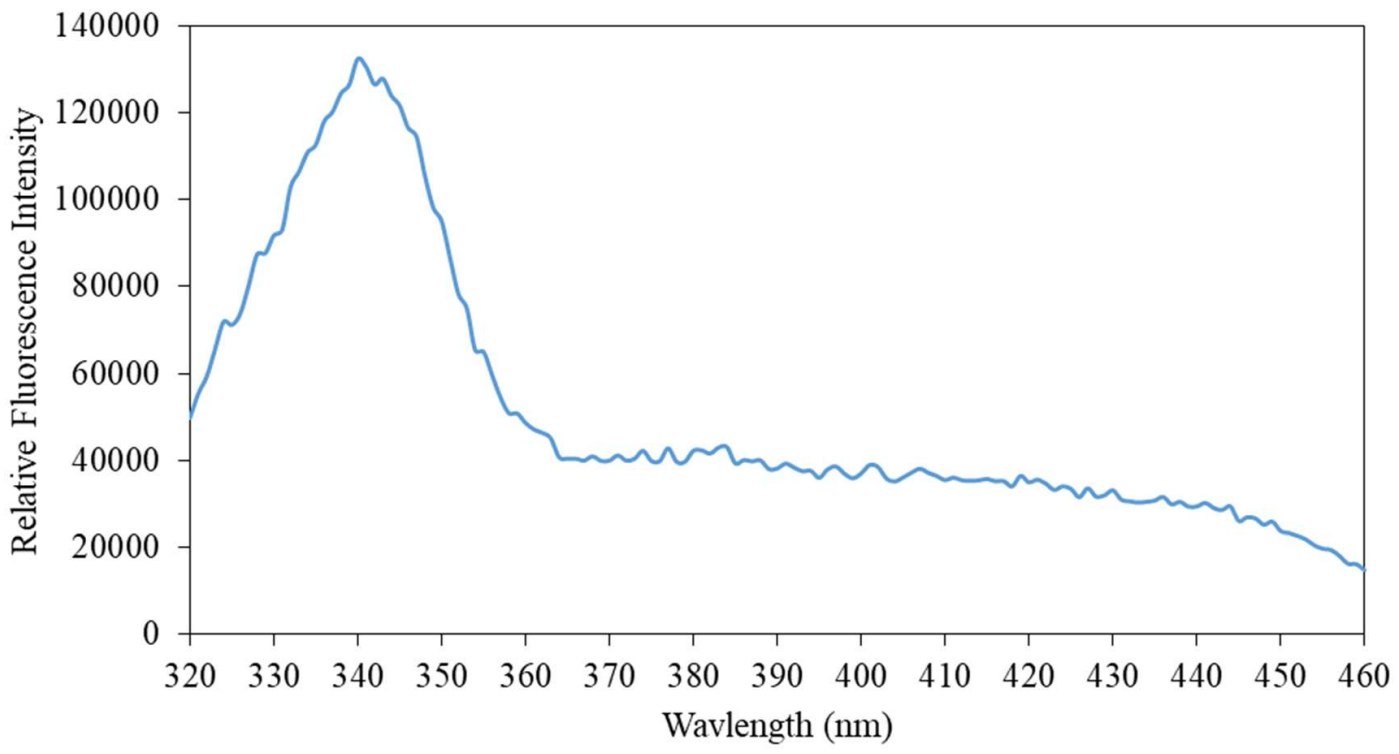

Figure S3: Excitation spectrum of $1(5 \mu \mathrm{M})$ in PBS buffer $52 \% \mathrm{MeOH}: 48 \% \mathrm{H}_{2} \mathrm{O}(\mathrm{v} / \mathrm{v}), \mathrm{pH}=8.2$ at $25{ }^{\circ} \mathrm{C}$ at $\lambda_{\mathrm{em}}=490$ (bandwidth 20) $\mathrm{nm}$. Fluorescence intensities were measured on a BMG Labtech CLARIOstar plate reader. 


\section{UV-Vis Absorption Spectra}
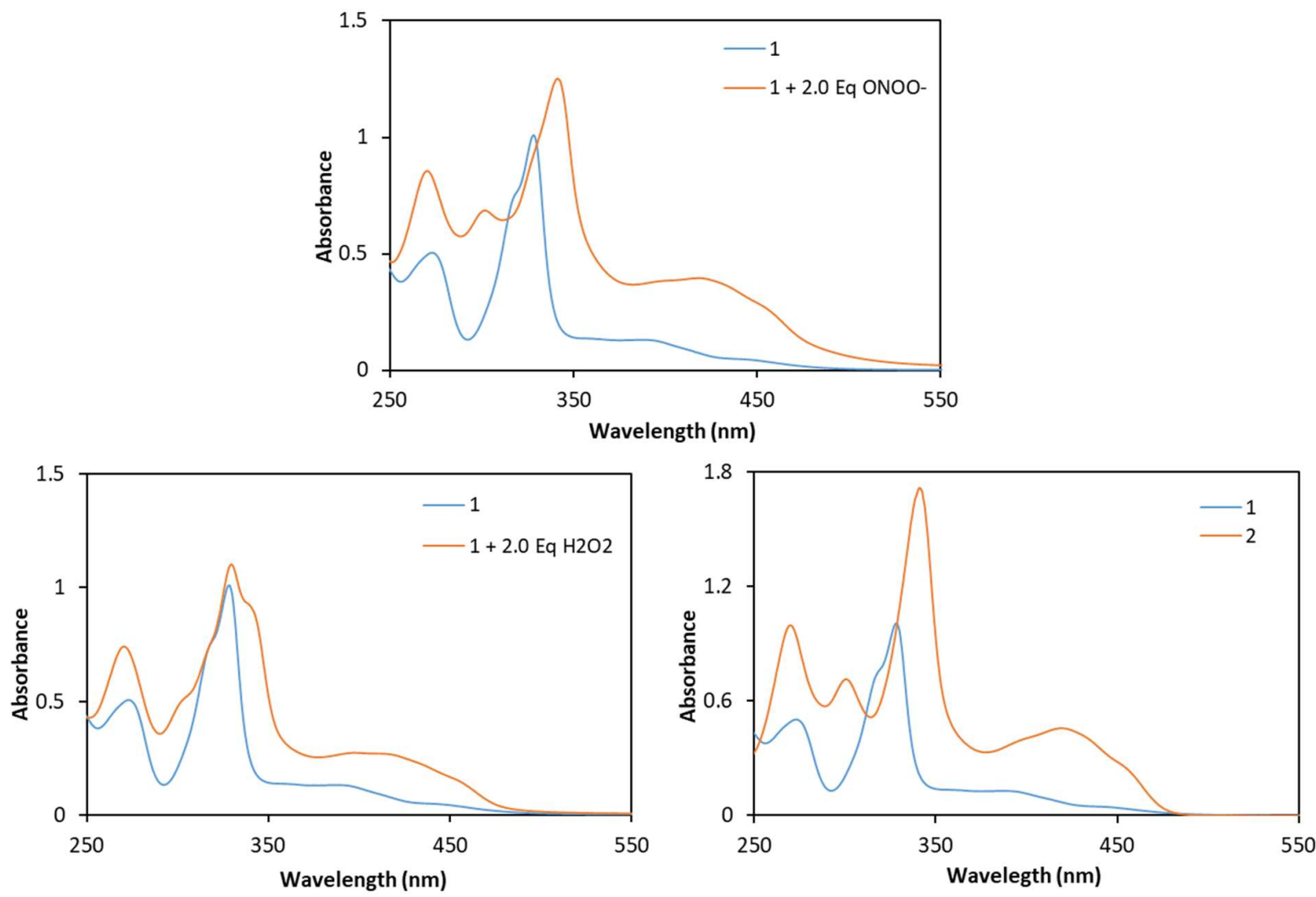

Figure S4. Top -1 (MeCN-PBS buffer* 1:9, v/v, $50 \mu \mathrm{M}, \lambda_{\max }=327 \mathrm{~nm}$ ) before and $30 \mathrm{~min}$ after the addition of $\mathrm{ONOO}^{-}\left(\mathrm{PBS}^{2}\right.$ buffer*, $100 \mu \mathrm{M}, \lambda_{\max }=335 \mathrm{~nm}$ ). Bottom Left -1 (MeCN-PBS buffer* 1:9, v/v, $50 \mu \mathrm{M}, \lambda_{\max }=327 \mathrm{~nm}$ ) before and 30 min after the addition of $\mathrm{H}_{2} \mathrm{O}_{2}$ (PBS buffer*, $100 \mu \mathrm{M}, \lambda_{\max }=335 \mathrm{~nm}$ ). Bottom Right $-\mathbf{1}$ (MeCN-PBS buffer* 1:9, v/v, $50 \mu \mathrm{M}, \lambda_{\max }$ $=327 \mathrm{~nm})$ compared to $2\left(\mathrm{MeCN}-\mathrm{PBS}\right.$ buffer* $\left.1: 9, \mathrm{v} / \mathrm{v}, 50 \mu \mathrm{M}, \lambda_{\max }=335 \mathrm{~nm}\right)$. 


\section{Fluorescence Dependence on Solvent Polarity}

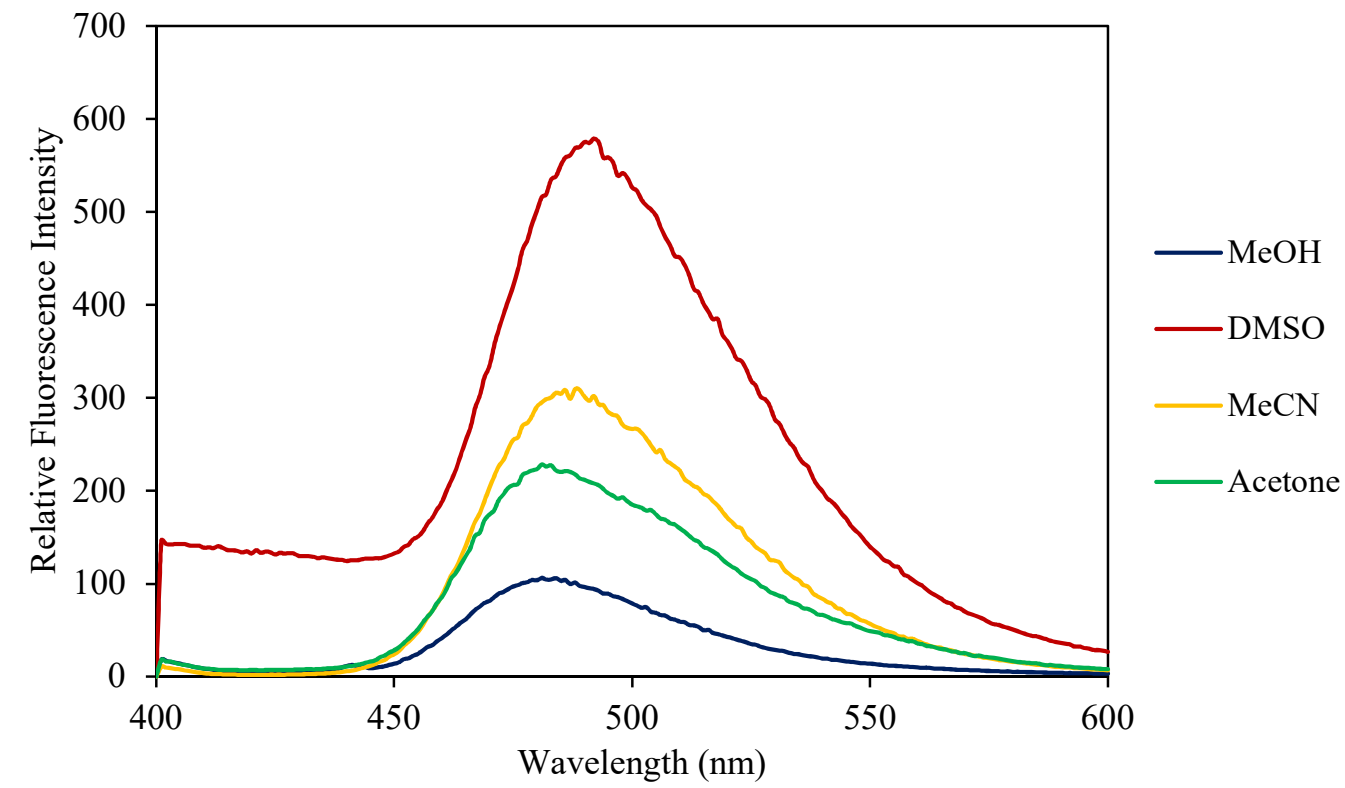

Figure S5. Fluorescence emission spectrum of 2 at $500 \mathrm{nM}$ in different solvents, $\lambda_{\max }=480,482,487$, and $491 \mathrm{~nm}$ for acetone, $\mathrm{MeOH}, \mathrm{MeCN}$, and DMSO respectively. Fluorescence emissions were measured with $\lambda_{\mathrm{ex}}=350$ (ex. slit 10, em. slit 20) nm on an Agilent Technologies Cary Eclipse Fluorescence Spectrometer. 


\section{Fluorescence Dependence on pH}

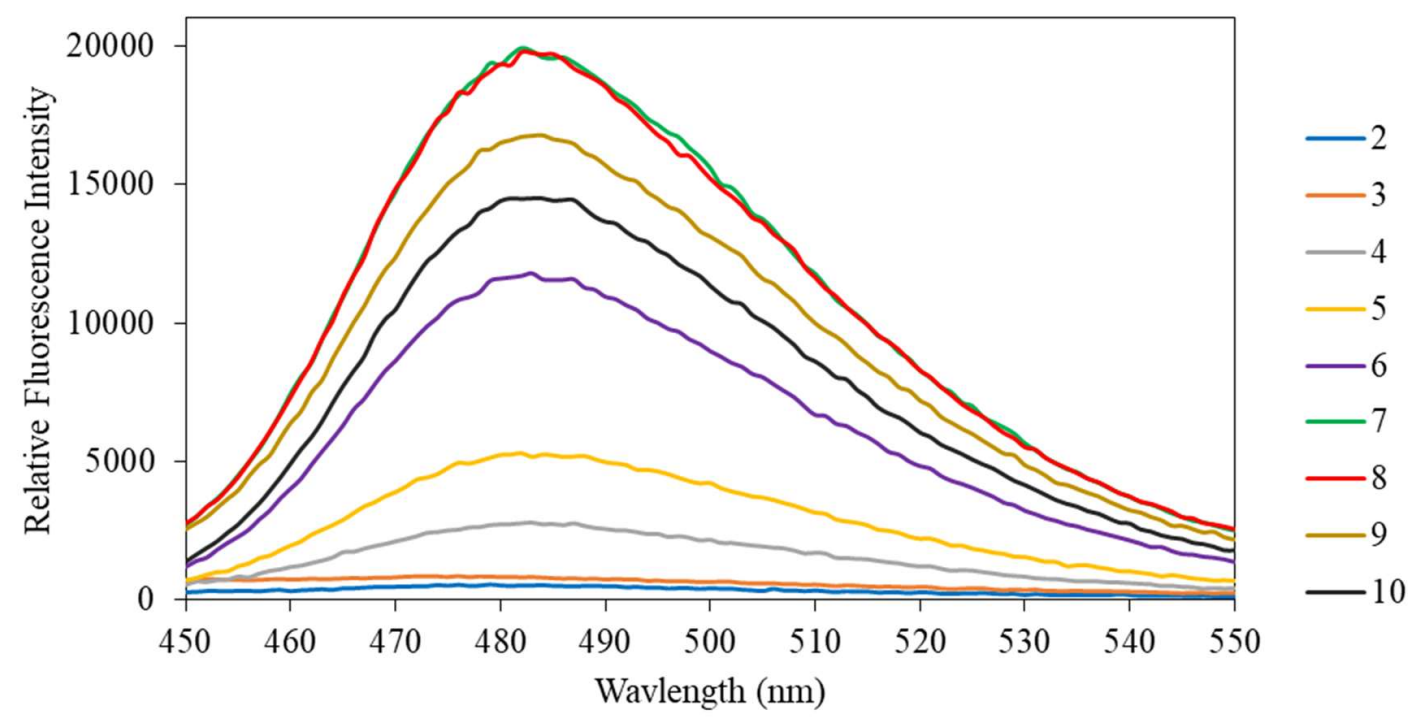

Figure S6. Emission spectra of $2(500 \mathrm{nM})$ at various $\mathrm{pH}$ in $52 \% \mathrm{MeOH}: 48 \% 0.1 \mathrm{M} \mathrm{NaCl}(\mathrm{v} / \mathrm{v})$ with $\lambda_{\mathrm{ex}}=350$ (bandwidth 20) $\mathrm{nm}$. (Data from this graph at $483 \mathrm{~nm}$ were extracted and re-plotted in Figure 4 in the main article) 


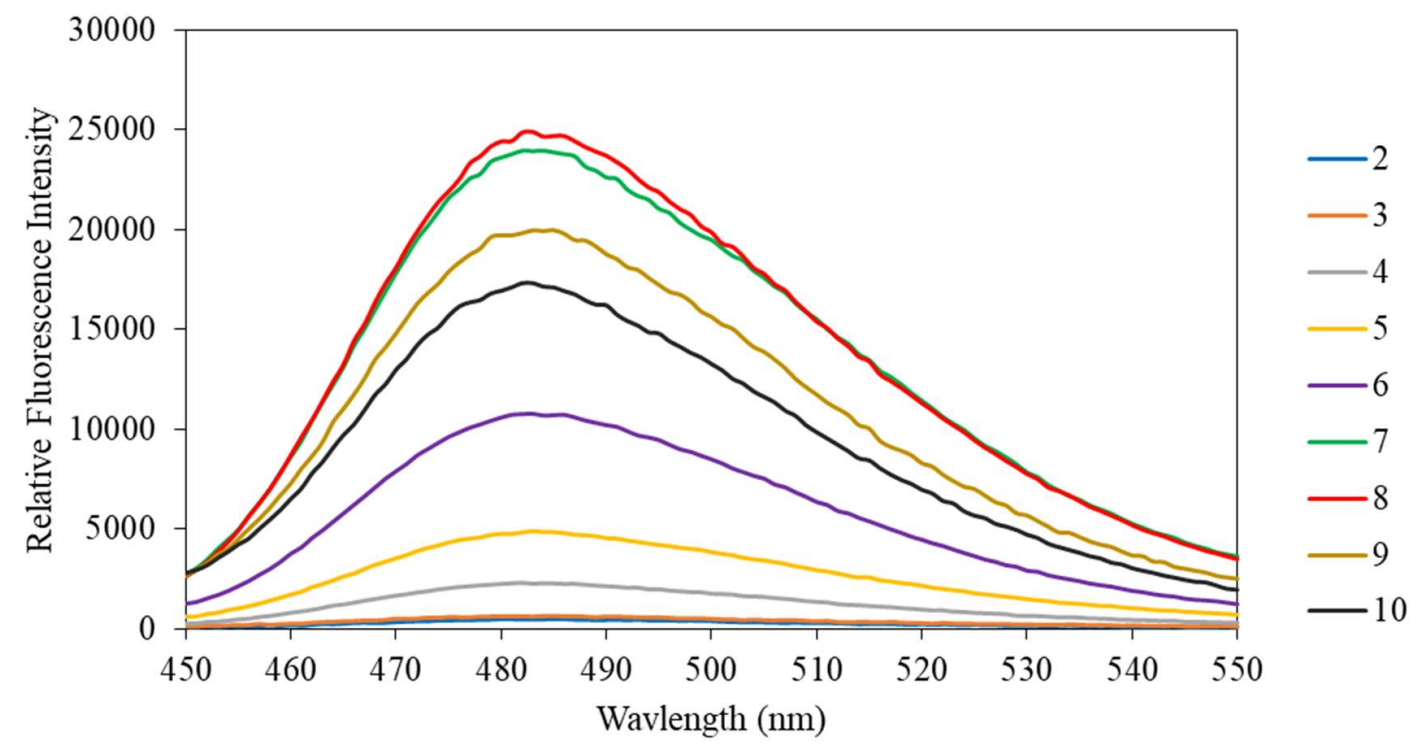

Figure S7. Emission spectra of $1(500 \mathrm{nM})$ with $\mathrm{ONOO}^{-}(10 \mu \mathrm{M})$ at various $\mathrm{pH}$ in $52 \% \mathrm{MeOH}: 48 \% 0.1 \mathrm{M} \mathrm{NaCl}(\mathrm{v} / \mathrm{v})$ with $\lambda_{\mathrm{ex}}=350$ (bandwidth 20) nm.

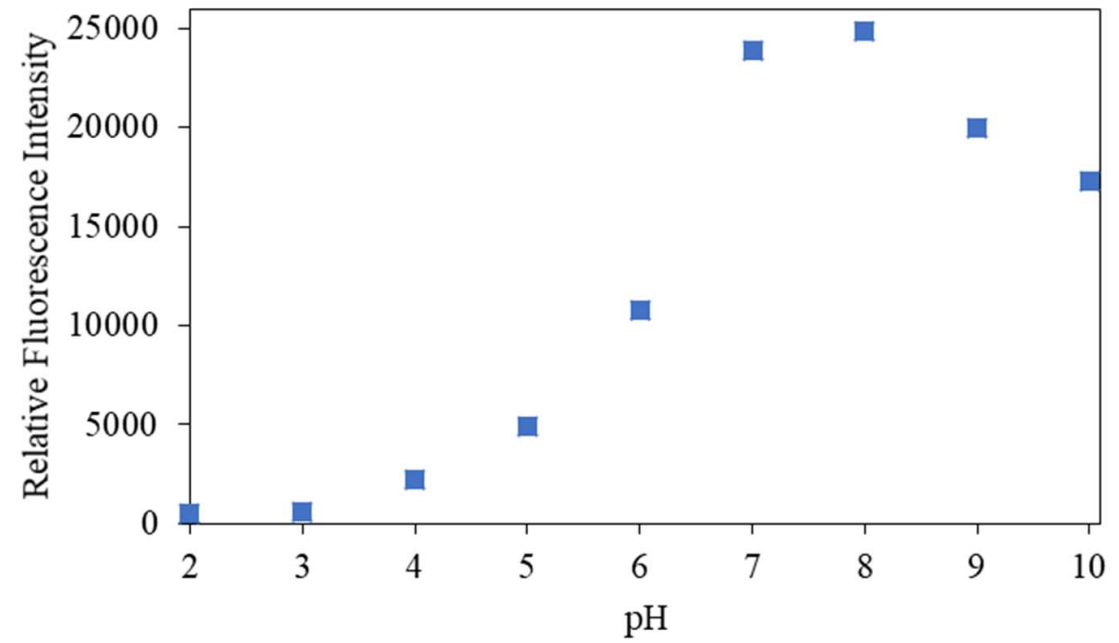

Figure S8. Effect of various $\mathrm{pH}$ on fluorescence intensity of $1(500 \mathrm{nM})$ with $\mathrm{ONOO}^{-}(10 \mu \mathrm{M})$ in $52 \% \mathrm{MeOH}: 48 \% 0.1 \mathrm{M} \mathrm{NaCl}$ $(\mathrm{v} / \mathrm{v})$ with $\lambda_{\max }=483 \mathrm{~nm}$. 


\section{NMR Study of 2}
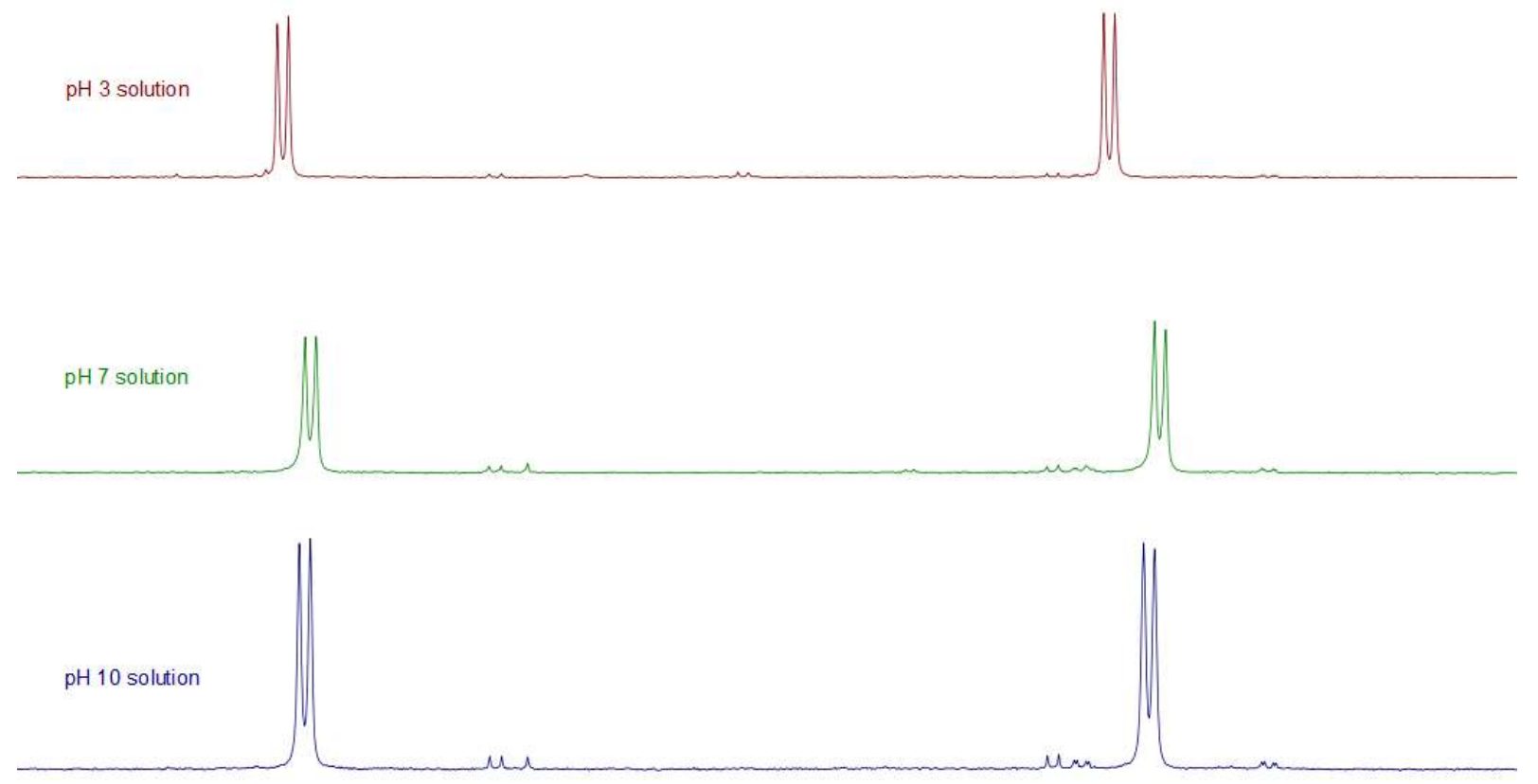

$\begin{array}{llllllllllllllllllllllllllllllllllll}9.4 & 9.3 & 9.2 & 9.1 & 9.0 & 8.9 & 8.8 & 8.7 & 8.6 & 8.5 & 8.4 & 8.3 & 8.2 & 8.1 & 8.0 & 7.9 & 7.8 & 7.7 & 7.6 & 7.5 & 7.4 & 7.3 & 7.2 & 7.1 & 7.0 & 6.9 & 6.8 & 6.7 & 6.6 & 6.5 & 6.4\end{array}$

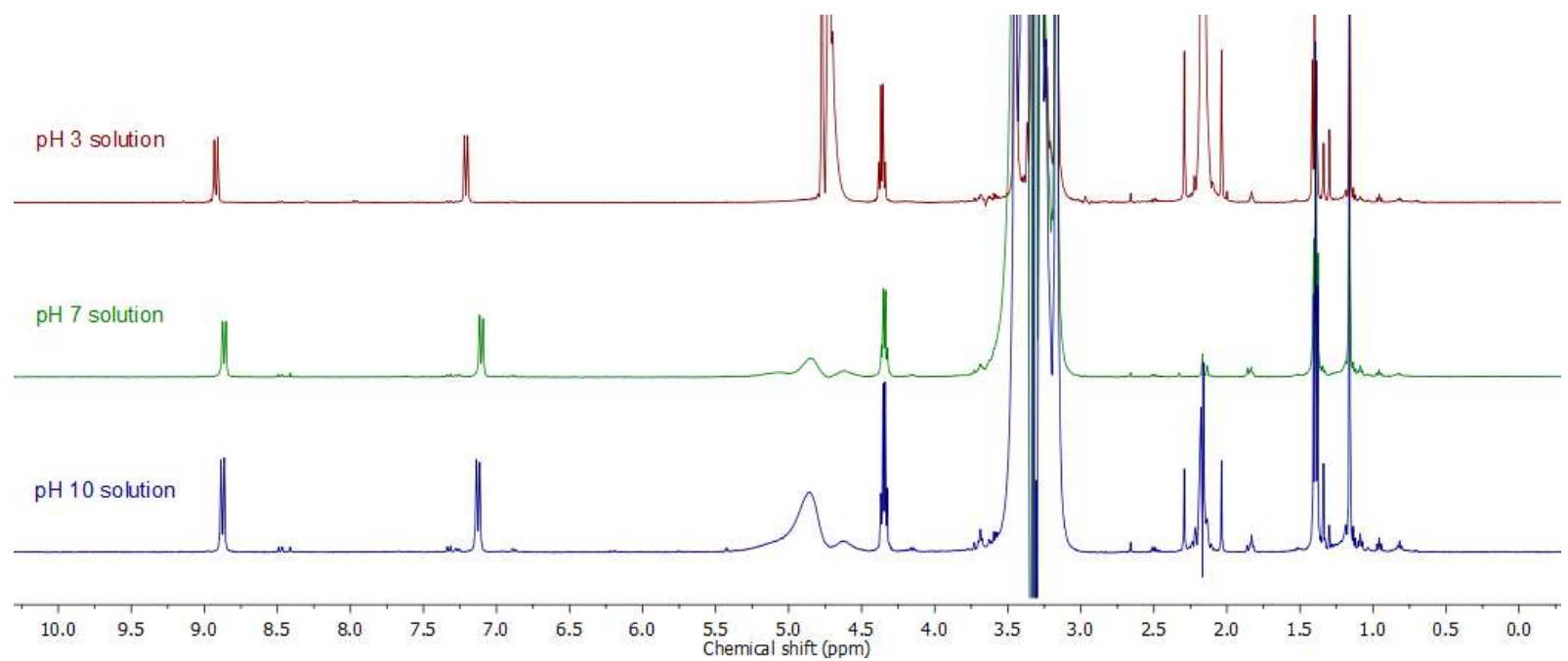

Figure S9. Effect of pH on ${ }^{1} \mathrm{H}-\mathrm{NMR}$ spectra of 2. Solvent suppressed spectra were acquired unlocked in 50:50 $\mathrm{CH}_{3} \mathrm{OH}$ :aqueous buffer on a Bruker Avance III with a nitrogen-cooled Prodigy cryoprobe. Pulse program used for multiple solvent suppression was the presaturation program lclpngpps. Top - enlargement of aromatic region. Bottom - entire spectra. 

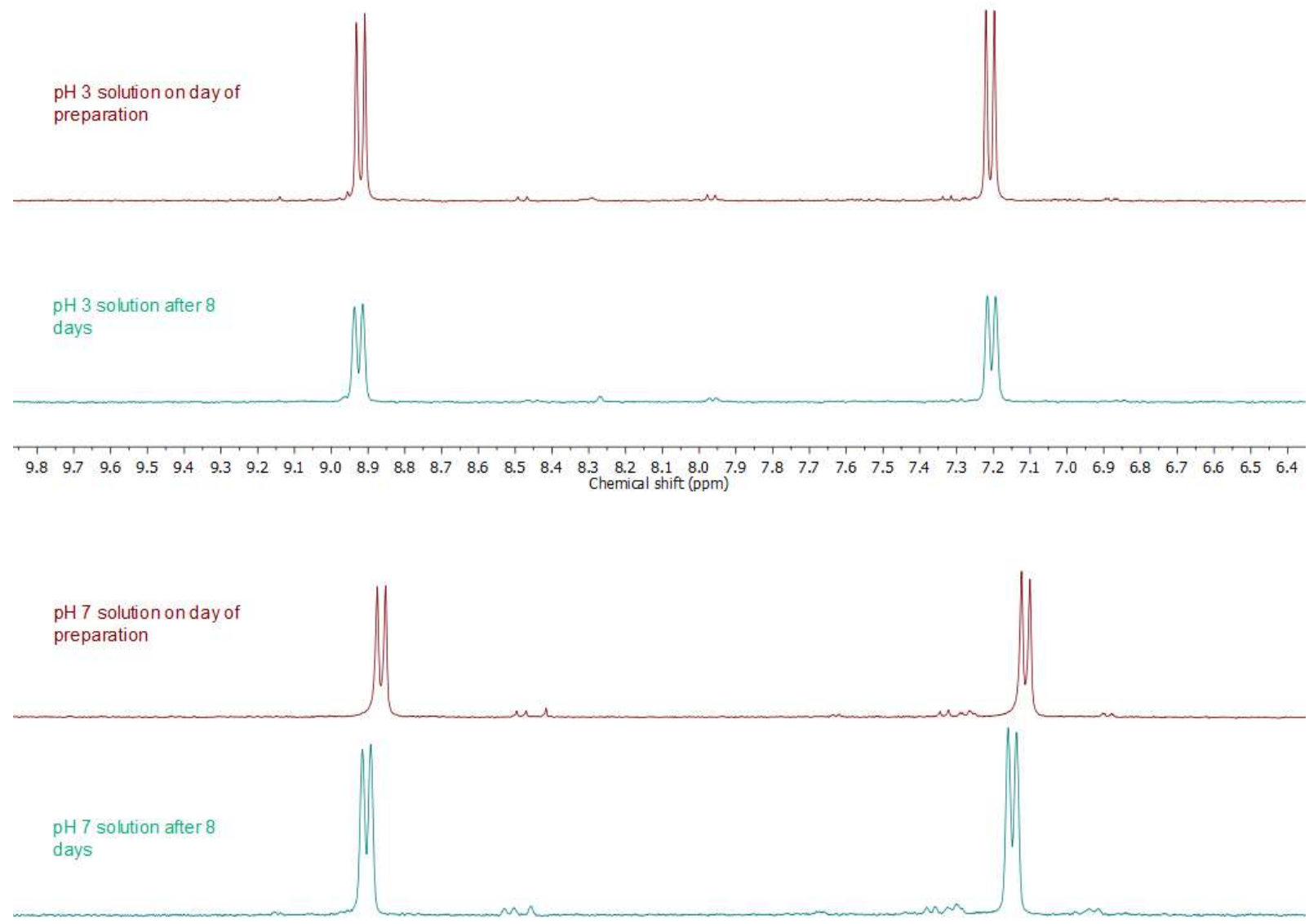
$\begin{array}{llllllllllllllllllllllllllllllllllllllllllll}9.8 & 9.7 & 9.6 & 9.5 & 9.4 & 9.3 & 9.2 & 9.1 & 9.0 & 8.9 & 8.8 & 8.7 & 8.6 & 8.5 & 8.4 & 8.3 & 8.2 & 8.1 & 8.0 & 7.9 & 7.8 & 7.7 & 7.6 & 7.5 & 7.4 & 7.3 & 7.2 & 7.1 & 7.0 & 6.9 & 6.8 & 6.7 & 6.6 & 6.5 & 6.4\end{array}$

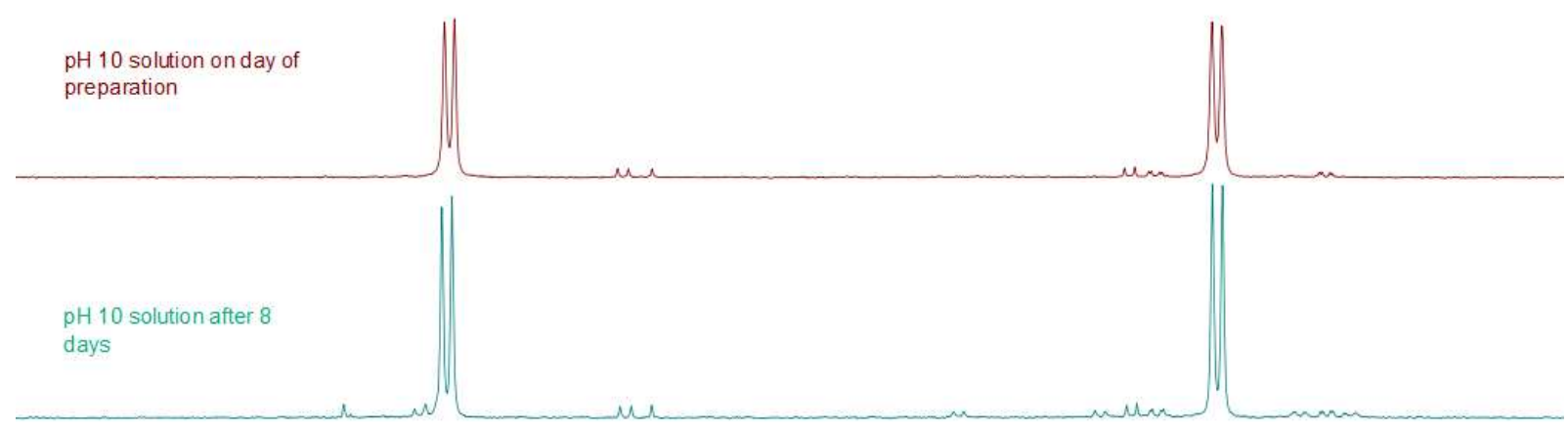

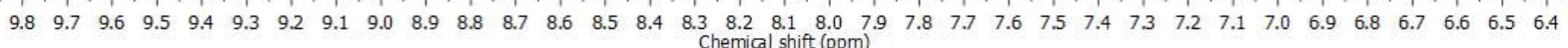

Figure S10. Effect of $\mathrm{pH}$ on ${ }^{1} \mathrm{H}-\mathrm{NMR}$ spectra of 2, upon prolonged standing in solution. Solvent suppressed spectra were acquired unlocked in 50:50 $\mathrm{CH}_{3} \mathrm{OH}$ :aqueous buffer on a Bruker Avance III with a nitrogen-cooled Prodigy cryoprobe. Pulse program used for multiple solvent suppression was the presaturation program lc1 pngpps. 


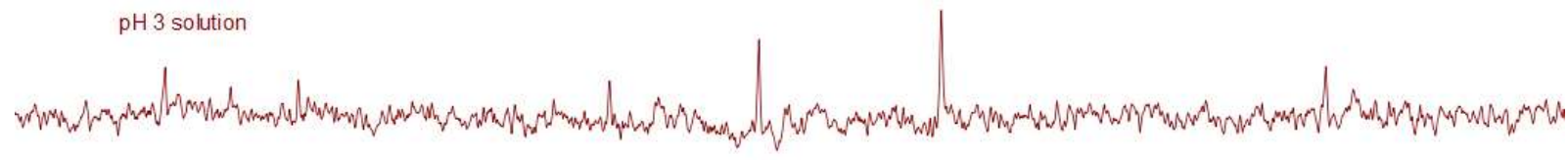

Amphom solution

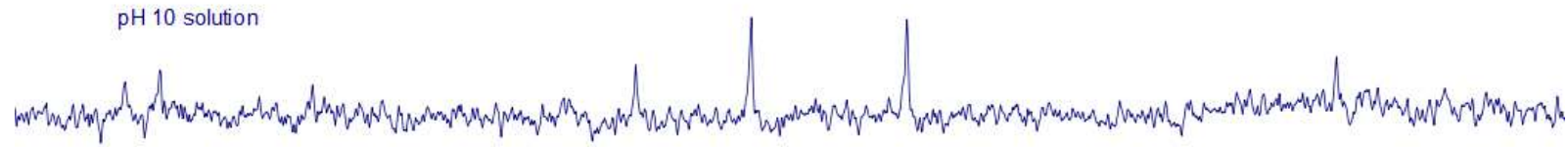

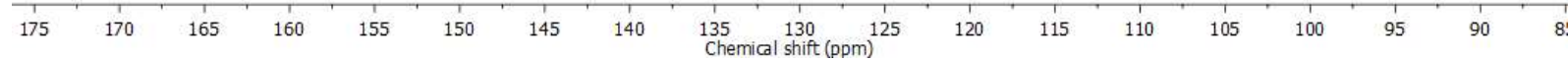

Figure S11. Effect of $\mathrm{pH}$ on ${ }^{13} \mathrm{C}-\mathrm{NMR}$ spectra of $2 .{ }^{13} \mathrm{C}\left\{{ }^{1} \mathrm{H}\right\}$ spectra were acquired unlocked in 50:50 $\mathrm{CH}_{3} \mathrm{OH}$ :aqueous buffer on a Bruker Avance III with a nitrogen-cooled Prodigy cryoprobe. 16,384 scans were acquired with the composite pulse decoupling program bi_waltz65_256. 


\section{Computational Prediction of pKa Values for 2}

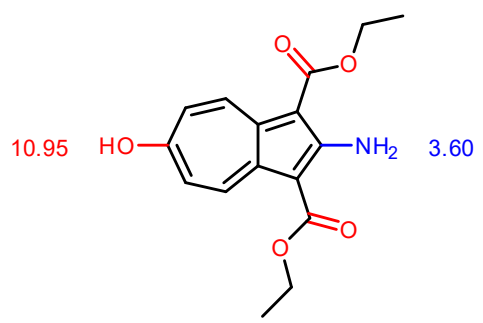

Figure S12. Predicted $\mathrm{p} K \mathrm{a}$ of the hydroxyl $(\mathrm{p} K \mathrm{a}=10.95)$ and the corresponding conjugate acid of the amine $(\mathrm{p} K \mathrm{a}=3.60)$ moieties of 2 using Chemicalize by ChemAxon (accessed at http://www.chemicalize.com on Oct-18-2019).

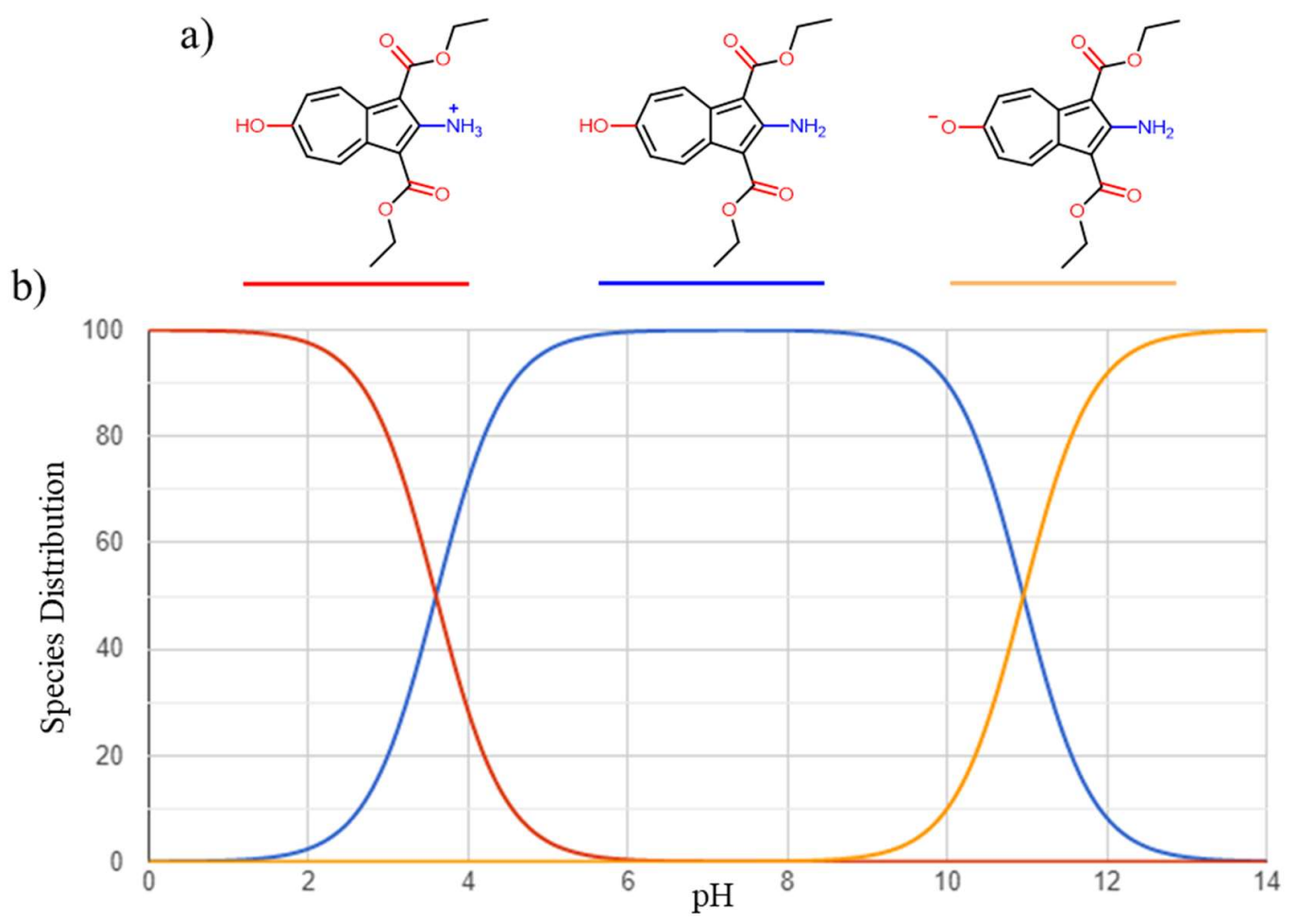

Figure S13. (a) Predicted protonated, neutral, and deprotonated structures of 2 (b) Predicted protonation states of 2 at $\mathrm{pH} 0-14$, using Chemicalize by ChemAxon (accessed through chemicalize.com). 


\section{Fluorescence Response of 1 to $\mathrm{H}_{2} \mathrm{O}_{2}$}

a)
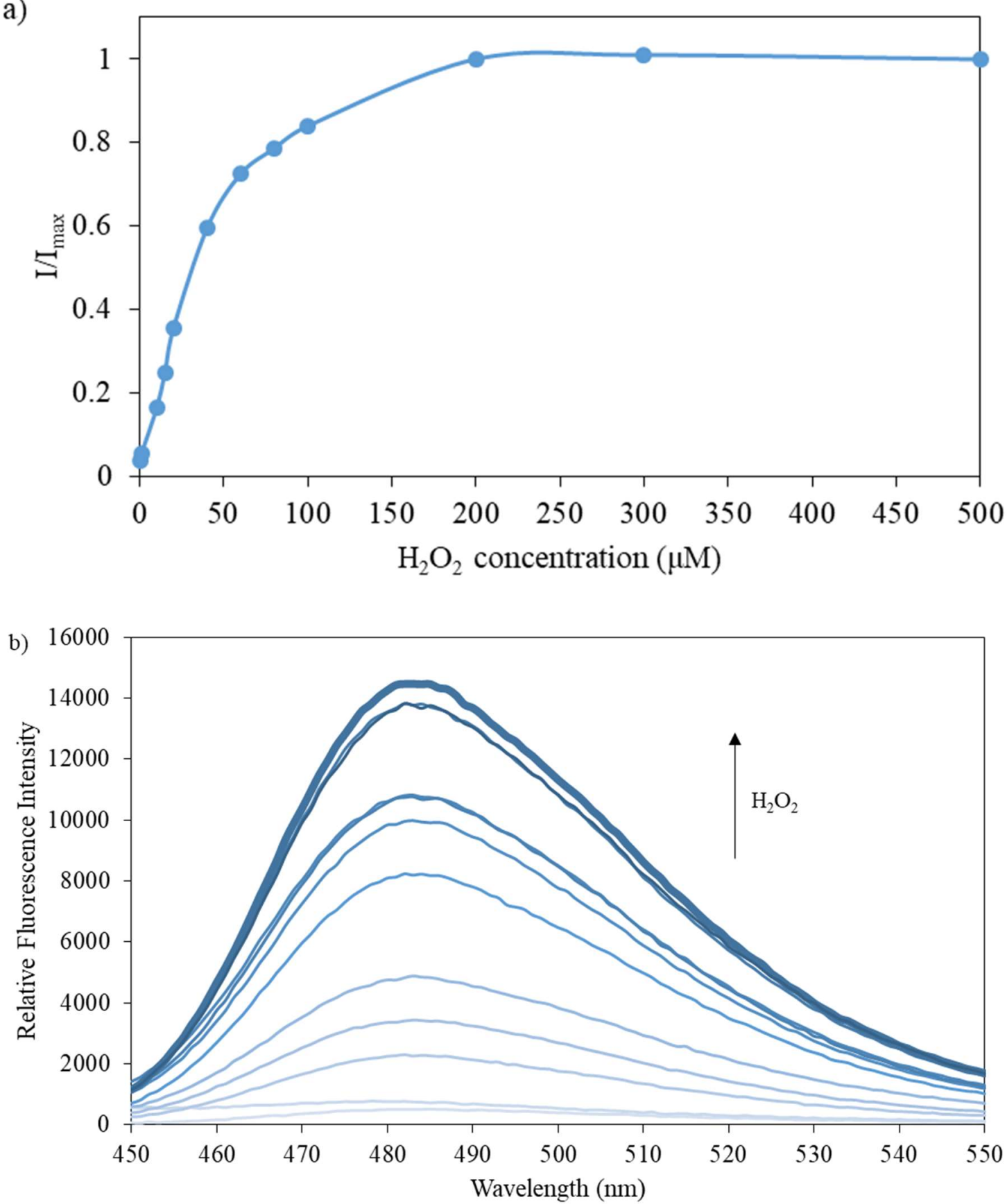

Figure S14: a) Dose dependence curve $(\mathrm{I} / \mathrm{I} \max )$ and b) Emission spectra for $1(500 \mathrm{nM})$ in the presence of $\mathrm{H}_{2} \mathrm{O}_{2}(1,10,15,20,40$, $60,80,100,200,300,400,500 \mu \mathrm{M})$ in PBS buffer $52 \% \mathrm{MeOH}: 48 \% \mathrm{H}_{2} \mathrm{O}(\mathrm{v} / \mathrm{v}), \mathrm{pH}=8.2$ at $25^{\circ} \mathrm{C}$. Fluorescence intensities were measured with $\lambda_{\mathrm{ex}}=350$ (bandwidth: 20$) \mathrm{nm}$ on a BMG Labtech CLARIOstar plate reader. 


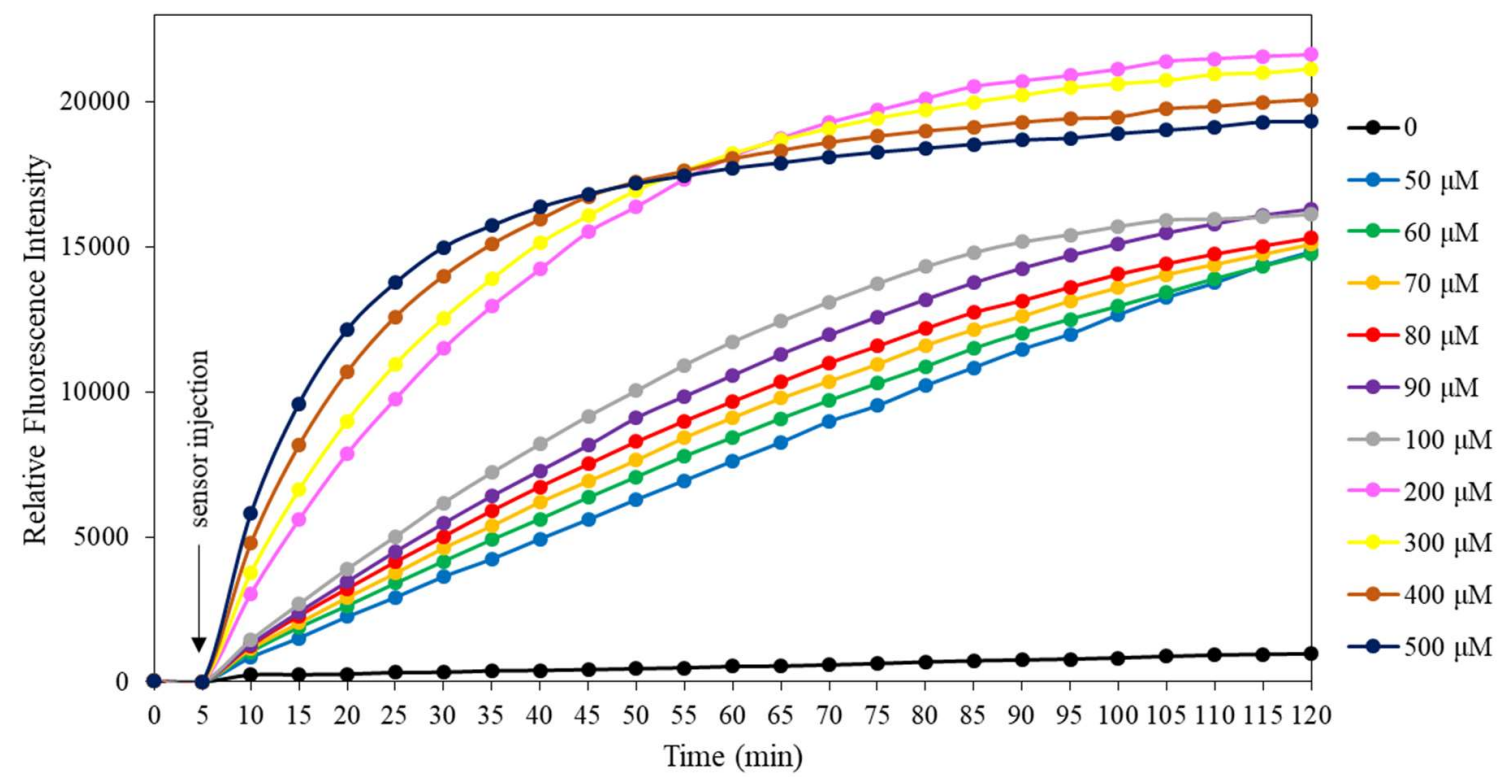

Figure S15. Fluorescence time drive data for $1(500 \mathrm{nM})$ in the presence of $\mathrm{H}_{2} \mathrm{O}_{2}(50,60,70,80,90,100,200,300,400,500$ $\mu \mathrm{M})$ in PBS buffer $52 \% \mathrm{MeOH}: 48 \% \mathrm{H}_{2} \mathrm{O}(\mathrm{v} / \mathrm{v}), \mathrm{pH}=8.2$ at $25{ }^{\circ} \mathrm{C}$. Fluorescence intensities were measured with $\lambda_{\mathrm{ex}}=350$ (bandwidth: 20) $\mathrm{nm}$ and $\lambda_{\mathrm{em}}=483$ (bandwidth: 20 ) $\mathrm{nm}$ on a BMG Labtech CLARIOstar plate reader. 


\section{Fluorescence Response of 1 to $\mathrm{ONOO}^{-}$}
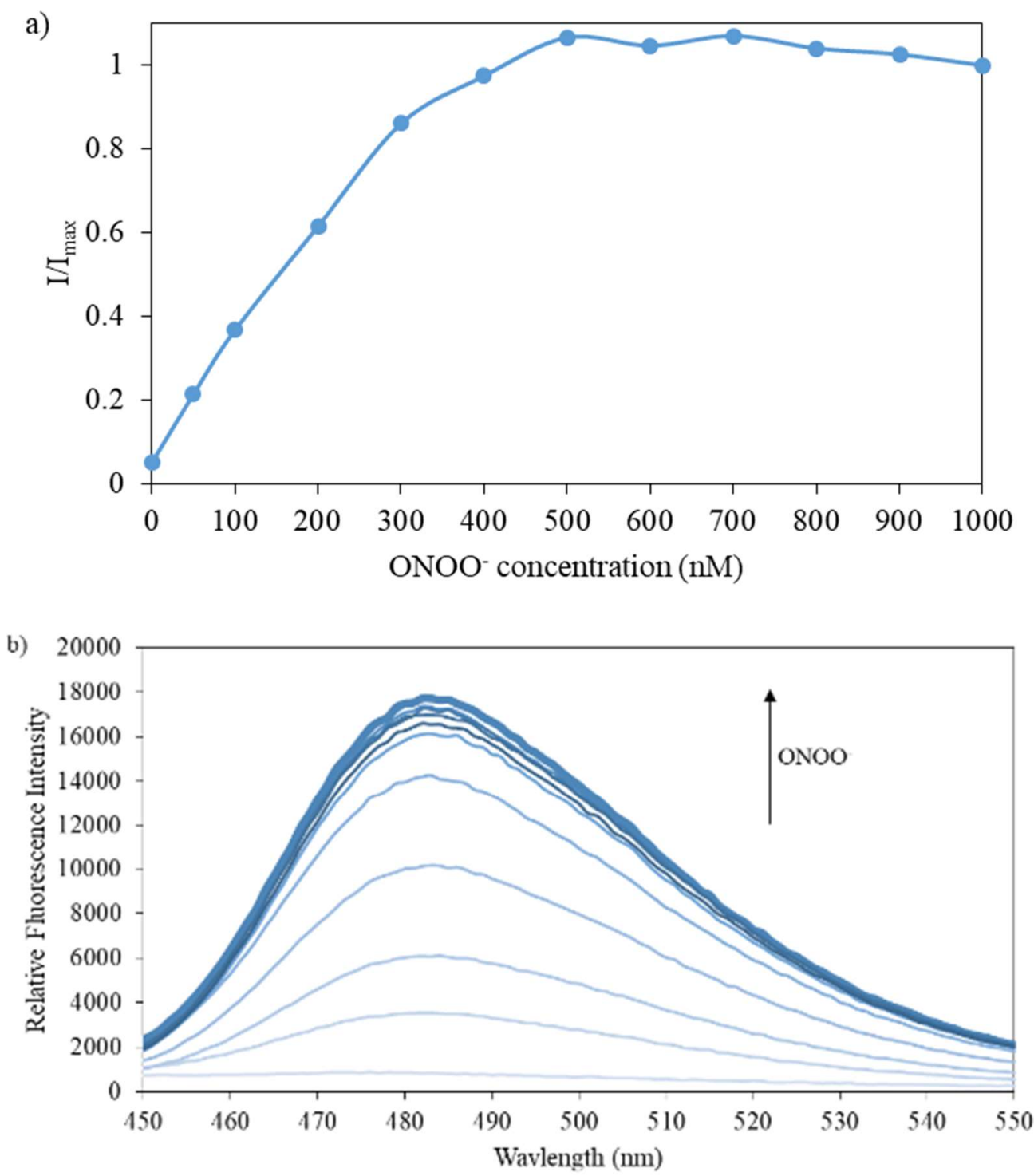

Figure S16: a) Dose dependence curve ( $\left.\mathrm{I} / \mathrm{I}_{\max }\right)$ and b) Emission spectra for $1(500 \mathrm{nM})$ in the presence of $\mathrm{ONOO}^{-}(50,100,200$, $300,400,500,600,700,800,900,1000 \mathrm{nM})$ in PBS buffer $52 \% \mathrm{MeOH}: 48 \% \mathrm{H}_{2} \mathrm{O}(\mathrm{v} / \mathrm{v}), \mathrm{pH}=8.2$ at $25{ }^{\circ} \mathrm{C}$. Fluorescence intensities were measured with $\lambda_{\mathrm{ex}}=350$ (bandwidth 20) $\mathrm{nm}$ on a BMG Labtech CLARIOstar plate reader. 


\section{Selectivity of 1 Towards Multiple ROS}
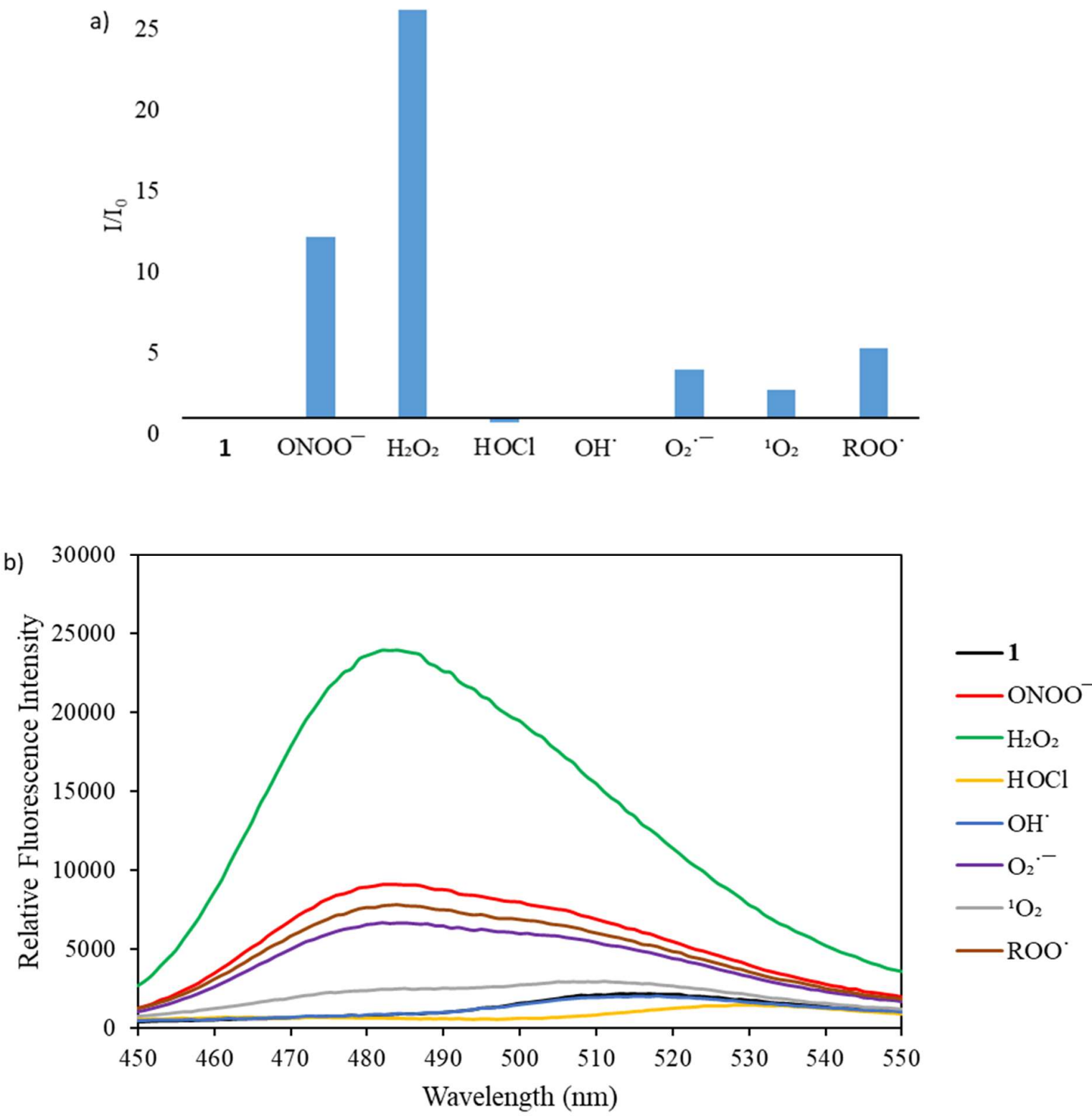

Figure S17. a) Selectivity data and b) Selectivity emission spectra for $1(500 \mathrm{nM})$ in the presence of $\mathrm{ONOO}^{-}(500 \mathrm{nM})$, $\mathrm{OH} \cdot(500 \mu \mathrm{M}), \mathrm{O}_{2}{ }^{-}{ }^{-}(500 \mu \mathrm{M}),{ }^{1} \mathrm{O}_{2}(500 \mu \mathrm{M})$ after 5 min. $\mathrm{H}_{2} \mathrm{O}_{2}(200 \mu \mathrm{M})$, ROO $(500 \mu \mathrm{M})$ and $\mathrm{HOCl}(500 \mu \mathrm{M})$ were measured after $30 \mathrm{~min}$. The data were obtained in PBS buffer $52 \% \mathrm{MeOH}: 48 \% \mathrm{H}_{2} \mathrm{O}(\mathrm{v} / \mathrm{v}), \mathrm{pH}=8.2$ at $25^{\circ} \mathrm{C}$ at $\lambda_{\max }=483 \mathrm{~nm}$. Fluorescence intensities were measured on a BMG Labtech CLARIOstar plate reader. 


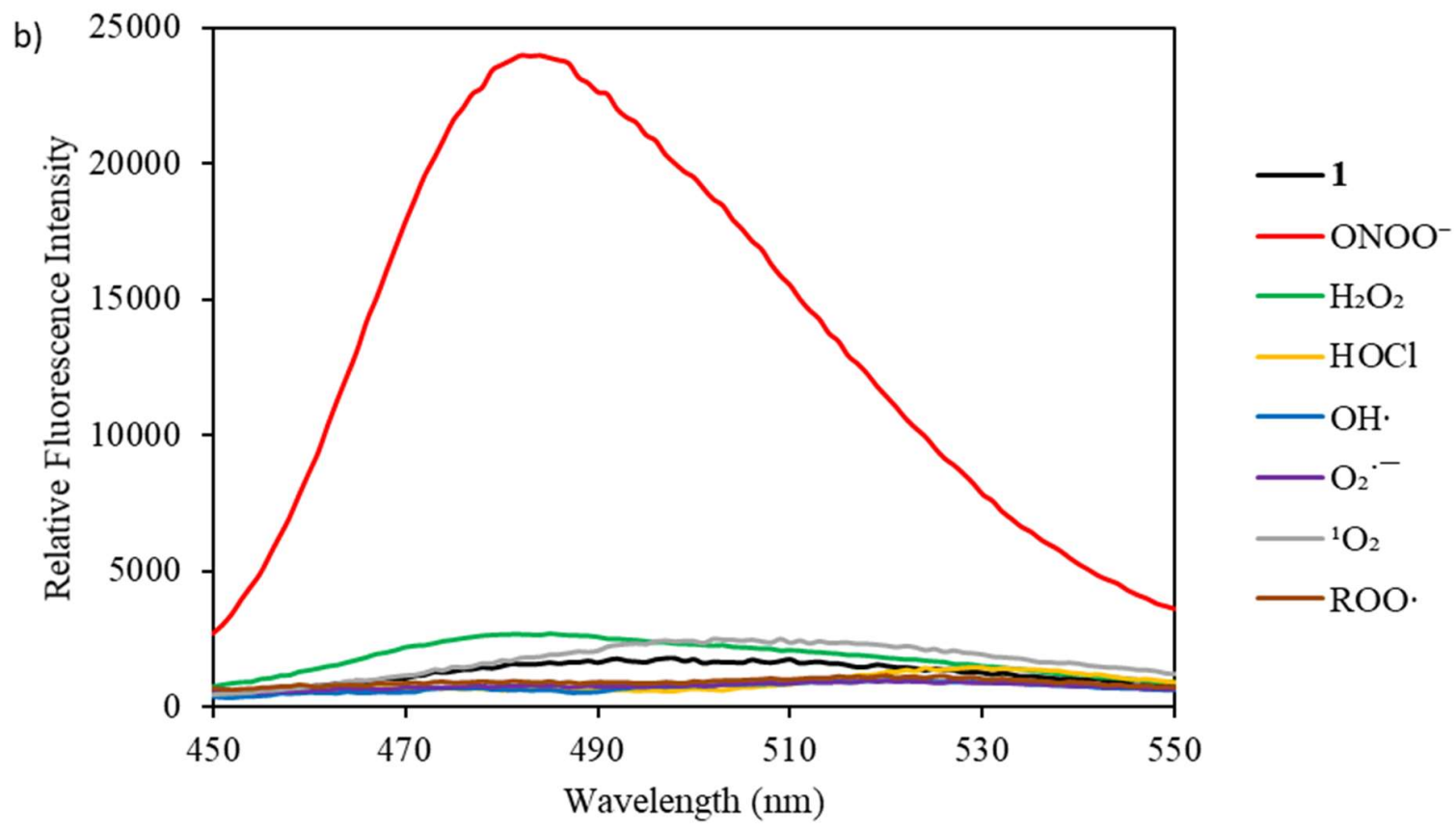

Figure S18. Selectivity emission spectrum for $1(500 \mathrm{nM})$ in the presence of $\mathrm{ONOO}^{-}(500 \mathrm{nM}), \mathrm{H}_{2} \mathrm{O}_{2}(500 \mathrm{nM}), \mathrm{HOCl}(500 \mathrm{nM})$, $\mathrm{OH}^{-}(500 \mathrm{nM}), \mathrm{O}_{2}{ }^{-}(500 \mathrm{nM}),{ }^{1} \mathrm{O}_{2}(500 \mathrm{nM})$, and ROO $(500 \mathrm{nM})$ were measured after $5 \mathrm{~min}$. The data were obtained in PBS buffer $52 \% \mathrm{MeOH}: 48 \% \mathrm{H}_{2} \mathrm{O}(\mathrm{v} / \mathrm{v}), \mathrm{pH}=8.2$ at $25{ }^{\circ} \mathrm{C}$ at $\lambda_{\max }=483 \mathrm{~nm}$. Fluorescence intensities were measured with $\lambda_{\mathrm{ex}}=350$ (bandwidth: 20) nm, on a BMG Labtech CLARIOstar plate reader. Data from this figure were extracted for $\lambda=483 \mathrm{~nm}$ and depicted as a bar chart in Figure 5 of the main article. 

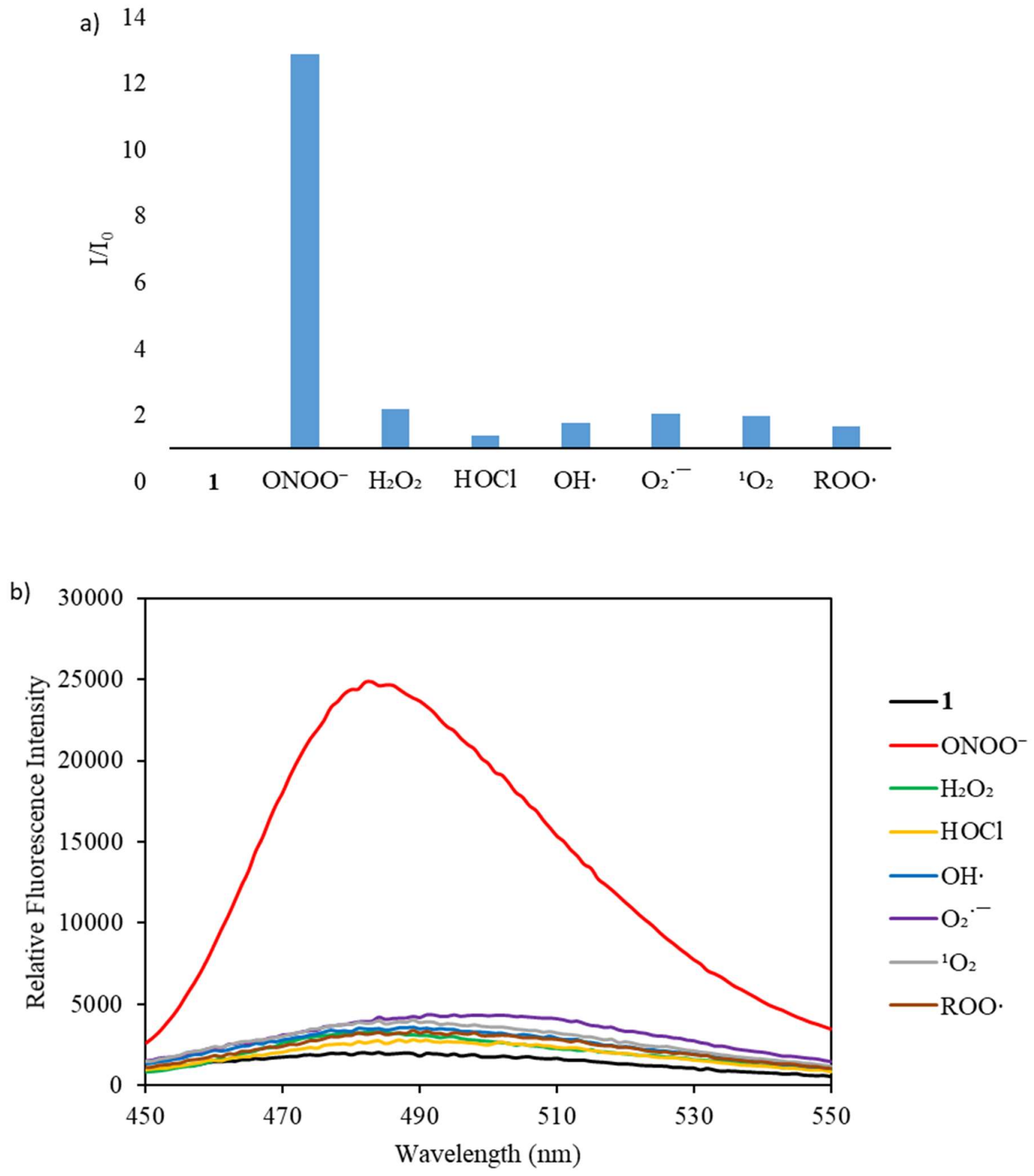

Figure S19. a) Selectivity data and b) Selectivity emission spectrum for $\mathbf{1}(500 \mathrm{nM})$ in the presence of ONOO- $\left(500 \mathrm{nM}^{-}, \mathrm{H}_{2} \mathrm{O}_{2}\right.$ $(500 \mathrm{nM}), \mathrm{HOCl}(500 \mathrm{nM}), \mathrm{OH}^{-}(500 \mathrm{nM}), \mathrm{O}_{2}{ }^{-}(500 \mathrm{nM}),{ }^{1} \mathrm{O}_{2}(500 \mathrm{nM})$, and ROO $(500 \mathrm{nM})$ were measured after $30 \mathrm{~min}$. The data were obtained in PBS buffer $52 \% \mathrm{MeOH}: 48 \% \mathrm{H}_{2} \mathrm{O}(\mathrm{v} / \mathrm{v}), \mathrm{pH}=8.2$ at $25{ }^{\circ} \mathrm{C}$ at $\lambda_{\max }=483 \mathrm{~nm}$. Fluorescence intensities were measured with $\lambda_{\mathrm{ex}}=350$ (bandwidth: 20 ) nm, on a BMG Labtech CLARIOstar plate reader. 


\section{UV-Vis Kinetic experiment with $\mathrm{H}_{2} \mathrm{O}_{2}$}

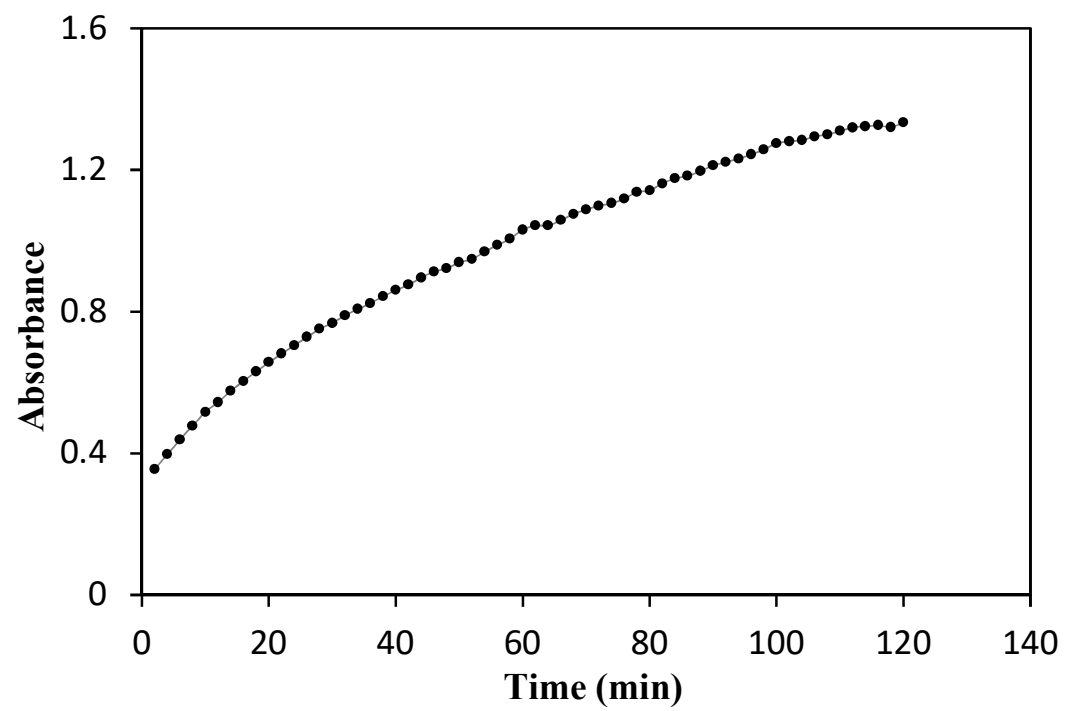

Figure S20. Exposure of 1 (MeCN-PBS Buffer* 1:99, v/v, $50 \mu \mathrm{M})$ to 2 equivalents of $\mathrm{H}_{2} \mathrm{O}_{2}(100 \mu \mathrm{M})$. The change in absorbance $(\lambda=335 \mathrm{~nm})$ was measured every 2 minutes for a total of 120 minutes.

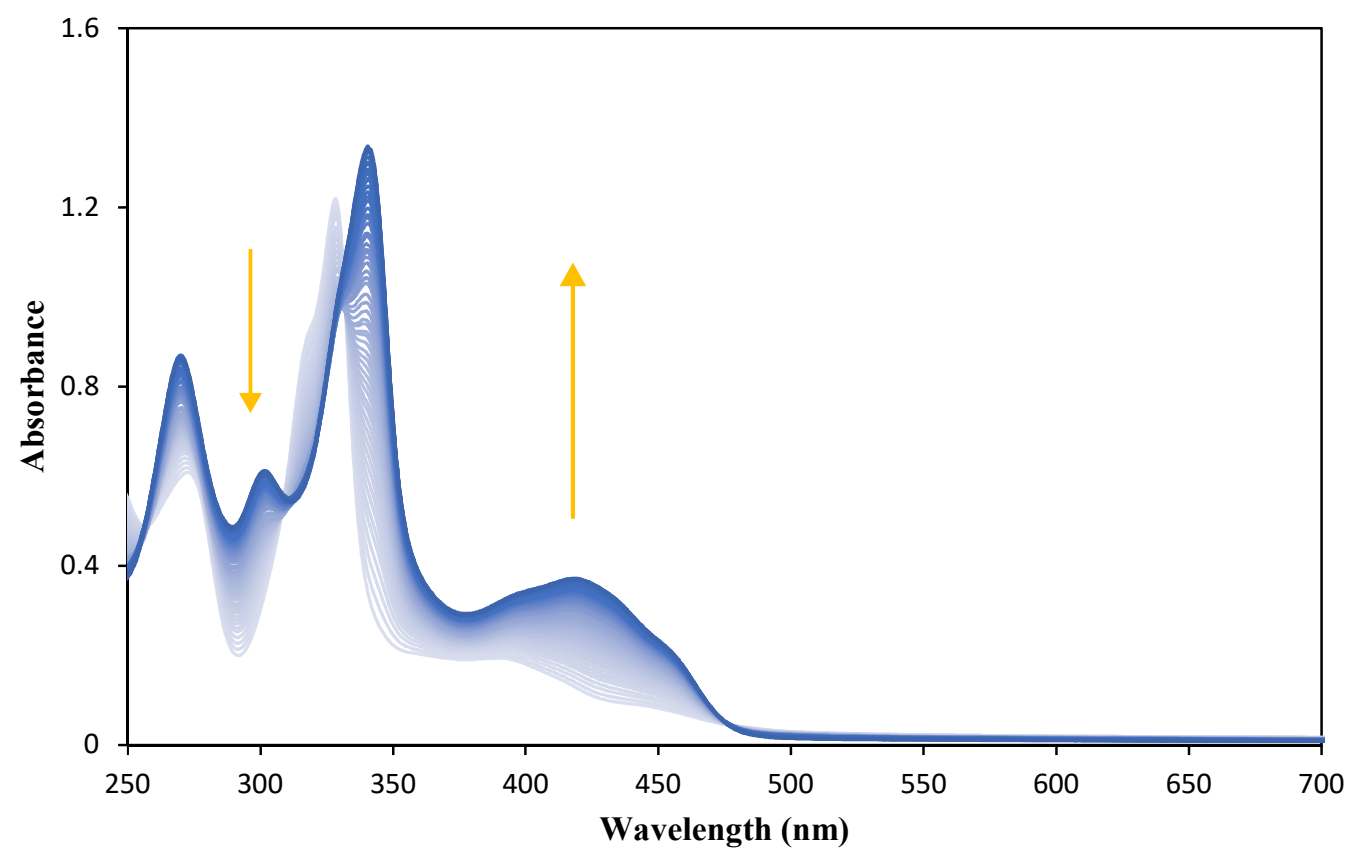

Figure S21. Exposure of 1 (MeCN-PBS buffer* 1:99, v/v, $50 \mu \mathrm{M})$ to 2 equivalents of $\mathrm{H}_{2} \mathrm{O}_{2}(100 \mu \mathrm{M})$. The change in absorbance $(\lambda=335 \mathrm{~nm})$ was measured every 2 minutes for a total of 120 minutes. Pale blue line: time $=0$ min. Dark blue line: time $=120 \mathrm{~min}$. 


\section{UV/Vis Titration with $\mathrm{H}_{2} \mathrm{O}_{2}$}

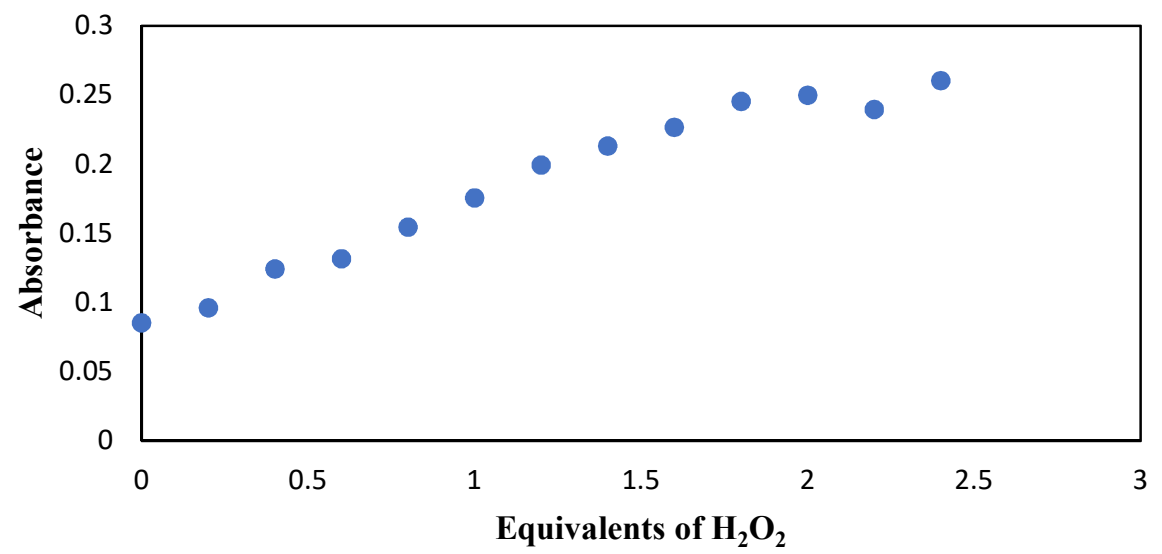

Figure S22. Calibration curve of $\mathbf{1}$ and $\mathrm{H}_{2} \mathrm{O}_{2}$ in DMSO : PBS buffer* solution (1:99, v/v), established by measuring the absorbance $(\lambda=335 \mathrm{~nm})$ of 1 with varying equivalence of $\mathrm{H}_{2} \mathrm{O}_{2}$, measured after a 30 min incubation period.

Table S1. Solutions used to establish calibration curve shown in Figure S22.

\begin{tabular}{|l|l|l|l|}
\hline \multicolumn{1}{|c|}{$\begin{array}{c}\text { Equivalents } \\
\mathrm{H}_{2} \mathrm{O}_{2}\end{array}$} & $\begin{array}{c}\text { Buffer volume } \\
(\mu \mathrm{L})\end{array}$ & \multicolumn{1}{c|}{$\begin{array}{c}\text { Volume 1 } \\
(5 \mathrm{mM} \text { in DMSO, } \mu \mathrm{L})\end{array}$} & $\begin{array}{c}\text { Volume } \mathrm{H}_{2} \mathrm{O}_{2} \\
(5 \mathrm{mM}, \mu \mathrm{L})\end{array}$ \\
\hline 0 & 9900 & 100 & 0 \\
\hline 0.1 & 9890 & 100 & 10 \\
\hline 0.2 & 9880 & 100 & 20 \\
\hline 0.3 & 9870 & 100 & 30 \\
\hline 0.4 & 9860 & 100 & 40 \\
\hline 0.5 & 9850 & 100 & 50 \\
\hline 0.6 & 9840 & 100 & 60 \\
\hline 0.7 & 9830 & 100 & 70 \\
\hline 0.8 & 9820 & 100 & 80 \\
\hline 0.9 & 9810 & 100 & 90 \\
\hline 1.0 & 9800 & 100 & 100 \\
\hline 1.2 & 9780 & 100 & 120 \\
\hline 1.4 & 9760 & 100 & 140 \\
\hline 1.6 & 9740 & 100 & 160 \\
\hline 1.8 & 9720 & 100 & 180 \\
\hline 2.0 & 9700 & 100 & 200 \\
\hline 2.2 & 9680 & 100 & 220 \\
\hline 2.4 & 9660 & 100 & 240 \\
\hline
\end{tabular}




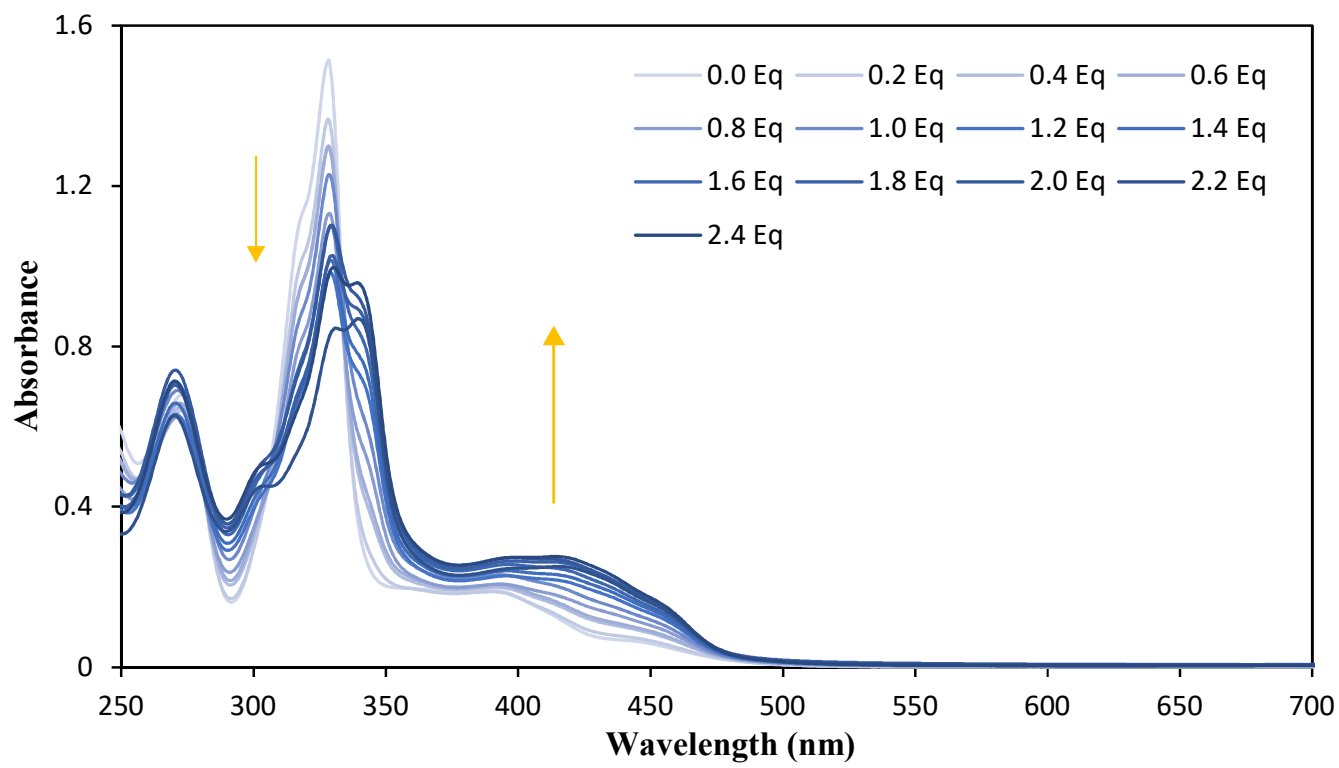

Figure S23. Absorbance titration of 1 against increasing equivalents of $\mathrm{H}_{2} \mathrm{O}_{2}$ in DMSO : PBS buffer* (1:99, v/v).

*PBS Buffer consisted of $52 \% \mathrm{MeOH}: 48 \% \mathrm{H}_{2} \mathrm{O}, \mathrm{v} / \mathrm{v}$ 


\section{UV/Vis Titration with ONOO-}

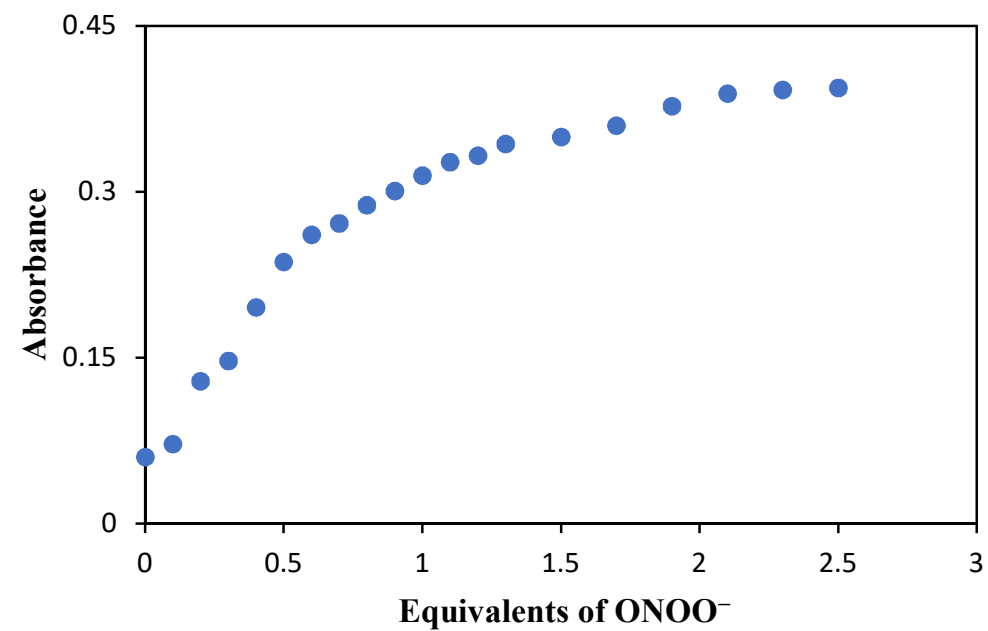

Figure S24. Calibration curve of 1 and $\mathrm{ONOO}^{-}$in DMSO : PBS buffer* (1:99, v/v), established by measuring the absorbance $(\lambda=335 \mathrm{~nm})$ of 1 with varying equivalents of $\mathrm{ONOO}^{-}$, measured after a 5 min incubation period.

Table S2. Solutions used to establish calibration curve Figure S24.

\begin{tabular}{|l|l|l|l|}
\hline $\begin{array}{c}\text { Equivalence } \\
\text { ONOO }^{-}\end{array}$ & $\begin{array}{c}\text { Buffer volume } \\
(\mu \mathrm{L})\end{array}$ & \multicolumn{1}{c|}{$\begin{array}{c}\text { Volume 1 } \\
(5 \mathrm{mM} \text { in DMSO, } \mu \mathrm{L})\end{array}$} & $\begin{array}{c}\text { Volume ONOO } \\
(5 \mathrm{mM}, \mu \mathrm{L})\end{array}$ \\
\hline 0 & 9900 & 100 & 0 \\
\hline 0.1 & 9890 & 100 & 10 \\
\hline 0.2 & 9880 & 100 & 20 \\
\hline 0.3 & 9870 & 100 & 30 \\
\hline 0.4 & 9860 & 100 & 40 \\
\hline 0.5 & 9850 & 100 & 50 \\
\hline 0.6 & 9840 & 100 & 60 \\
\hline 0.7 & 9830 & 100 & 70 \\
\hline 0.8 & 9820 & 100 & 80 \\
\hline 0.9 & 9810 & 100 & 90 \\
\hline 1.0 & 9800 & 100 & 100 \\
\hline 1.1 & 9790 & 100 & 110 \\
\hline 1.2 & 9780 & 100 & 120 \\
\hline 1.3 & 9770 & 100 & 130 \\
\hline 1.5 & 9750 & 100 & 150 \\
\hline 1.7 & 9730 & 100 & 170 \\
\hline 1.9 & 9710 & 100 & 190 \\
\hline 2.1 & 9690 & 100 & 210 \\
\hline 2.3 & 9670 & 100 & 230 \\
\hline 2.5 & 9650 & 100 & 250 \\
\hline
\end{tabular}

*PBS Buffer consisted of $52 \% \mathrm{MeOH}: 48 \% \mathrm{H}_{2} \mathrm{O}, \mathrm{v} / \mathrm{v}$ 


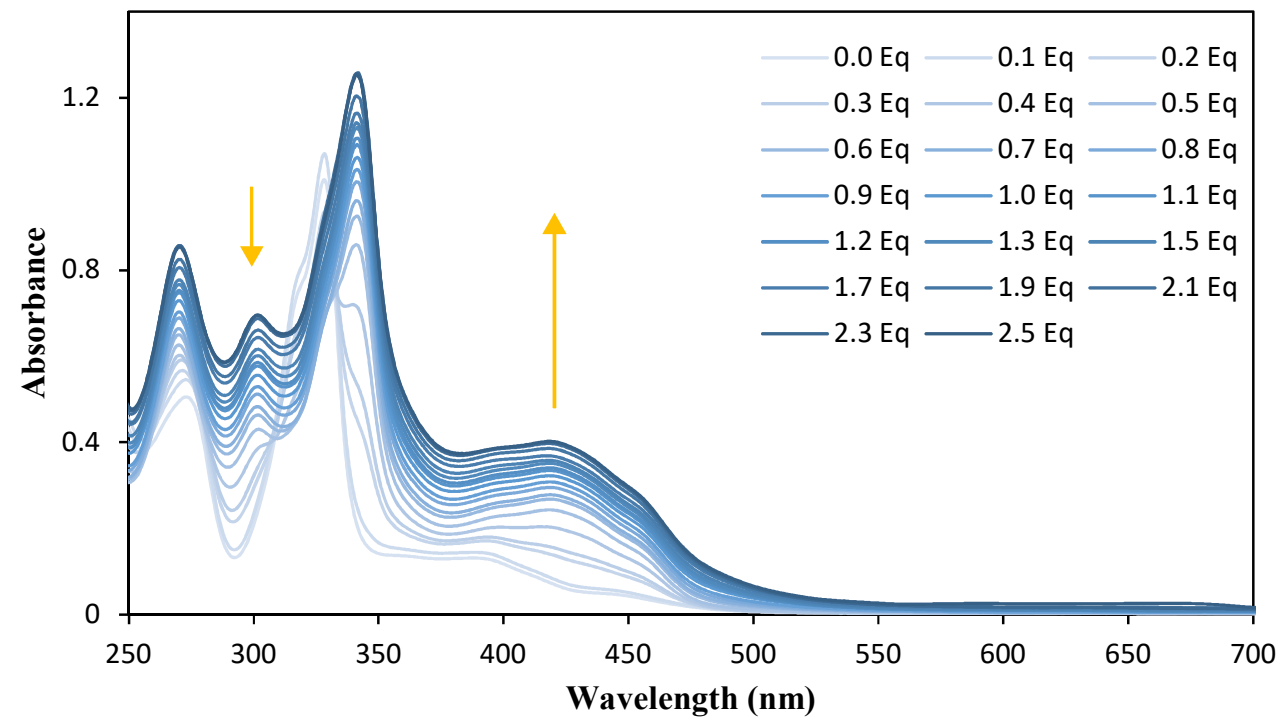

Figure S25. Absorbance titration of 1 against increasing equivalents of ONOO- in DMSO : PBS buffer* (1:99, v/v).

*PBS Buffer consisted of $52 \% \mathrm{MeOH}: 48 \% \mathrm{H}_{2} \mathrm{O}, \mathrm{v} / \mathrm{v}$ 


\section{Two-Photon Microscopy Results}

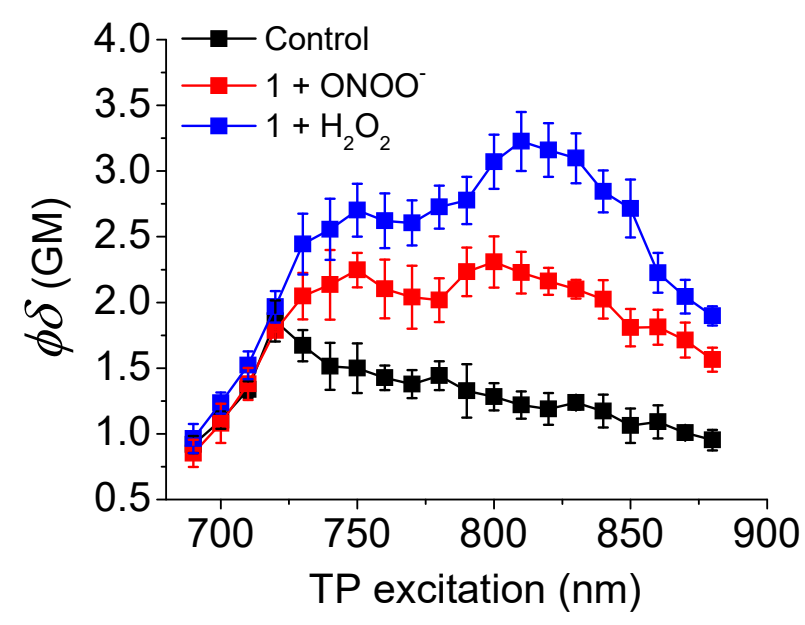

Figure S26. Two-photon action spectra of $1(500 \mathrm{nM})$ only (control), and with $\mathrm{ONOO}^{-}(500 \mathrm{nM})$ and $\mathrm{H}_{2} \mathrm{O}_{2}(200 \mu \mathrm{M})$ in PBS buffer $52 \% \mathrm{H}_{2} \mathrm{O}: 48 \% \mathrm{MeOH}, \mathrm{pH}=8.2$.

(a)
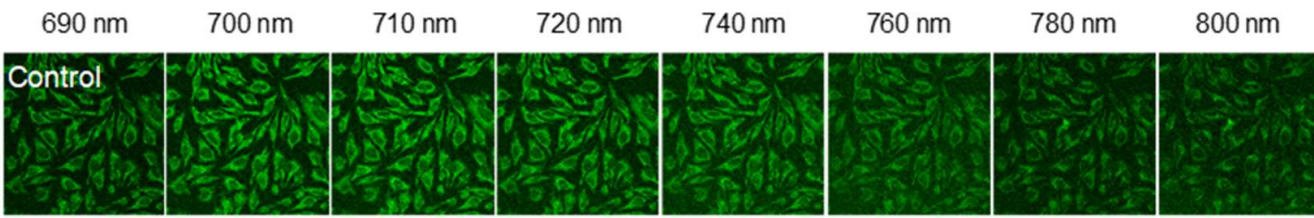

$820 \mathrm{~nm}$
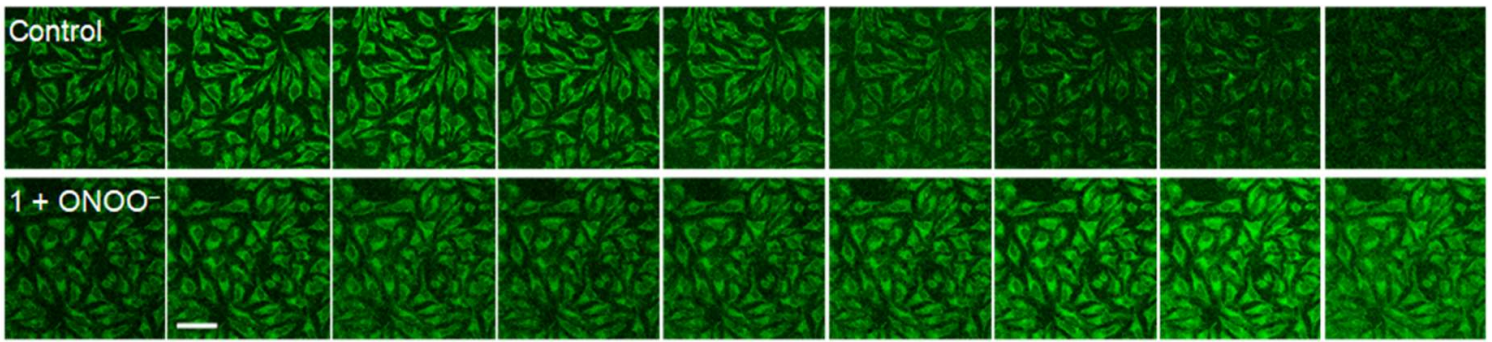

(b)

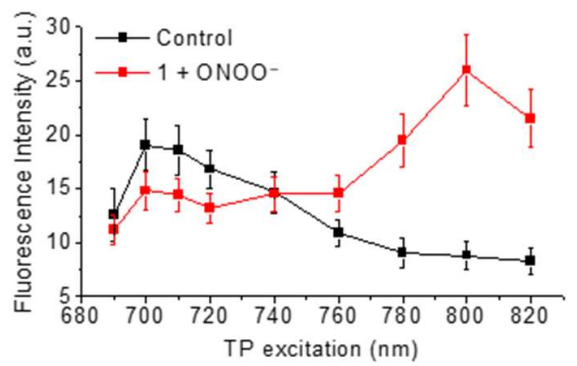

(c)

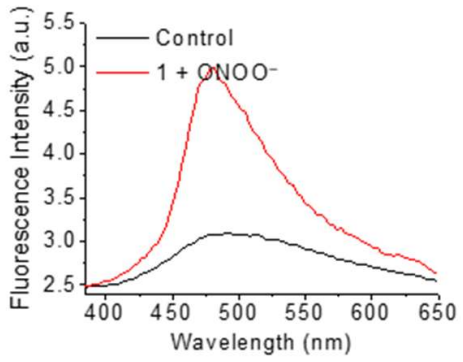

Figure S27. (a) TPM images: HeLa cells were stained with 1 ( $5 \mu \mathrm{M}, 30 \mathrm{~min}$ ) before (upper) and after (lower) pretreatment with exogenously added $\mathrm{ONOO}^{-}(100 \mu \mathrm{M}, 30 \mathrm{~min})$ before labeling with 1 at different excitation wavelengths from $690 \mathrm{~nm}$ to $820 \mathrm{~nm}$. (b) Average fluorescence intensities of corresponding to TPM images highlighted in ESI Fig. 17a. (c) Cell spectrum of 1 at 800 $\mathrm{nm}$ excitation. Images were obtained at $400-600 \mathrm{~nm}$ emission windows. Scale bars $=50 \mu \mathrm{m}$. 


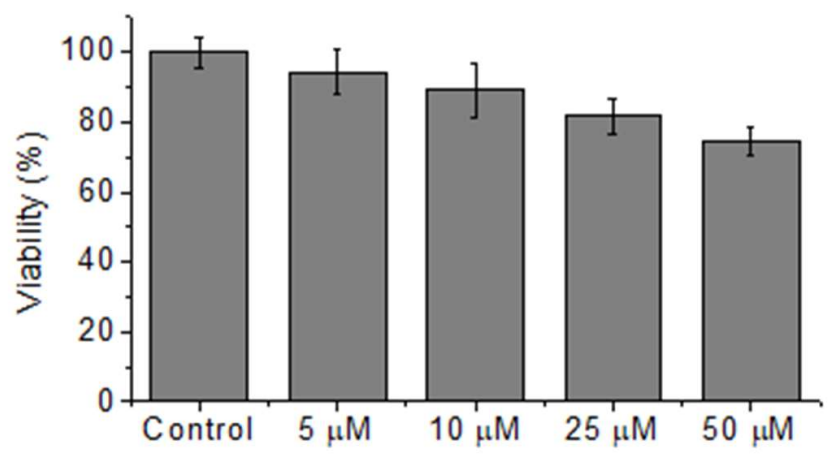

Figure S28. Cytotoxicity of $\mathbf{1}$ in RAW 264.7 macrophages was measured using MTT assays. Cells were incubated with $\mathbf{1}(0-50$ $\mu \mathrm{M})$ for $4 \mathrm{~h}$.

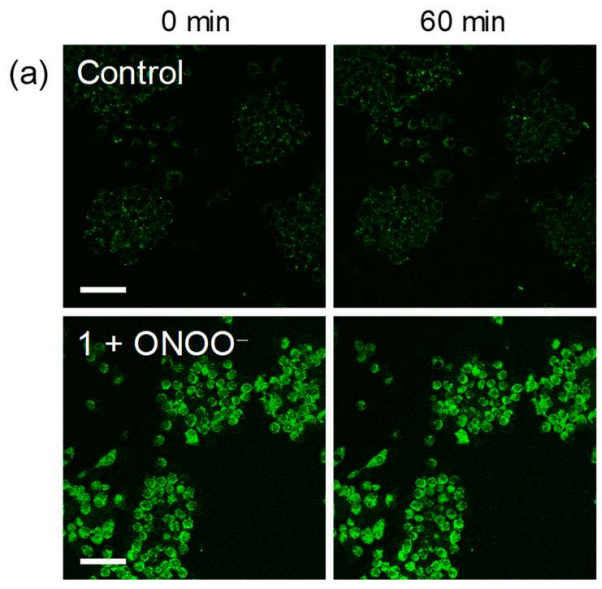

(b)

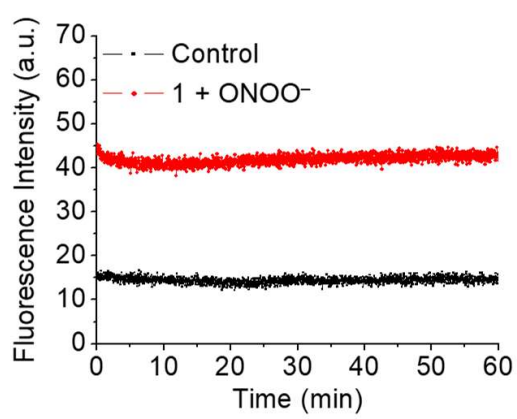

Figure S29. (a) TPM images: RAW 264.7 macrophages stained with 1 ( $5 \mu \mathrm{M}, 30 \mathrm{~min})$ at different time points before (upper) and after (lower) pretreatment with exogenously added $\mathrm{ONOO}^{-}(100 \mu \mathrm{M}, 30 \mathrm{~min})$. (b) Fluorescence intensity changing as a function of time. The fluorescence intensities were recorded at 2 second intervals for $1 \mathrm{~h}$. Images were obtained using $800 \mathrm{~nm}$ as the excitation wavelength and $400-600 \mathrm{~nm}$ emission windows. Scale bars $=50 \mu \mathrm{m}$. 

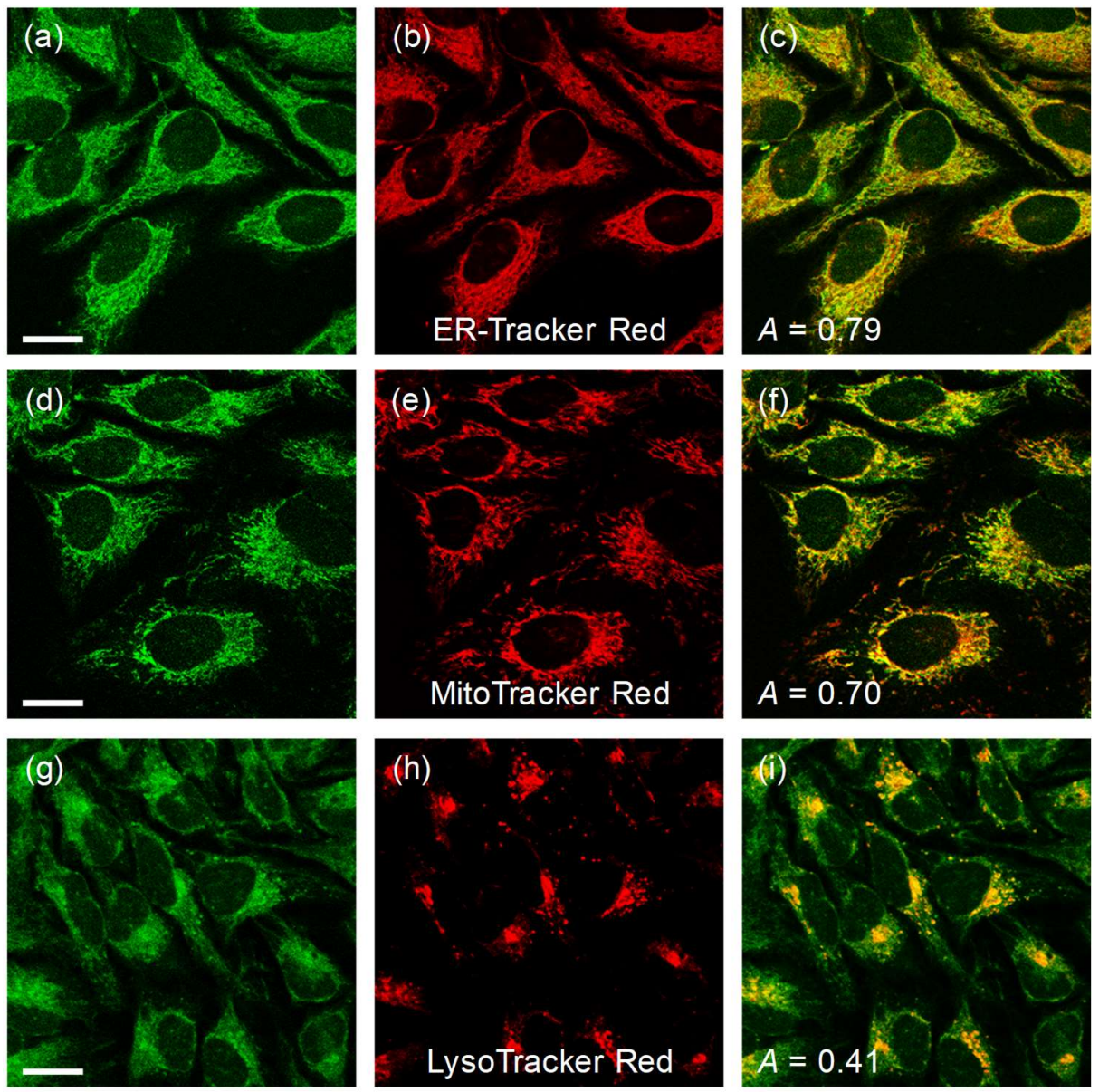

Figure S30. Co-localization assays with (a, d, and g) $1(5 \mu \mathrm{M})$ and $(b, e$, and $h)$ organelle trackers $(1 \mu \mathrm{M})$ in HeLa cells. (c, f, and i) Merged images. Images were obtained at $720 \mathrm{~nm}$ (for 1) and $552 \mathrm{~nm}$ (for organelle trackers) excitation wavelengths and 400 $550 \mathrm{~nm}$ (for 1) and 640-690 nm (for organelle trackers) emission windows, respectively. Scale bars $=20 \mu \mathrm{m}$. 


\section{Comparison of 2 with other Fluorophores}

Table S3. Comparison of $\mathbf{2}$ with other Fluorophores.

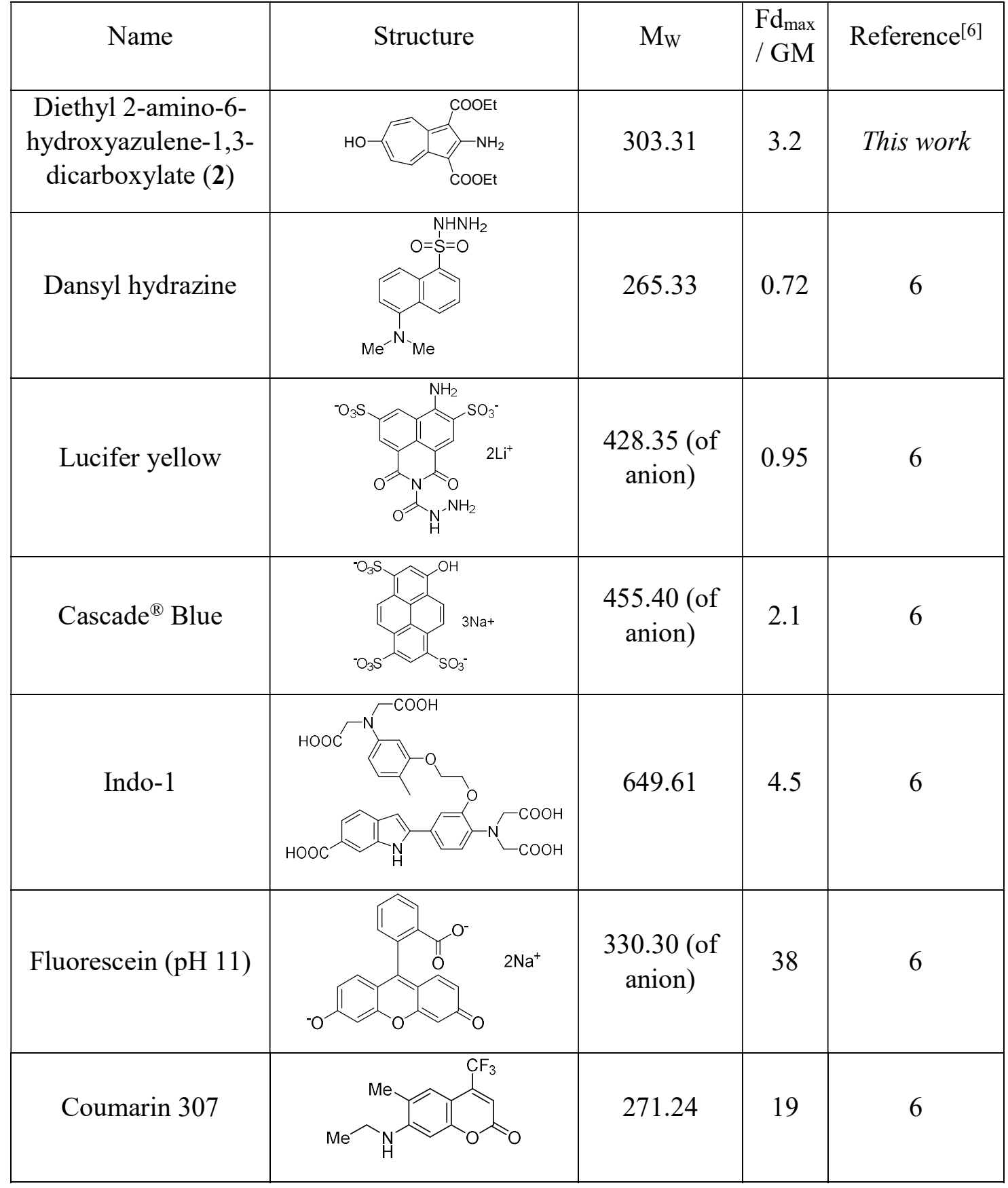




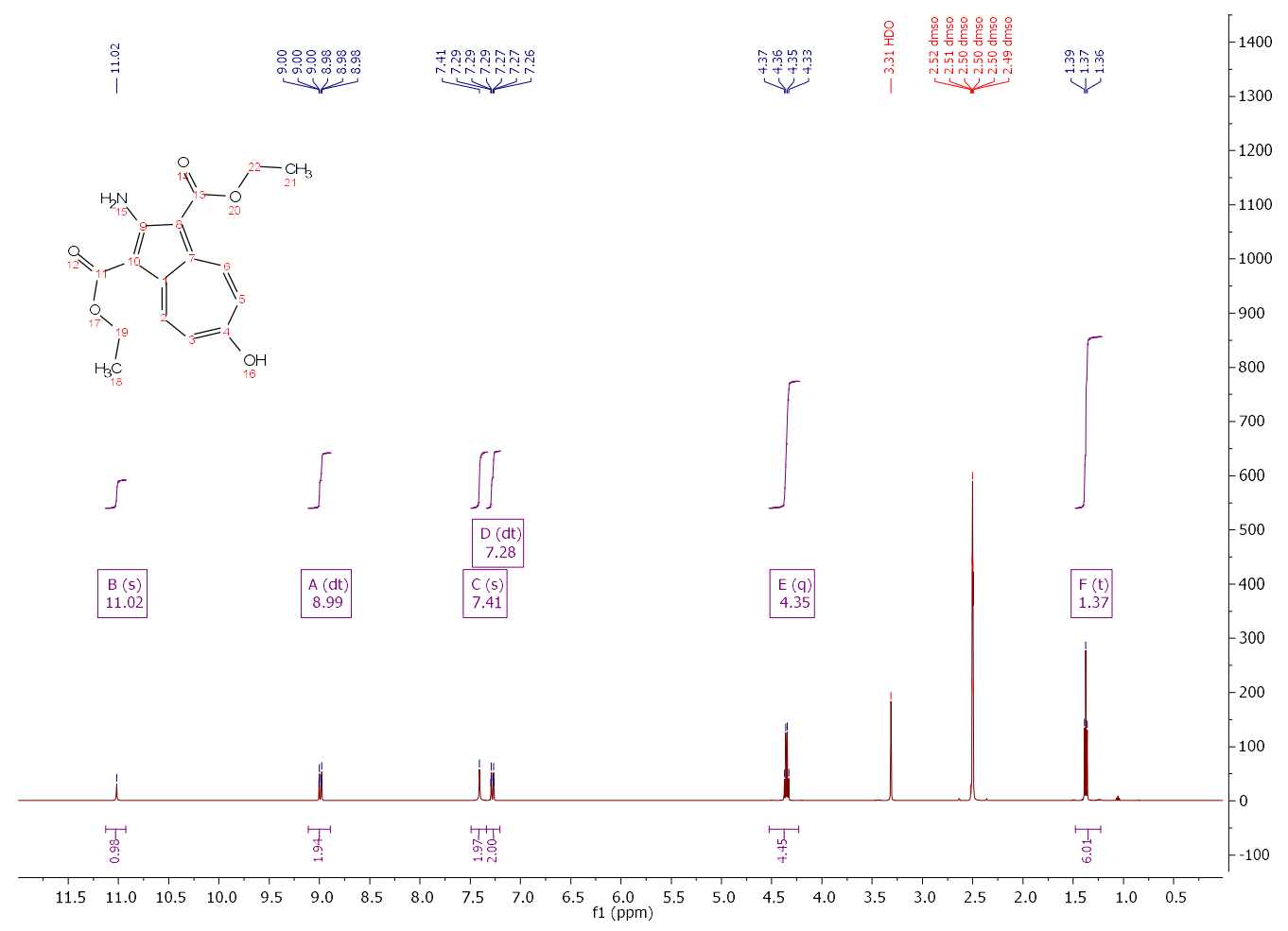

Figure S31: ${ }^{1} \mathrm{H}-\mathrm{NMR}$ spectrum of 2 in DMSO- $d_{6}$

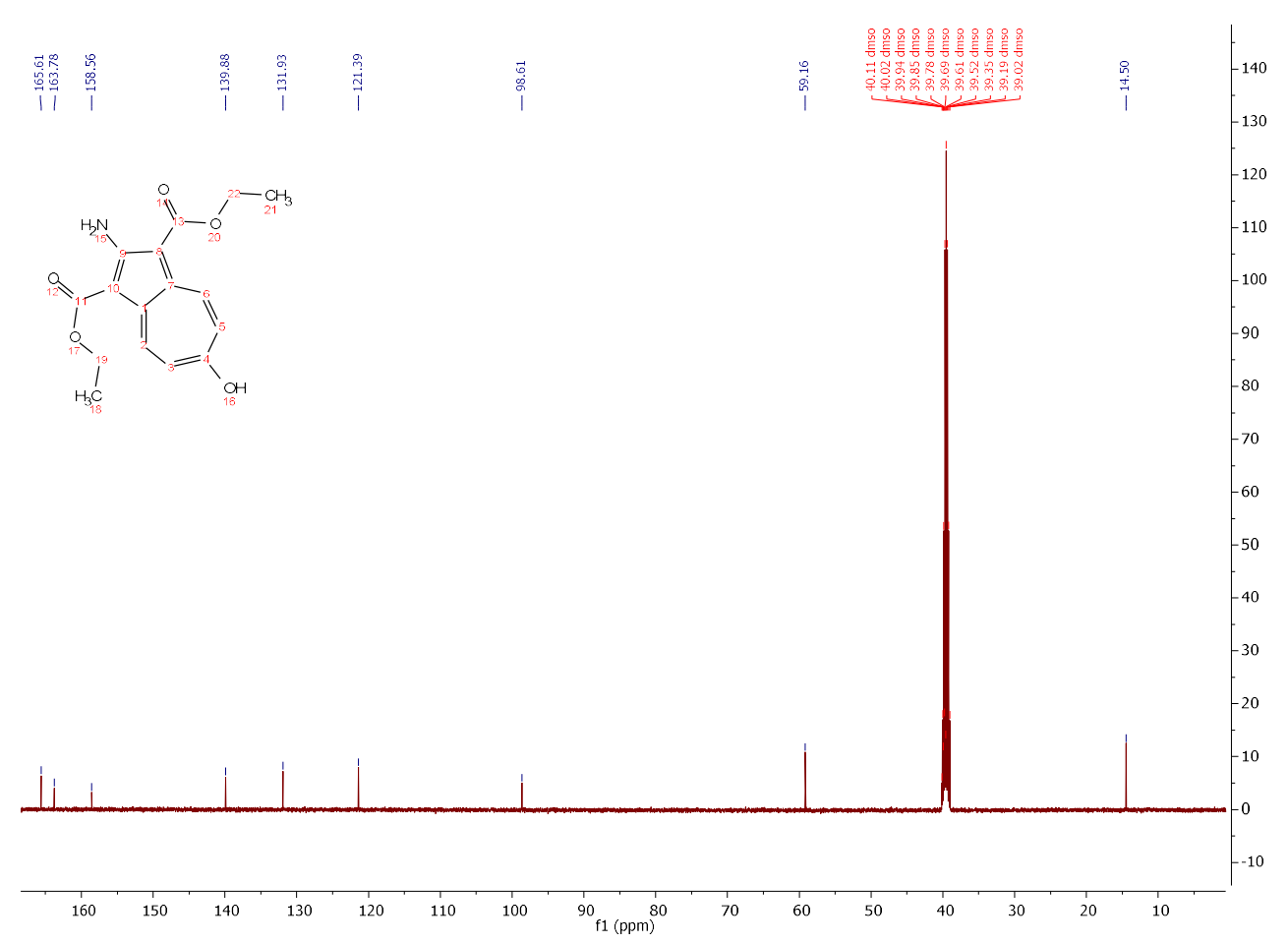

Figure S32: ${ }^{13} \mathrm{C}-\mathrm{NMR}$ spectrum of $\mathbf{2}$ in DMSO- $d_{6}$ 


\section{X-ray crystallographic details}

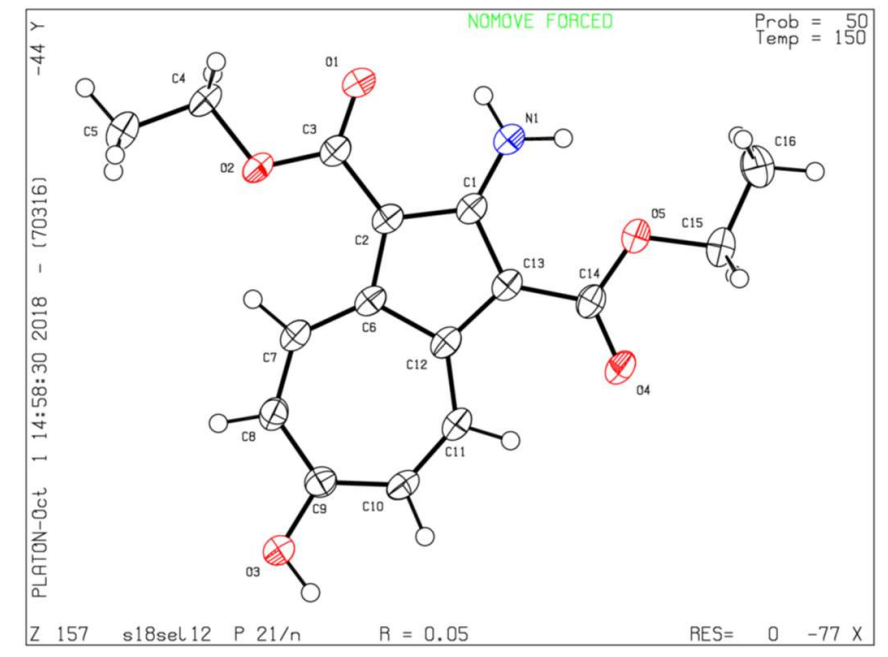

Figure S33: ORTEP plot of $\mathbf{2}$, with ellipsoids shown at 50\% probability and hydrogens shown as spheres of arbitrary radius.

Table S4. Crystal data and structure refinement for 2.

CCDC Number

Empirical formula

Formula weight

Temperature

Wavelength

Crystal system

Space group

Unit cell dimensions

Volume

Z

Density (calculated)

Absorption coefficient

$\mathrm{F}(000)$

Crystal size

Theta range for data collection

Index ranges

Reflections collected

Independent reflections

Completeness to theta $=67.684^{\circ}$

Absorption correction

Max. and min. transmission

Refinement method

Data / restraints / parameters

Goodness-of-fit on $\mathrm{F}^{2}$

Final $\mathrm{R}$ indices [I $>2$ sigma(I)]

$\mathrm{R}$ indices (all data)

Extinction coefficient

Largest diff. peak and hole
1899490

$\mathrm{C}_{16} \mathrm{H}_{17} \mathrm{NO}_{5}$

303.30

$150.00(10) \mathrm{K}$

$1.54184 \AA$

Monoclinic

$\mathrm{P} 21 / \mathrm{n}$

$\mathrm{a}=4.8891(2) \AA$

$\alpha=90^{\circ}$.

$\mathrm{b}=9.6866(3) \AA$

$\beta=91.778(3)^{\circ}$.

$\mathrm{c}=30.5833(9) \AA$

$\gamma=90^{\circ}$.

1447.69(9) $\AA^{3}$

4

$1.392 \mathrm{Mg} / \mathrm{m}^{3}$

$0.868 \mathrm{~mm}^{-1}$

640

$0.405 \times 0.058 \times 0.043 \mathrm{~mm}^{3}$

2.891 to $72.783^{\circ}$.

$-4<=\mathrm{h}<=5,-11<=\mathrm{k}<=11,-37<=\mathrm{l}<=36$

8799

$2832[\mathrm{R}($ int $)=0.0353]$

$100.0 \%$

Semi-empirical from equivalents

1.00000 and 0.76609

Full-matrix least-squares on $\mathrm{F}^{2}$

$2832 / 0 / 213$

1.035

$\mathrm{R} 1=0.0455, \mathrm{wR} 2=0.1122$

$\mathrm{R} 1=0.0570, \mathrm{wR} 2=0.1192$

$\mathrm{n} / \mathrm{a}$

0.226 and -0.226 e. $\AA^{-3}$ 
Table S5. Atomic coordinates $\left(\mathrm{x} 10^{4}\right)$ and equivalent isotropic displacement parameters $\left(\AA^{2} \times 10^{3}\right)$ for 2. $U(\mathrm{eq})$ is defined as one third of the trace of the orthogonalized $U^{i j}$ tensor.

\begin{tabular}{lrrrr}
\hline & $\mathrm{x}$ & $\mathrm{y}$ & $\mathrm{z}$ & $\mathrm{U}(\mathrm{eq})$ \\
\hline $\mathrm{N}(1)$ & $4018(3)$ & $5212(2)$ & $4238(1)$ & $34(1)$ \\
$\mathrm{O}(1)$ & $7229(3)$ & $6070(2)$ & $4929(1)$ & $42(1)$ \\
$\mathrm{O}(2)$ & $10251(3)$ & $7767(1)$ & $4830(1)$ & $34(1)$ \\
$\mathrm{O}(3)$ & $13176(3)$ & $10679(1)$ & $2990(1)$ & $35(1)$ \\
$\mathrm{O}(4)$ & $3482(3)$ & $5997(1)$ & $2854(1)$ & $35(1)$ \\
$\mathrm{O}(5)$ & $1906(3)$ & $4801(1)$ & $3422(1)$ & $32(1)$ \\
$\mathrm{C}(1)$ & $5522(4)$ & $6126(2)$ & $4024(1)$ & $27(1)$ \\
$\mathrm{C}(2)$ & $7616(4)$ & $6981(2)$ & $4218(1)$ & $28(1)$ \\
$\mathrm{C}(3)$ & $8316(4)$ & $6881(2)$ & $4683(1)$ & $31(1)$ \\
$\mathrm{C}(4)$ & $11072(4)$ & $7621(2)$ & $5288(1)$ & $38(1)$ \\
$\mathrm{C}(5)$ & $13131(5)$ & $8732(2)$ & $5390(1)$ & $45(1)$ \\
$\mathrm{C}(6)$ & $8759(4)$ & $7809(2)$ & $3886(1)$ & $27(1)$ \\
$\mathrm{C}(7)$ & $10873(4)$ & $8772(2)$ & $3940(1)$ & $29(1)$ \\
$\mathrm{C}(8)$ & $12092(4)$ & $9613(2)$ & $3638(1)$ & $30(1)$ \\
$\mathrm{C}(9)$ & $11568(4)$ & $9737(2)$ & $3187(1)$ & $29(1)$ \\
$\mathrm{C}(10)$ & $9615(4)$ & $9014(2)$ & $2937(1)$ & $32(1)$ \\
$\mathrm{C}(11)$ & $7792(4)$ & $8016(2)$ & $3064(1)$ & $31(1)$ \\
$\mathrm{C}(12)$ & $7330(4)$ & $7450(2)$ & $3475(1)$ & $27(1)$ \\
$\mathrm{C}(13)$ & $5366(4)$ & $6413(2)$ & $3567(1)$ & $27(1)$ \\
$\mathrm{C}(14)$ & $3551(4)$ & $5756(2)$ & $3247(1)$ & $28(1)$ \\
$\mathrm{C}(15)$ & $95(4)$ & $4050(2)$ & $3121(1)$ & $36(1)$ \\
$\mathrm{C}(16)$ & $-1502(4)$ & $3057(2)$ & $3390(1)$ & $42(1)$ \\
& & & & \\
\hline
\end{tabular}

Table S6. Bond lengths $[\AA]$ for 2.

\begin{tabular}{llll}
\hline $\mathrm{N}(1)-\mathrm{C}(1)$ & $1.335(2)$ & $\mathrm{C}(5)-\mathrm{H}(5 \mathrm{C})$ & 0.9800 \\
$\mathrm{~N}(1)-\mathrm{H}(1 \mathrm{~A})$ & $0.93(3)$ & $\mathrm{C}(6)-\mathrm{C}(7)$ & $1.398(3)$ \\
$\mathrm{N}(1)-\mathrm{H}(1 \mathrm{~B})$ & $0.86(2)$ & $\mathrm{C}(6)-\mathrm{C}(12)$ & $1.462(2)$ \\
$\mathrm{O}(1)-\mathrm{C}(3)$ & $1.220(2)$ & $\mathrm{C}(7)-\mathrm{C}(8)$ & $1.380(3)$ \\
$\mathrm{O}(2)-\mathrm{C}(3)$ & $\mathrm{C}(7)-\mathrm{H}(7)$ & 0.9500 \\
$\mathrm{O}(2)-\mathrm{C}(4)$ & $1.343(2)$ & $\mathrm{C}(8)-\mathrm{C}(9)$ & $1.402(2)$ \\
$\mathrm{O}(3)-\mathrm{C}(9)$ & $1.454(2)$ & $\mathrm{C}(8)-\mathrm{H}(8)$ & 0.9500 \\
$\mathrm{O}(3)-\mathrm{H}(3)$ & $\mathrm{C}(9)-\mathrm{C}(10)$ & $1.393(3)$ \\
$\mathrm{O}(4)-\mathrm{C}(14)$ & $\mathrm{C}(10)-\mathrm{C}(11)$ & $1.379(3)$ \\
$\mathrm{O}(5)-\mathrm{C}(14)$ & $\mathrm{C}(10)-\mathrm{H}(10)$ & 0.9500 \\
$\mathrm{O}(5)-\mathrm{C}(15)$ & $\mathrm{C}(11)-\mathrm{C}(12)$ & $1.396(2)$ \\
$\mathrm{C}(1)-\mathrm{C}(13)$ & $1.358(2)$ & $\mathrm{C}(11)-\mathrm{H}(11)$ & 0.9500 \\
$\mathrm{C}(1)-\mathrm{C}(2)$ & $\mathrm{C}(12)-\mathrm{C}(13)$ & $1.423(3)$ \\
$\mathrm{C}(2)-\mathrm{C}(6)$ & $\mathrm{C}(13)-\mathrm{C}(14)$ & $1.447(2)$ \\
$\mathrm{C}(2)-\mathrm{C}(3)$ & $1.226(2)$ & $\mathrm{C}(15)-\mathrm{C}(16)$ & $1.501(3)$ \\
$\mathrm{C}(4)-\mathrm{C}(5)$ & $1.452(2)$ & $\mathrm{C}(15)-\mathrm{H}(15 \mathrm{~A})$ & 0.9900 \\
$\mathrm{C}(4)-\mathrm{H}(4 \mathrm{~A})$ & $1.426(2)$ & $\mathrm{C}(15)-\mathrm{H}(15 \mathrm{~B})$ & 0.9900 \\
$\mathrm{C}(4)-\mathrm{H}(4 \mathrm{~B})$ & $1.431(2)$ & $\mathrm{C}(16)-\mathrm{H}(16 \mathrm{~A})$ & 0.9800 \\
$\mathrm{C}(5)-\mathrm{H}(5 \mathrm{~A})$ & $1.421(2)$ & $\mathrm{C}(16)-\mathrm{H}(16 \mathrm{~B})$ & 0.9800 \\
$\mathrm{C}(5)-\mathrm{H}(5 \mathrm{~B})$ & $1.457(2)$ & $\mathrm{C}(16)-\mathrm{H}(16 \mathrm{C})$ & 0.9800 \\
\end{tabular}


Table S7. Bond angles $\left[{ }^{\circ}\right]$ for 2.

\begin{tabular}{|c|c|c|c|}
\hline $\bar{C}(1)-\mathrm{N}(1)-\mathrm{H}(1 \mathrm{~A})$ & $119.5(15)$ & $\mathrm{C}(7)-\mathrm{C}(8)-\mathrm{H}(8)$ & 115.1 \\
\hline $\mathrm{C}(1)-\mathrm{N}(1)-\mathrm{H}(1 \mathrm{~B})$ & $121.2(15)$ & $\mathrm{C}(9)-\mathrm{C}(8)-\mathrm{H}(8)$ & 115.1 \\
\hline $\mathrm{H}(1 \mathrm{~A})-\mathrm{N}(1)-\mathrm{H}(1 \mathrm{~B})$ & $118(2)$ & $\mathrm{O}(3)-\mathrm{C}(9)-\mathrm{C}(10)$ & $119.43(15)$ \\
\hline $\mathrm{C}(3)-\mathrm{O}(2)-\mathrm{C}(4)$ & $115.45(14)$ & $\mathrm{O}(3)-\mathrm{C}(9)-\mathrm{C}(8)$ & $113.83(16)$ \\
\hline $\mathrm{C}(9)-\mathrm{O}(3)-\mathrm{H}(3)$ & $111.5(17)$ & $\mathrm{C}(10)-\mathrm{C}(9)-\mathrm{C}(8)$ & $126.74(17)$ \\
\hline $\mathrm{C}(14)-\mathrm{O}(5)-\mathrm{C}(15)$ & $117.01(14)$ & $\mathrm{C}(11)-\mathrm{C}(10)-\mathrm{C}(9)$ & $129.47(16)$ \\
\hline $\mathrm{N}(1)-\mathrm{C}(1)-\mathrm{C}(13)$ & $126.61(16)$ & $\mathrm{C}(11)-\mathrm{C}(10)-\mathrm{H}(10)$ & 115.3 \\
\hline $\mathrm{N}(1)-\mathrm{C}(1)-\mathrm{C}(2)$ & $125.38(15)$ & $\mathrm{C}(9)-\mathrm{C}(10)-\mathrm{H}(10)$ & 115.3 \\
\hline $\mathrm{C}(13)-\mathrm{C}(1)-\mathrm{C}(2)$ & $108.01(15)$ & $\mathrm{C}(10)-\mathrm{C}(11)-\mathrm{C}(12)$ & $130.84(16)$ \\
\hline$C(6)-C(2)-C(1)$ & $108.88(15)$ & $\mathrm{C}(10)-\mathrm{C}(11)-\mathrm{H}(11)$ & 114.6 \\
\hline$C(6)-C(2)-C(3)$ & $130.44(17)$ & $\mathrm{C}(12)-\mathrm{C}(11)-\mathrm{H}(11)$ & 114.6 \\
\hline $\mathrm{C}(1)-\mathrm{C}(2)-\mathrm{C}(3)$ & $120.65(16)$ & $\mathrm{C}(11)-\mathrm{C}(12)-\mathrm{C}(13)$ & $125.70(16)$ \\
\hline $\mathrm{O}(1)-\mathrm{C}(3)-\mathrm{O}(2)$ & $121.44(16)$ & $C(11)-C(12)-C(6)$ & $126.46(17)$ \\
\hline $\mathrm{O}(1)-\mathrm{C}(3)-\mathrm{C}(2)$ & $123.42(17)$ & $\mathrm{C}(13)-\mathrm{C}(12)-\mathrm{C}(6)$ & $107.84(15)$ \\
\hline $\mathrm{O}(2)-\mathrm{C}(3)-\mathrm{C}(2)$ & $115.13(16)$ & $C(12)-C(13)-C(1)$ & $108.34(15)$ \\
\hline $\mathrm{O}(2)-\mathrm{C}(4)-\mathrm{C}(5)$ & $107.09(16)$ & $\mathrm{C}(12)-\mathrm{C}(13)-\mathrm{C}(14)$ & $125.52(16)$ \\
\hline $\mathrm{O}(2)-\mathrm{C}(4)-\mathrm{H}(4 \mathrm{~A})$ & 110.3 & $\mathrm{C}(1)-\mathrm{C}(13)-\mathrm{C}(14)$ & $126.13(16)$ \\
\hline $\mathrm{C}(5)-\mathrm{C}(4)-\mathrm{H}(4 \mathrm{~A})$ & 110.3 & $\mathrm{O}(4)-\mathrm{C}(14)-\mathrm{O}(5)$ & $121.40(16)$ \\
\hline $\mathrm{O}(2)-\mathrm{C}(4)-\mathrm{H}(4 \mathrm{~B})$ & 110.3 & $\mathrm{O}(4)-\mathrm{C}(14)-\mathrm{C}(13)$ & $125.23(17)$ \\
\hline $\mathrm{C}(5)-\mathrm{C}(4)-\mathrm{H}(4 \mathrm{~B})$ & 110.3 & $\mathrm{O}(5)-\mathrm{C}(14)-\mathrm{C}(13)$ & $113.36(15)$ \\
\hline $\mathrm{H}(4 \mathrm{~A})-\mathrm{C}(4)-\mathrm{H}(4 \mathrm{~B})$ & 108.6 & $\mathrm{O}(5)-\mathrm{C}(15)-\mathrm{C}(16)$ & $106.92(15)$ \\
\hline $\mathrm{C}(4)-\mathrm{C}(5)-\mathrm{H}(5 \mathrm{~A})$ & 109.5 & $\mathrm{O}(5)-\mathrm{C}(15)-\mathrm{H}(15 \mathrm{~A})$ & 110.3 \\
\hline $\mathrm{C}(4)-\mathrm{C}(5)-\mathrm{H}(5 \mathrm{~B})$ & 109.5 & $\mathrm{C}(16)-\mathrm{C}(15)-\mathrm{H}(15 \mathrm{~A})$ & 110.3 \\
\hline $\mathrm{H}(5 \mathrm{~A})-\mathrm{C}(5)-\mathrm{H}(5 \mathrm{~B})$ & 109.5 & $\mathrm{O}(5)-\mathrm{C}(15)-\mathrm{H}(15 \mathrm{~B})$ & 110.3 \\
\hline $\mathrm{C}(4)-\mathrm{C}(5)-\mathrm{H}(5 \mathrm{C})$ & 109.5 & $\mathrm{C}(16)-\mathrm{C}(15)-\mathrm{H}(15 \mathrm{~B})$ & 110.3 \\
\hline $\mathrm{H}(5 \mathrm{~A})-\mathrm{C}(5)-\mathrm{H}(5 \mathrm{C})$ & 109.5 & $\mathrm{H}(15 \mathrm{~A})-\mathrm{C}(15)-\mathrm{H}(15 \mathrm{~B})$ & 108.6 \\
\hline $\mathrm{H}(5 \mathrm{~B})-\mathrm{C}(5)-\mathrm{H}(5 \mathrm{C})$ & 109.5 & $\mathrm{C}(15)-\mathrm{C}(16)-\mathrm{H}(16 \mathrm{~A})$ & 109.5 \\
\hline$C(7)-C(6)-C(2)$ & $126.81(15)$ & $\mathrm{C}(15)-\mathrm{C}(16)-\mathrm{H}(16 \mathrm{~B})$ & 109.5 \\
\hline$C(7)-C(6)-C(12)$ & $126.26(16)$ & $\mathrm{H}(16 \mathrm{~A})-\mathrm{C}(16)-\mathrm{H}(16 \mathrm{~B})$ & 109.5 \\
\hline$C(2)-C(6)-C(12)$ & $106.92(15)$ & $\mathrm{C}(15)-\mathrm{C}(16)-\mathrm{H}(16 \mathrm{C})$ & 109.5 \\
\hline $\mathrm{C}(8)-\mathrm{C}(7)-\mathrm{C}(6)$ & $130.44(16)$ & $\mathrm{H}(16 \mathrm{~A})-\mathrm{C}(16)-\mathrm{H}(16 \mathrm{C})$ & 109.5 \\
\hline $\mathrm{C}(8)-\mathrm{C}(7)-\mathrm{H}(7)$ & 114.8 & $\mathrm{H}(16 \mathrm{~B})-\mathrm{C}(16)-\mathrm{H}(16 \mathrm{C})$ & 109.5 \\
\hline $\mathrm{C}(6)-\mathrm{C}(7)-\mathrm{H}(7)$ & 114.8 & & \\
\hline
\end{tabular}


Table S8. Anisotropic displacement parameters $\left(\AA^{2} \times 10^{3}\right)$ for 2. The anisotropic displacement factor exponent takes the form: $-2 \pi^{2}\left[h^{2} a^{* 2} U^{11}+\ldots+2 h k a^{*} b^{*} U^{12}\right]$

\begin{tabular}{lcccccc}
\hline & $\mathrm{U}^{11}$ & $\mathrm{U}^{22}$ & $\mathrm{U}^{33}$ & $\mathrm{U}^{23}$ & $\mathrm{U}^{13}$ & $\mathrm{U}^{12}$ \\
\hline $\mathrm{N}(1)$ & $37(1)$ & $41(1)$ & $24(1)$ & $2(1)$ & $-4(1)$ & $-6(1)$ \\
$\mathrm{O}(1)$ & $51(1)$ & $52(1)$ & $24(1)$ & $7(1)$ & $-5(1)$ & $-16(1)$ \\
$\mathrm{O}(2)$ & $43(1)$ & $39(1)$ & $20(1)$ & $2(1)$ & $-6(1)$ & $-5(1)$ \\
$\mathrm{O}(3)$ & $40(1)$ & $40(1)$ & $26(1)$ & $5(1)$ & $-5(1)$ & $-8(1)$ \\
$\mathrm{O}(4)$ & $39(1)$ & $42(1)$ & $22(1)$ & $-5(1)$ & $-4(1)$ & $-3(1)$ \\
$\mathrm{O}(5)$ & $32(1)$ & $36(1)$ & $28(1)$ & $-3(1)$ & $-6(1)$ & $-3(1)$ \\
$\mathrm{C}(1)$ & $29(1)$ & $30(1)$ & $24(1)$ & $-1(1)$ & $-2(1)$ & $4(1)$ \\
$\mathrm{C}(2)$ & $32(1)$ & $30(1)$ & $22(1)$ & $0(1)$ & $-1(1)$ & $2(1)$ \\
$\mathrm{C}(3)$ & $34(1)$ & $34(1)$ & $23(1)$ & $-1(1)$ & $-2(1)$ & $0(1)$ \\
$\mathrm{C}(4)$ & $46(1)$ & $48(1)$ & $21(1)$ & $2(1)$ & $-9(1)$ & $-4(1)$ \\
$\mathrm{C}(5)$ & $50(1)$ & $54(1)$ & $30(1)$ & $-6(1)$ & $-9(1)$ & $-6(1)$ \\
$\mathrm{C}(6)$ & $30(1)$ & $29(1)$ & $21(1)$ & $0(1)$ & $-2(1)$ & $6(1)$ \\
$\mathrm{C}(7)$ & $34(1)$ & $32(1)$ & $21(1)$ & $-2(1)$ & $-4(1)$ & $3(1)$ \\
$\mathrm{C}(8)$ & $32(1)$ & $32(1)$ & $27(1)$ & $-2(1)$ & $-5(1)$ & $-1(1)$ \\
$\mathrm{C}(9)$ & $30(1)$ & $30(1)$ & $28(1)$ & $1(1)$ & $0(1)$ & $2(1)$ \\
$\mathrm{C}(10)$ & $36(1)$ & $38(1)$ & $20(1)$ & $2(1)$ & $-4(1)$ & $2(1)$ \\
$\mathrm{C}(11)$ & $34(1)$ & $36(1)$ & $22(1)$ & $-2(1)$ & $-6(1)$ & $1(1)$ \\
$\mathrm{C}(12)$ & $28(1)$ & $30(1)$ & $22(1)$ & $-2(1)$ & $-2(1)$ & $7(1)$ \\
$\mathrm{C}(13)$ & $29(1)$ & $29(1)$ & $23(1)$ & $-2(1)$ & $-2(1)$ & $5(1)$ \\
$\mathrm{C}(14)$ & $28(1)$ & $29(1)$ & $26(1)$ & $-5(1)$ & $-3(1)$ & $5(1)$ \\
$\mathrm{C}(15)$ & $34(1)$ & $39(1)$ & $35(1)$ & $-8(1)$ & $-7(1)$ & $-2(1)$ \\
$\mathrm{C}(16)$ & $41(1)$ & $34(1)$ & $51(1)$ & $-6(1)$ & $-1(1)$ & $-3(1)$ \\
& & & & & & \\
\hline
\end{tabular}

Table S9. Hydrogen coordinates $\left(\mathrm{x} 10^{4}\right)$ and isotropic displacement parameters $\left(\AA^{2} \mathrm{x} 10^{3}\right)$ for 2.

\begin{tabular}{|c|c|c|c|c|}
\hline & $\mathrm{x}$ & $\mathrm{y}$ & $\mathrm{z}$ & $\mathrm{U}(\mathrm{eq})$ \\
\hline$\overline{\mathrm{H}(1 \mathrm{~A})}$ & $2550(50)$ & $4790(20)$ & $4094(8)$ & $43(6)$ \\
\hline $\mathrm{H}(1 \mathrm{~B})$ & $4150(40)$ & $5140(20)$ & $4519(8)$ & $35(6)$ \\
\hline $\mathrm{H}(3)$ & $12800(50)$ & $10730(30)$ & $2702(9)$ & $53(7)$ \\
\hline $\mathrm{H}(4 \mathrm{~A})$ & 11891 & 6700 & 5342 & 46 \\
\hline $\mathrm{H}(4 \mathrm{~B})$ & 9467 & 7724 & 5475 & 46 \\
\hline $\mathrm{H}(5 \mathrm{~A})$ & 14667 & 8646 & 5193 & 67 \\
\hline $\mathrm{H}(5 \mathrm{~B})$ & 13803 & 8639 & 5694 & 67 \\
\hline $\mathrm{H}(5 \mathrm{C})$ & 12270 & 9639 & 5349 & 67 \\
\hline $\mathrm{H}(7)$ & 11585 & 8863 & 4231 & 35 \\
\hline $\mathrm{H}(8)$ & 13499 & 10196 & 3754 & 36 \\
\hline $\mathrm{H}(10)$ & 9527 & 9241 & 2635 & 38 \\
\hline $\mathrm{H}(11)$ & 6661 & 7654 & 2834 & 37 \\
\hline $\mathrm{H}(15 \mathrm{~A})$ & 1169 & 3544 & 2903 & 43 \\
\hline $\mathrm{H}(15 \mathrm{~B})$ & -1158 & 4695 & 2963 & 43 \\
\hline $\mathrm{H}(16 \mathrm{~A})$ & -2742 & 2521 & 3198 & 63 \\
\hline $\mathrm{H}(16 \mathrm{~B})$ & -2569 & 3572 & 3602 & 63 \\
\hline $\mathrm{H}(16 \mathrm{C})$ & -238 & 2431 & 3547 & 63 \\
\hline
\end{tabular}


Table S10. Torsion angles $\left[^{\circ}\right]$ for 2 .

\begin{tabular}{|c|c|}
\hline $\mathrm{N}(1)-\mathrm{C}(1)-\mathrm{C}(2)-\mathrm{C}(6)$ & $179.69(17)$ \\
\hline$C(13)-C(1)-C(2)-C(6)$ & $0.4(2)$ \\
\hline $\mathrm{N}(1)-\mathrm{C}(1)-\mathrm{C}(2)-\mathrm{C}(3)$ & $1.4(3)$ \\
\hline $\mathrm{C}(13)-\mathrm{C}(1)-\mathrm{C}(2)-\mathrm{C}(3)$ & $-177.85(16)$ \\
\hline $\mathrm{C}(4)-\mathrm{O}(2)-\mathrm{C}(3)-\mathrm{O}(1)$ & $4.1(3)$ \\
\hline $\mathrm{C}(4)-\mathrm{O}(2)-\mathrm{C}(3)-\mathrm{C}(2)$ & $-176.66(16)$ \\
\hline$C(6)-C(2)-C(3)-O(1)$ & $-176.58(19)$ \\
\hline $\mathrm{C}(1)-\mathrm{C}(2)-\mathrm{C}(3)-\mathrm{O}(1)$ & $1.3(3)$ \\
\hline $\mathrm{C}(6)-\mathrm{C}(2)-\mathrm{C}(3)-\mathrm{O}(2)$ & $4.2(3)$ \\
\hline $\mathrm{C}(1)-\mathrm{C}(2)-\mathrm{C}(3)-\mathrm{O}(2)$ & $-177.94(15)$ \\
\hline $\mathrm{C}(3)-\mathrm{O}(2)-\mathrm{C}(4)-\mathrm{C}(5)$ & $-177.56(17)$ \\
\hline$C(1)-C(2)-C(6)-C(7)$ & $-179.40(16)$ \\
\hline$C(3)-C(2)-C(6)-C(7)$ & $-1.4(3)$ \\
\hline$C(1)-C(2)-C(6)-C(12)$ & $-0.17(19)$ \\
\hline$C(3)-C(2)-C(6)-C(12)$ & $177.87(17)$ \\
\hline$C(2)-C(6)-C(7)-C(8)$ & $-179.92(18)$ \\
\hline$C(12)-C(6)-C(7)-C(8)$ & $1.0(3)$ \\
\hline$C(6)-C(7)-C(8)-C(9)$ & $-0.5(3)$ \\
\hline $\mathrm{C}(7)-\mathrm{C}(8)-\mathrm{C}(9)-\mathrm{O}(3)$ & 179.99(18) \\
\hline$C(7)-C(8)-C(9)-C(10)$ & $0.4(3)$ \\
\hline $\mathrm{O}(3)-\mathrm{C}(9)-\mathrm{C}(10)-\mathrm{C}(11)$ & $179.54(18)$ \\
\hline$C(8)-C(9)-C(10)-C(11)$ & $-0.9(3)$ \\
\hline $\mathrm{C}(9)-\mathrm{C}(10)-\mathrm{C}(11)-\mathrm{C}(12)$ & $0.9(4)$ \\
\hline$C(10)-C(11)-C(12)-C(13)$ & 179.98(19) \\
\hline $\mathrm{C}(10)-\mathrm{C}(11)-\mathrm{C}(12)-\mathrm{C}(6)$ & $0.0(3)$ \\
\hline$C(7)-C(6)-C(12)-C(11)$ & $-0.9(3)$ \\
\hline $\mathrm{C}(2)-\mathrm{C}(6)-\mathrm{C}(12)-\mathrm{C}(11)$ & $179.82(17)$ \\
\hline $\mathrm{C}(7)-\mathrm{C}(6)-\mathrm{C}(12)-\mathrm{C}(13)$ & $179.09(16)$ \\
\hline$C(2)-C(6)-C(12)-C(13)$ & $-0.14(19)$ \\
\hline $\mathrm{C}(11)-\mathrm{C}(12)-\mathrm{C}(13)-\mathrm{C}(1)$ & $-179.56(17)$ \\
\hline$C(6)-C(12)-C(13)-C(1)$ & $0.40(19)$ \\
\hline $\mathrm{C}(11)-\mathrm{C}(12)-\mathrm{C}(13)-\mathrm{C}(14)$ & $1.2(3)$ \\
\hline$C(6)-C(12)-C(13)-C(14)$ & $-178.88(16)$ \\
\hline $\mathrm{N}(1)-\mathrm{C}(1)-\mathrm{C}(13)-\mathrm{C}(12)$ & $-179.76(17)$ \\
\hline$C(2)-C(1)-C(13)-C(12)$ & $-0.51(19)$ \\
\hline $\mathrm{N}(1)-\mathrm{C}(1)-\mathrm{C}(13)-\mathrm{C}(14)$ & $-0.5(3)$ \\
\hline$C(2)-C(1)-C(13)-C(14)$ & 178.77(16) \\
\hline $\mathrm{C}(15)-\mathrm{O}(5)-\mathrm{C}(14)-\mathrm{O}(4)$ & $1.3(2)$ \\
\hline $\mathrm{C}(15)-\mathrm{O}(5)-\mathrm{C}(14)-\mathrm{C}(13)$ & $-177.55(15)$ \\
\hline $\mathrm{C}(12)-\mathrm{C}(13)-\mathrm{C}(14)-\mathrm{O}(4)$ & $0.7(3)$ \\
\hline $\mathrm{C}(1)-\mathrm{C}(13)-\mathrm{C}(14)-\mathrm{O}(4)$ & $-178.46(17)$ \\
\hline $\mathrm{C}(12)-\mathrm{C}(13)-\mathrm{C}(14)-\mathrm{O}(5)$ & $179.52(15)$ \\
\hline $\mathrm{C}(1)-\mathrm{C}(13)-\mathrm{C}(14)-\mathrm{O}(5)$ & $0.4(2)$ \\
\hline $\mathrm{C}(14)-\mathrm{O}(5)-\mathrm{C}(15)-\mathrm{C}(16)$ & $179.90(15)$ \\
\hline
\end{tabular}

Table S11. Hydrogen bonds for 2 [ $\AA$ and $\left.{ }^{\circ}\right]$.

\begin{tabular}{|c|c|c|c|c|}
\hline D-H...A & $\mathrm{d}(\mathrm{D}-\mathrm{H})$ & $\mathrm{d}(\mathrm{H} \ldots \mathrm{A})$ & d(D...A) & $<(\mathrm{DHA})$ \\
\hline $\mathrm{N}(1)-\mathrm{H}(1 \mathrm{~A}) \ldots \mathrm{O}(5)$ & $0.93(3)$ & $2.07(2)$ & $2.701(2)$ & $124.1(19)$ \\
\hline $\mathrm{N}(1)-\mathrm{H}(1 \mathrm{~B}) \ldots \mathrm{O}(1)$ & $0.86(2)$ & $2.13(2)$ & $2.724(2)$ & $125.5(18)$ \\
\hline $\mathrm{N}(1)-\mathrm{H}(1 \mathrm{~B}) \ldots \mathrm{O}(1) \# 1$ & $0.86(2)$ & $2.18(2)$ & $2.916(2)$ & 143(2) \\
\hline $\mathrm{O}(3)-\mathrm{H}(3) \ldots \mathrm{O}(4) \# 2$ & $0.90(3)$ & $1.81(3)$ & $2.6980(17)$ & $170(2)$ \\
\hline
\end{tabular}

Symmetry transformations used to generate equivalent atoms:

$\# 1-x+1,-y+1,-z+1 \quad \# 2-x+3 / 2, y+1 / 2,-z+1 / 2$

\section{Computational Data}




\section{DFT Calculations}

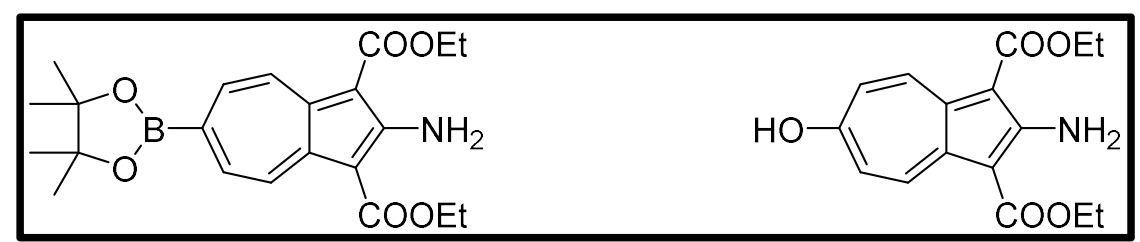

There are three conformers ( $\mathbf{a}, \mathbf{b}$ and $\mathbf{c}$ ), defined by the orientation of the ester groups. The most stable conformer a has both the carbonyl oxygen atoms directed towards the hydrogens of the amine group. These have an $\mathrm{O} \cdots \mathrm{H}$ distance of $1.9566 \AA$ (Y $=$ Bpin) and $1.9696 / 1.9722 \AA(Y=\mathrm{OH})$. The free energies below are given in kcal mol-1, and are the difference in free energy between the higher energy conformers and the lowest Y conformer a.<smiles>[Y]c1ccc2c(C(=O)OCC)c(N)c(C(=O)OCC)c(N)c2c1</smiles>

$\mathbf{Y}$

$\mathrm{OH}$

Bpin

$\Delta \mathrm{G}\left[\mathrm{kcal} \mathrm{mol}^{-1}\right]$<smiles></smiles><smiles></smiles>

b

C

0.8

1.8

1.2 


\section{Computational Methodology:}

DFT calculations were run with Gaussian 09 (Revision D.01).[7] The 6-31G** basis set was used for all atoms. ${ }^{[8]}$ Initial BP86 ${ }^{[9]}$ optimizations were performed using the "grid = ultrafine' option, with all stationary points being fully characterized via analytical frequency calculations as minima (all positive eigenvalues). The BP86-optimised geometries were used for the NBO (Natural Bonding Orbital) studies to generate molecular orbital pictures.

\section{Cartesian Coordinates}

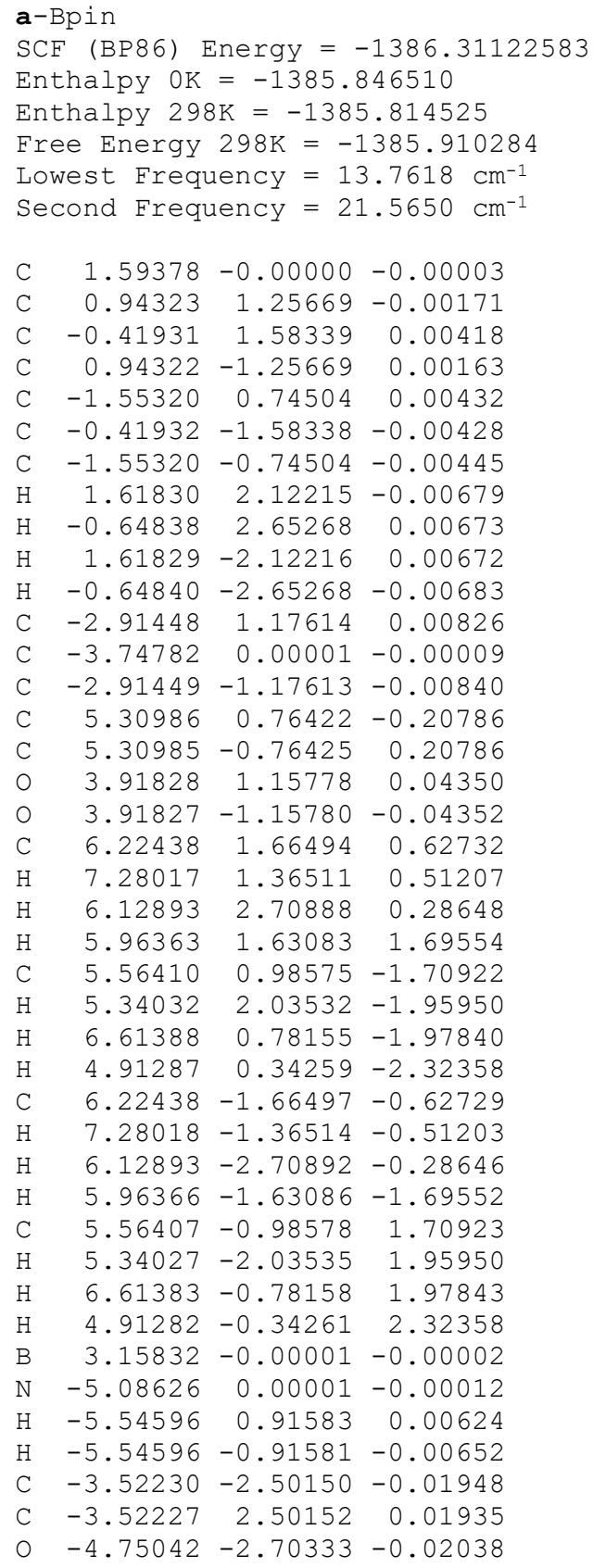




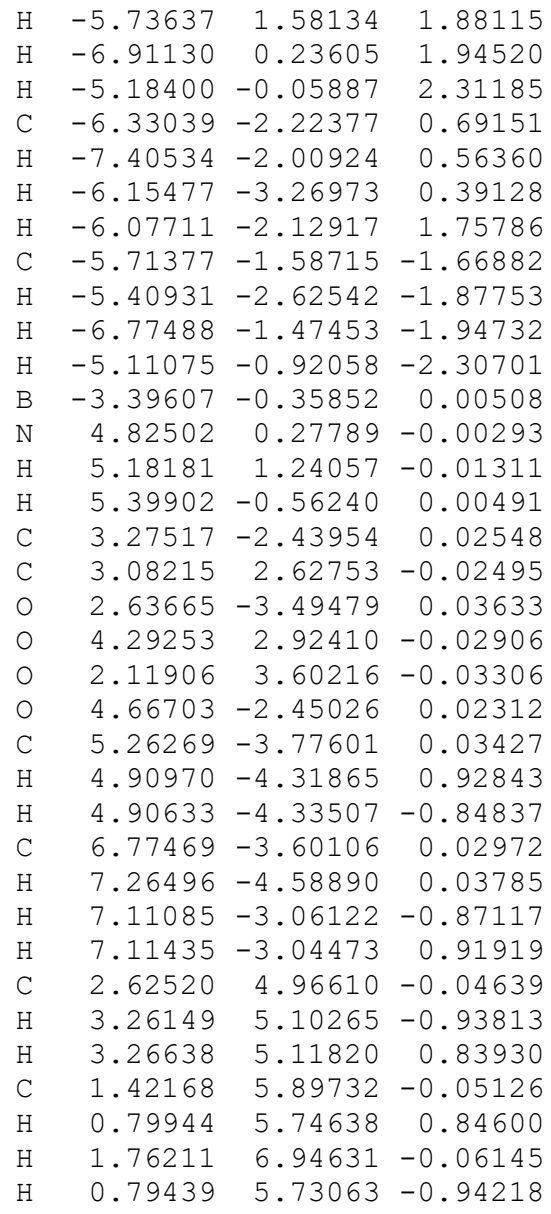

c-Bpin

$\mathrm{SCF}$ (BP86) Energy $=-1386.30643651$

Enthalpy OK $=-1385.842080$

Enthalpy $298 \mathrm{~K}=-1385.809857$

Free Energy 298K $=-1385.906553$

Lowest Frequency $=9.3026 \mathrm{~cm}^{-1}$

Second Frequency $=19.7196 \mathrm{~cm}^{-1}$

$\begin{array}{lrrr}\mathrm{C} & 2.10166 & -0.00002 & -0.00005 \\ \mathrm{C} & 1.45434 & 1.25900 & 0.00686 \\ \mathrm{C} & 0.09195 & 1.58795 & 0.01343 \\ \mathrm{C} & 1.45433 & -1.25902 & -0.00698 \\ \mathrm{C} & -1.03325 & 0.73985 & 0.00757 \\ \mathrm{C} & 0.09194 & -1.58796 & -0.01358 \\ \mathrm{C} & -1.03325 & -0.73986 & -0.00766 \\ \mathrm{H} & 2.13143 & 2.12281 & 0.00830 \\ \mathrm{H} & -0.15372 & 2.65529 & 0.02233 \\ \mathrm{H} & 2.13142 & -2.12284 & -0.00845 \\ \mathrm{H} & -0.15374 & -2.65530 & -0.02252 \\ \mathrm{C} & -2.39602 & 1.17397 & 0.01283 \\ \mathrm{C} & -3.23320 & 0.00000 & 0.00003 \\ \mathrm{C} & -2.39602 & -1.17397 & -0.01285 \\ \mathrm{C} & 5.81903 & 0.76731 & -0.19629 \\ \mathrm{C} & 5.81902 & -0.76732 & 0.19637 \\ \mathrm{O} & 4.42703 & 1.15689 & 0.05966 \\ \mathrm{O} & 4.42705 & -1.15690 & -0.05967 \\ \mathrm{C} & 6.73235 & 1.65568 & 0.65328\end{array}$

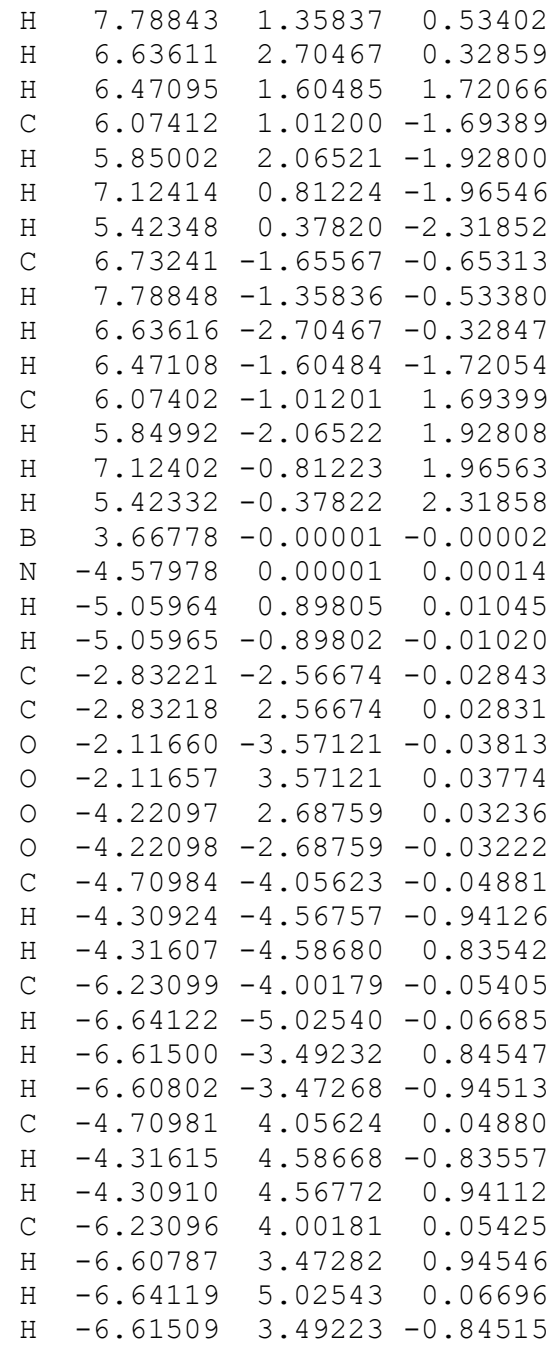

a-OH

$\mathrm{SCF}$ (BP86) Energy $=-1050.85723254$

Enthalpy $0 \mathrm{~K}=-1050.555388$

Enthalpy 298K $=-1050.532780$

Free Energy 298K $=-1050.607066$

Lowest Frequency $=22.1210 \mathrm{~cm}^{-1}$

Second Frequency $=34.4762 \mathrm{~cm}^{-1}$

$\begin{array}{rrrr}\text { C } & -0.00248 & 3.62396 & 0.00002 \\ \mathrm{C} & 1.26254 & 2.99862 & 0.00008 \\ \mathrm{C} & 1.57797 & 1.63931 & 0.00011 \\ \mathrm{C} & -1.26347 & 2.99369 & -0.00001 \\ \mathrm{C} & 0.74026 & 0.50208 & 0.00010 \\ \mathrm{C} & -1.57858 & 1.63103 & 0.00000 \\ \mathrm{C} & -0.73859 & 0.49930 & 0.00006 \\ \mathrm{H} & 2.10535 & 3.69904 & 0.00010 \\ \mathrm{H} & 2.64730 & 1.41164 & 0.00014 \\ \mathrm{H} & -2.12985 & 3.67181 & -0.00006 \\ \mathrm{H} & -2.64758 & 1.40112 & -0.00003 \\ \mathrm{C} & 1.17621 & -0.86048 & 0.00010 \\ \mathrm{C} & 0.00364 & -1.69804 & 0.00016 \\ \mathrm{C} & -1.17096 & -0.86640 & 0.00005 \\ \mathrm{~N} & 0.00704 & -3.03952 & 0.00033\end{array}$




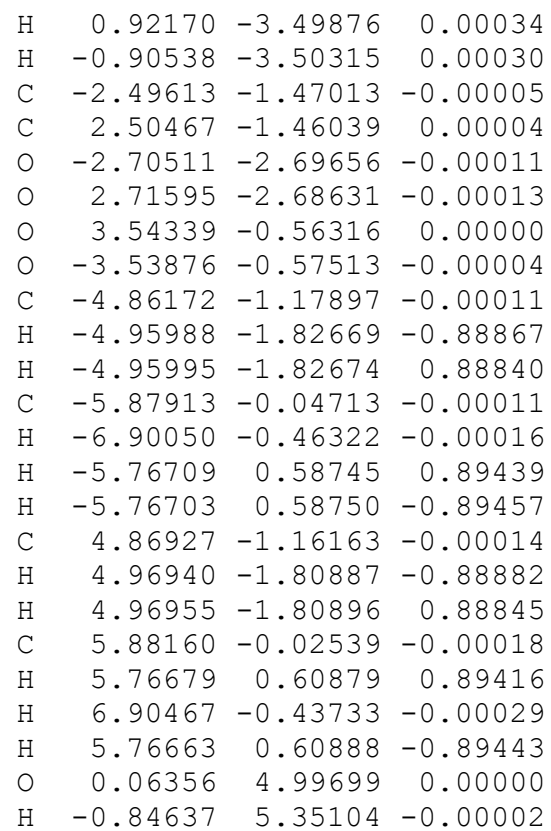

b- $\mathrm{OH}$

SCF (BP86) Energy $=-1050.85573558$

Enthalpy OK $=-1050.554029$

Enthalpy 298K $=-1050.531337$

Free Energy 298K $=-1050.605832$

Lowest Frequency $=25.3940 \mathrm{~cm}^{-1}$

Second Frequency $=29.7491 \mathrm{~cm}^{-1}$

$\begin{array}{lrrr}\mathrm{C} & -1.85100 & 3.52058 & -0.00005 \\ \mathrm{C} & -0.44166 & 3.60645 & 0.00008 \\ \mathrm{C} & 0.50404 & 2.58147 & 0.00011 \\ \mathrm{C} & -2.63525 & 2.34848 & -0.00016 \\ \mathrm{C} & 0.32875 & 1.17996 & 0.00006 \\ \mathrm{C} & -2.23750 & 1.00729 & -0.00009 \\ \mathrm{C} & -0.94682 & 0.44209 & 0.00005 \\ \mathrm{H} & -0.05711 & 4.63260 & 0.00016 \\ \mathrm{H} & 1.55356 & 2.89522 & 0.00019 \\ \mathrm{H} & -3.72353 & 2.51036 & -0.00031 \\ \mathrm{H} & -3.05358 & 0.27964 & -0.00015 \\ \mathrm{C} & 1.39332 & 0.22313 & 0.00007 \\ \mathrm{C} & 0.80232 & -1.08942 & 0.00012 \\ \mathrm{C} & -0.63321 & -0.95658 & 0.00004 \\ \mathrm{~N} & 1.44515 & -2.27117 & 0.00027 \\ \mathrm{H} & 2.46195 & -2.27458 & 0.00008 \\ \mathrm{H} & 0.85308 & -3.10823 & 0.00006 \\ \mathrm{C} & -1.48189 & -2.13881 & -0.00005 \\ \mathrm{C} & 2.81691 & 0.54483 & 0.00006 \\ \mathrm{O} & -1.05659 & -3.30954 & -0.00030 \\ \mathrm{O} & 3.32634 & 1.66920 & 0.00005 \\ \mathrm{O} & 3.61215 & -0.59590 & -0.00002 \\ \mathrm{O} & -2.83108 & -1.88038 & 0.00012 \\ \mathrm{C} & -3.68041 & -3.06060 & -0.00003 \\ \mathrm{H} & -3.44479 & -3.67175 & -0.88871 \\ \mathrm{H} & -3.44474 & -3.67202 & 0.88845 \\ \mathrm{C} & -5.12507 & -2.58193 & 0.00010\end{array}$

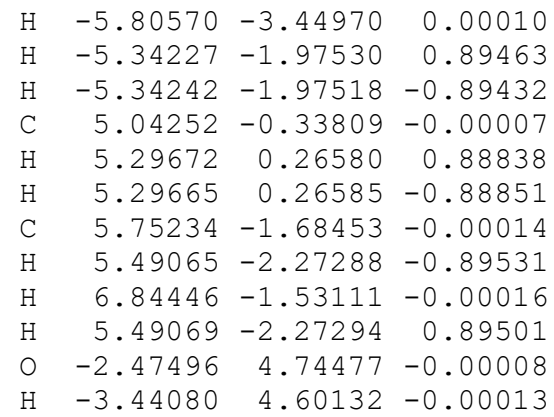

c-OH

$\mathrm{SCF}$ (BP86) Energy $=-1050.85370910$

Enthalpy OK $=-1050.552192$

Enthalpy 298K $=-1050.529352$

Free Energy 298K $=-1050.604177$

Lowest Frequency $=27.2161 \mathrm{~cm}^{-1}$

Second Frequency $=28.9999 \mathrm{~cm}^{-1}$ |

$\begin{array}{rrrr}\mathrm{C} & -4.32309 & -0.05311 & 0.00007 \\ \mathrm{C} & -3.68412 & -1.31272 & -0.00010 \\ \mathrm{C} & -2.32178 & -1.61274 & -0.00012 \\ \mathrm{C} & -3.71157 & 1.21853 & 0.00016 \\ \mathrm{C} & -1.20361 & -0.75047 & -0.00001 \\ \mathrm{C} & -2.35448 & 1.55331 & 0.00009 \\ \mathrm{C} & -1.22006 & 0.71777 & 0.00003 \\ \mathrm{H} & -4.37590 & -2.16265 & -0.00022 \\ \mathrm{H} & -2.06281 & -2.67694 & -0.00025 \\ \mathrm{H} & -4.40312 & 2.07431 & 0.00028 \\ \mathrm{H} & -2.12004 & 2.62339 & 0.00009 \\ \mathrm{C} & 0.16566 & -1.17139 & 0.00002 \\ \mathrm{C} & 0.99164 & 0.01015 & 0.00008 \\ \mathrm{C} & 0.14055 & 1.17137 & 0.00003 \\ \mathrm{~N} & 2.34122 & 0.02465 & 0.00021 \\ \mathrm{H} & 2.83174 & -0.86668 & 0.00009 \\ \mathrm{H} & 2.81228 & 0.92639 & -0.00001 \\ \mathrm{C} & 0.55283 & 2.56966 & -0.00001 \\ \mathrm{C} & 0.61186 & -2.56058 & -0.00015 \\ \mathrm{O} & -0.18244 & 3.56191 & -0.00003 \\ \mathrm{O} & -0.09874 & -3.56978 & -0.00050 \\ \mathrm{O} & 2.00004 & -2.67304 & 0.00015 \\ \mathrm{O} & 1.93793 & 2.71618 & -0.00002 \\ \mathrm{C} & 2.40235 & 4.09304 & -0.00007 \\ \mathrm{H} & 1.99624 & 4.60727 & -0.88845 \\ \mathrm{H} & 1.99637 & 4.60728 & 0.88837 \\ \mathrm{C} & 3.92426 & 4.06530 & -0.00017 \\ \mathrm{H} & 4.31680 & 5.09591 & -0.00020 \\ \mathrm{H} & 4.31359 & 3.55239 & 0.89506 \\ \mathrm{H} & 4.31347 & 3.55239 & -0.89546 \\ \mathrm{H} & 2.49760 & -4.03855 & -0.00005 \\ \mathrm{H} & 2.10403 & -4.56200 & -0.88865 \\ \mathrm{H} & 2.10363 & -4.56239 & 0.88814 \\ \mathrm{H} & 4.01836 & -3.97420 & 0.00031 \\ \mathrm{H} & 4.39508 & -3.45237 & 0.89579 \\ \mathrm{H} & 4.39550 & -3.45204 & -0.89480 \\ \mathrm{H} & -69591 & 0.76995 & 0.00006\end{array}$




\section{Fluorescence Quantum Yield Calculations}

The quantum yield of $\mathbf{2}$ was determined by comparison with the fluorophore of quinine sulfate, for which $\Phi=0.54$. Quinine was dissolved in $0.1 \mathrm{M} \mathrm{H}_{2} \mathrm{SO}_{4(\mathrm{aq})}$ and 2 was dissolved in buffer ( $\mathrm{PBS} / \mathrm{MeOH} 48: 52, \mathrm{pH}=8.2$ ). The refractive index of the quinine solution was approximated to be equivalent to the value for water alone $\left(\eta_{\text {water }}=1.3326\right) .{ }^{[10]}$ The refractive index of the solution of 2 was approximated to be equivalent to the value for water-methanol 50:50 ( $\eta_{\text {water-methanol }}=$ 1.3389). ${ }^{[10]}$ Absorption spectra for these solutions were acquired to determine the concentrations necessary to achieve an absorbance of 0.1 at the relevant $\lambda_{\max }$.
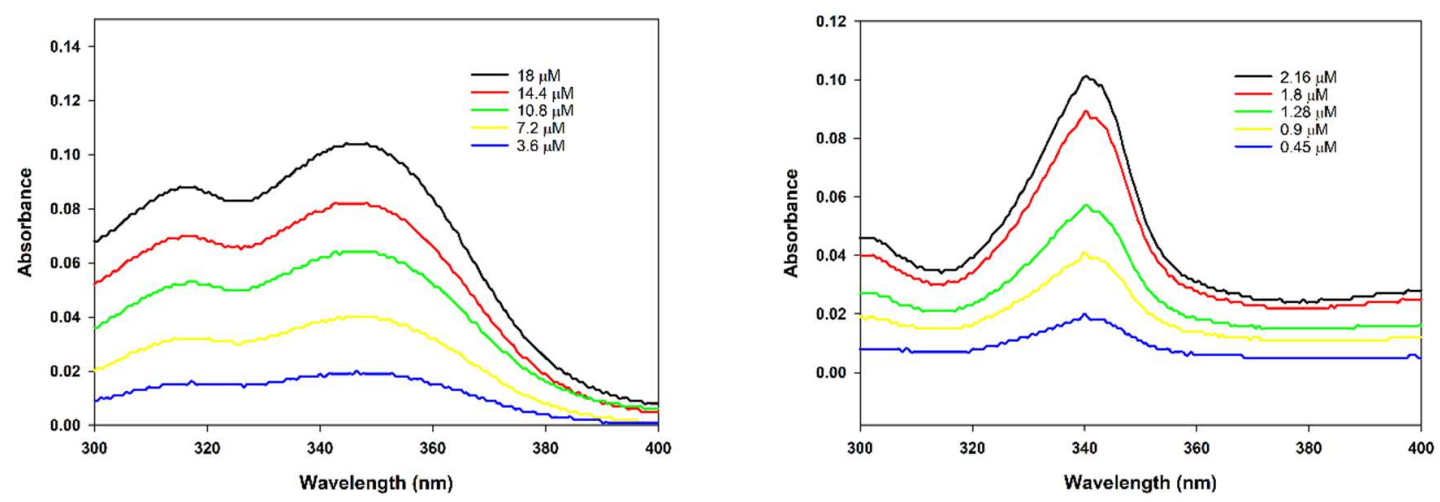

Figure S34. Absorption spectra of quinine sulfate (left) and 2 (right) at various concentrations.

Fluorescence spectra of the two samples were then acquired at multiple optical densities, using an Applied Photophysics Chirascan spectrophotometer, with path lengths of $10 \mathrm{~mm}$. Spectra were integrated using the Spectrogryph ${ }^{\circledR}$ software.
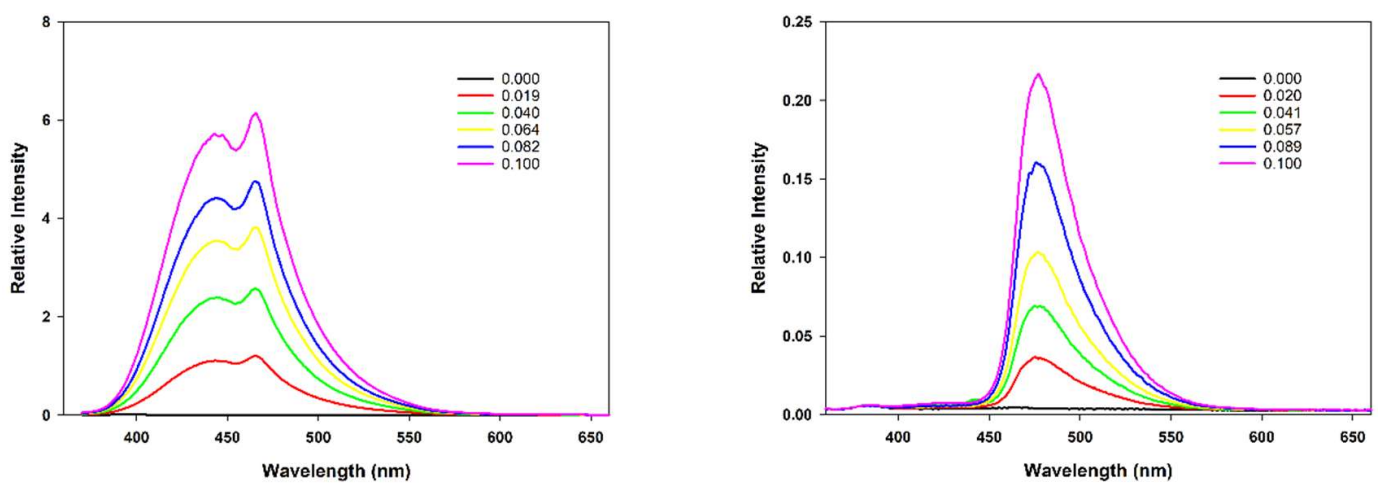

Figure S35. Fluorescence emission spectra of quinine sulfate (left, $\lambda_{\mathrm{ex}}=347 \mathrm{~nm}$ ) and 2 (right, $\lambda_{\mathrm{ex}}=340 \mathrm{~nm}$ ) at optical densities between 0.000 and 0.100 . Bandwidth $=10 \mathrm{~nm}$. 
Table S11. Peak areas for fluorescence spectra of quinine.

\begin{tabular}{|c|c|c|c|c|c|c|}
\hline Optical density & 0 & 0.019 & 0.04 & 0.064 & 0.082 & 0.1 \\
\hline Area under curve & 0.106 & 89.4 & 192.8 & 287.8 & 359.4 & 466 \\
\hline
\end{tabular}

Table S12. Peak areas for fluorescence spectra of 2 .

\begin{tabular}{|c|c|c|c|c|c|l|}
\hline Optical density & 0 & 0.02 & 0.041 & 0.057 & 0.089 & 0.1 \\
\hline Area under curve & 0.0465 & 1.423 & 2.763 & 4.289 & 6.736 & 8.948 \\
\hline
\end{tabular}

Linear regression was then performed on the acquired data, plotted below.
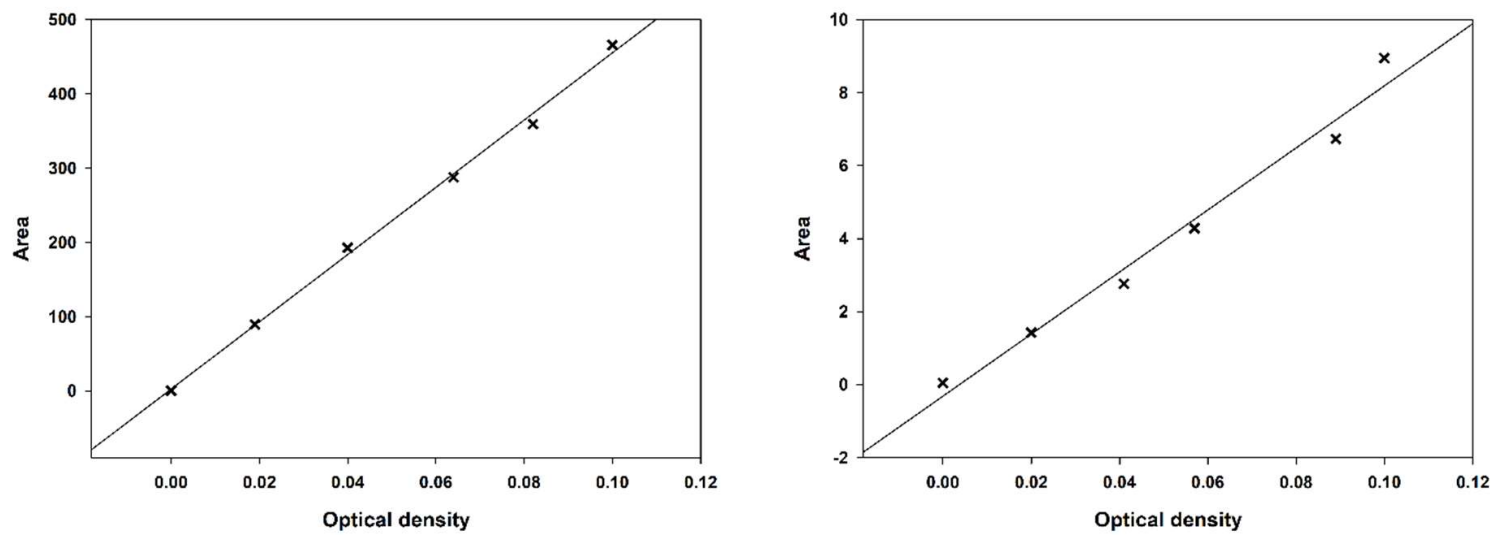

Figure S36. Plots of optical density against peak area for quinine (left) and 2 (right).

For quinine, $y=4529.8 x+2.321 \quad \mathrm{R}^{2}=0.9971$

For 2, $y=85.115 x-0.3208 \quad \mathrm{R}^{2}=0.9785$

$\Phi_{(\mathbf{2})}=\Phi_{(\text {quinine })} *\left(\operatorname{Gradient}_{(\mathbf{2})} / \operatorname{Gradient}_{(\text {quinine })}\right) *\left(\eta_{\text {water-methanol }}{ }^{2} / \eta_{\text {water }^{2}}\right)$

$\Phi_{(2)}=0.54 *(85.115 / 4529.8) *\left(1.3389^{2} / 1.3326^{2}\right)$

$\Phi_{(2)}=0.010$ 


\section{References}

1. $\quad$ Patel, R. P.; Darley-Usmar, V. M. Methods Enzymol. 1996, 269, 375-384.

2. Nolting, D. D.; Nickels, M.; Price, R.; Gore, J. C.; Pham, W. Nat. Protoc. 2009, 4, 1113 1117.

3. Nozoe, T.; Takase, K.; Kato, M.; Nogi, T.Tetrahedron, 1971, 27, 6023-6035.

4. Holovics, T. C.; Robinson, R. E.; Weintrob, E. C.; Toriyama, M.; Lushington, G. H.; Barybin, M. V. J. Am. Chem. Soc. 2006, 128, 2300-2309.

5. Kurotobi, K.; Tabata, H.; Miyauchi, M.; Murafuji, T.; Sugihara, Y. Synthesis 2002, 10131016.

6. Xu, C.; Webb, W. W. J. Opt. Soc. Am. B 1996, 13, 481-491.

7. Frisch, M. J.; Trucks, G. W.; Schlegel, H. B.; Scuseria, G. E.; Robb, M. A.; Cheeseman, J. R.; Scalmani, G.; Barone, V.; Mennucci, B.; Petersson, G. A.; Nakatsuji, H.; Caricato, M.; Li, X.; Hratchian, H. P.; Izmaylov, A. F.; Bloino, J.; Zheng, G.; Sonnenberg, J. L.; Hada, M.; Ehara, M.; Toyota, K.; Fukuda, R.; Hasegawa, J.; Ishida, M.; Nakajima, T.; Honda, Y.; Kitao, O.; Nakai, H.; Vreven, T.; Montgomery, J. A., Jr.; Peralta, J. E.; Ogliaro, F.; Bearpark, M.; Heyd, J. J.; Brothers, E.; Kudin, K. N.; Staroverov, V. N.; Kobayashi, R.; Normand, J.; Raghavachari, K.; Rendell, A.; Burant, J. C.; Iyengar, S. S.; Tomasi, J.; Cossi, M.; Rega, N.; Millam, J. M.; Klene, M.; Knox, J. E.; Cross, J. B.; Bakken, V.; Adamo, C.; Jaramillo, J.; Gomperts, R.; Stratmann, R. E.; Yazyev, O.; Austin, A. J.; Cammi, R.; Pomelli, C.; Ochterski, J. W.; Martin, R. L.; Morokuma, K.; Zakrzewski, V. G.; Voth, G. A.; Salvador, P.; Dannenberg, J. J.; Dapprich, S.; Daniels, A. D.; Farkas, O.; Foresman, J. B.; Ortiz, J. V.; Cioslowski, J.; Fox, D. J. Gaussian 09 (Revision D.01); Gaussian Inc.: Wallingford, CT, 2009.

8. (a) Hariharan, P. C., Pople, J. A. Theor. Chim. Acta 1973, 28, 213-222. (b) Hehre, W. J., Ditchfield, R., Pople, J. A. J. Chem. Phys. 1972, 56, 2257.

9. (a) Becke, A. D. Phys. Rev. A: At., Mol., Opt. Phys. 1988, 38, 3098. (b) Perdew, J. P. Phys. Rev. B: Condens. Matter Mater. Phys. 1986, 33, 8822-8824.

10. Herraez, J. V.; Belda, R. J. Solution Chem. 2006, 35, 1315-1328. 